\title{
Emissions from biomass burning in the Yucatan
}

\author{
R. J. Yokelson ${ }^{1}$, J. D. Crounse ${ }^{2}$, P. F. DeCarlo ${ }^{3, *}$, T. Karl $^{4}$, S. Urbanski ${ }^{5}$, E. Atlas ${ }^{6}$, T. Campos $^{4}$, Y. Shinozuka ${ }^{7}$, \\ V. Kapustin ${ }^{7}$, A. D. Clarke ${ }^{7}$, A. Weinheimer ${ }^{4}$, D. J. Knapp ${ }^{4}$, D. D. Montzka ${ }^{4}$, J. Holloway ${ }^{8}$, P. Weibring ${ }^{4}$, F. Flocke ${ }^{4}$, \\ W. Zheng ${ }^{4}$, D. Toohey ${ }^{9}$, P. O. Wennberg ${ }^{10}$, C. Wiedinmyer ${ }^{4}$, L. Mauldin ${ }^{4}$, A. Fried ${ }^{4}$, D. Richter ${ }^{4}$, J. Walega ${ }^{4}$, \\ J. L. Jimenez ${ }^{11}$, K. Adachi ${ }^{12}$, P. R. Buseck ${ }^{12}$, S. R. Hall ${ }^{4}$, and R. Shetter ${ }^{4}$ \\ ${ }^{1}$ University of Montana, Department of Chemistry, Missoula, MT 59812, USA \\ ${ }^{2}$ Division of Chemistry and Chemical Engineering, California Institute of Technology, Pasadena, USA \\ ${ }^{3}$ University of Colorado, Cooperative Institute for Research in the Environmental Sciences (CIRES), and Department of \\ Atmospheric and Oceanic Sciences, Boulder, USA \\ ${ }^{4}$ National Center for Atmospheric Research, Boulder, CO, USA \\ ${ }^{5}$ USDA Forest Service, Fire Sciences Laboratory, Missoula, MT, USA \\ ${ }^{6}$ University of Miami, Rosenstiel School of Marine and Atmospheric Science, USA \\ ${ }^{7}$ School of Ocean and Earth Sciences and Department of Oceanography, University of Hawaii, Honolulu, USA \\ ${ }^{8}$ NOAA ESRL/CSD, Boulder, CO, USA \\ ${ }^{9}$ University of Colorado, Department of Atmospheric and Oceanic Sciences, Boulder, USA \\ ${ }^{10}$ Divisions of Engineering and Applied Science and Geological and Planetary Science, California Institute of Technology, \\ Pasadena, USA \\ ${ }^{11}$ University of Colorado, Cooperative Institute for Research in the Environmental Sciences (CIRES) and Department of \\ Chemistry and Biochemistry, Boulder, USA \\ ${ }^{12}$ School of Earth and Space Exploration and Department of Chemistry and Biochemistry, Arizona State University, \\ Tempe, USA \\ *now at: The Paul Scherrer Institut, Villigen, Switzerland
}

Received: 2 October 2008 - Published in Atmos. Chem. Phys. Discuss.: 9 January 2009

Revised: 30 June 2009 - Accepted: 28 July 2009 - Published: 12 August 2009

\begin{abstract}
In March 2006 two instrumented aircraft made the first detailed field measurements of biomass burning (BB) emissions in the Northern Hemisphere tropics as part of the MILAGRO project. The aircraft were the National Center for Atmospheric Research C-130 and a University of Montana/US Forest Service Twin Otter. The initial emissions of up to 49 trace gas or particle species were measured from 20 deforestation and crop residue fires on the Yucatan peninsula. This included two trace gases useful as indicators of BB (HCN and acetonitrile) and several rarely, or never before, measured species: $\mathrm{OH}$, peroxyacetic acid, propanoic acid, hydrogen peroxide, methane sulfonic acid, and sulfuric acid. Crop residue fires emitted more organic acids and ammonia than deforestation fires, but the emissions from the main fire types were otherwise fairly similar. The Yucatan fires
\end{abstract}

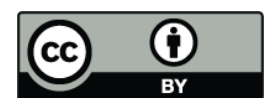

Correspondence to: R. J. Yokelson (bob.yokelson@umontana.edu) emitted unusually high amounts of $\mathrm{SO}_{2}$ and particle chloride, likely due to a strong marine influence on this peninsula. As smoke from one fire aged, the ratio $\Delta \mathrm{O}_{3} / \Delta \mathrm{CO}$ increased to $\sim 15 \%$ in $<\sim 1 \mathrm{~h}$ similar to the fast net production of $\mathrm{O}_{3}$ in $\mathrm{BB}$ plumes observed earlier in Africa. The rapid change in $\mathrm{O}_{3}$ occurs at a finer spatial scale than is employed in global models and is also faster than predicted by microscale models. Fast increases in PAN, $\mathrm{H}_{2} \mathrm{O}_{2}$, and two organic acids were also observed. The amount of secondary organic acid is larger than the amount of known precursors. Rapid secondary formation of organic and inorganic aerosol was observed with the ratio $\Delta \mathrm{PM}_{2.5} / \Delta \mathrm{CO}$ more than doubling in $\sim 1.4 \pm 0.7 \mathrm{~h}$. The $\mathrm{OH}$ measurements revealed high initial levels $\left(>1 \times 10^{7}\right.$ molecules $\left./ \mathrm{cm}^{3}\right)$ that were likely caused in part by high initial HONO $\left(\sim 10 \%\right.$ of $\left.\mathrm{NO}_{\mathrm{y}}\right)$. Thus, more research is needed to understand critical post emission processes for the second-largest trace gas source on Earth. It is estimated that $\sim 44 \mathrm{Tg}$ of biomass burned in the Yucatan in the spring 
of 2006. Mexican BB (including Yucatan BB) and urban emissions from the Mexico City area can both influence the March-May air quality in much of Mexico and the US.

\section{Introduction}

The MILAGRO (Megacity Initiative Local and Global $R$ esearch $O$ bservations) project was designed to study the local to global atmospheric affects of pollution from megacities (http://www.eol.ucar.edu/projects/milagro). Megacities have a population $>10$ million and are rapidly increasing in number on the five most populated continents. The first MILAGRO field campaigns occurred in March 2006 and studied the impact of trace gases and particles generated in Mexico City (MC, North America's largest metropolitan area) on regional atmospheric chemistry (Fast et al., 2007; Molina et al., 2007). Regional biomass burning (BB) was also studied because it is a major emission source in Mexico that peaks during the February-May dry season. Earlier papers estimated that BB located adjacent to MC accounted for $\sim 20-30 \%$ of the $\mathrm{CO}$ (and several other important trace gases) and about one-half of the particle mass in the March 2006 MC outflow (Yokelson et al., 2007a; Crounse et al., 2009). Another very important source of BB emissions in the MILAGRO study region is the Yucatan, which accounts for 7\% of Mexico's land area, but almost $30 \%$ of the total biomass burned in Mexico annually (2002-2006 average) and almost $40 \%$ of the biomass burned in Mexico in 2006. (Sect. 4 describes the model used to generate these estimates.) From the perspective of the MILAGRO campaign, Yucatan BB emissions are important because $\mathrm{MC}$ and the Yucatan impact nearly the same regional environment and Yucatan emissions can be transported to MC or interact with the MC plume downwind of the city. For example, in 1998 intense BB in the Yucatan impacted air quality in much of Mexico and the US (Kreidenweis et al., 2001).

Yucatan BB is also of interest beyond the scope of the MILAGRO campaign. On a global basis, BB is the largest source of primary fine carbonaceous particles, the second largest source of trace gases, and it occurs mostly in the tropics, which play a critical role in global atmospheric chemistry (Andreae and Merlet, 2001; Kreidenweis et al., 1999). However, both the initial emissions from BB and the postemission chemistry in smoke are poorly characterized and MILAGRO offered an opportunity to study these topics with well-equipped research aircraft. Further, most of the research on BB has been done in the Southern Hemisphere (SH) tropics during the SH dry season June-October (Andreae and Merlet, 2001). However, significant amounts of BB also occur in the Northern Hemisphere (NH) tropics, which experience a dry season and a peak in BB in February-May. Major fire theatres in the NH tropics include the Indochina peninsula, the Indian subcontinent, the Sahel region of Africa,
Northern South America, Central America, and the Yucatan (Lacaux et al., 1996; http://maps.geog.umd.edu). Finally, the tropical dry forests of the Yucatan are an example of the ecosystem that accounts for the most biomass burned globally (IGBP, 1997). Emissions measurements have been made in the tropical dry, "Miombo" forests of Africa (Sinha et al., 2004). However, the Miombo region is minimally developed with mostly understory burning and only limited, primitive slash and burn agriculture (IGBP, 1997). In contrast, the Yucatan has high rates of forest clearing (using fire) for conversion to mechanized agriculture and also burning of residues from existing crops.

This paper presents the first detailed measurements of the initial trace gas and particle emissions from fires in the $\mathrm{NH}$ tropics (up to 49 species on 20 fires). It includes the first insitu measurement of $\mathrm{OH}$ in a $\mathrm{BB}$ plume and measurements of numerous post-emission changes in trace gas and particle species in one plume. Only a few observations of the chemical evolution of individual BB plumes have been made (Goode et al., 2000; Yokelson et al., 2003; Jost et al., 2003; Hobbs et al., 2003; Abel et al., 2003) and the observed evolution is only partially reproduced by models (Tabazadeh et al., 2004; Trentmann et al., 2005; Mason et al., 2006; Alvarado and Prinn, 2009). Thus, these measurements of smoke evolution add substantially to our limited knowledge of this topic. We estimate the monthly to annual production of fire emissions from the Yucatan and summarize their regional transport to show the impact of these fires on the region. Finally, some general comments on global NH tropical biomass burning are offered.

\section{Experimental details}

Due to the large number of instruments deployed on the two research aircraft we can only present a list of the species measured and a few basic details here. More detail is found on all the instruments on the Twin Otter in Yokelson et al. (2007a) and in various other papers cited for each C-130 measurement.

\subsection{Measurements on the Twin Otter}

The University of Montana airborne Fourier transform infrared spectrometer (AFTIR) measured samples temporarily detained in the flow-through gas cell to quantify water vapor $\left(\mathrm{H}_{2} \mathrm{O}\right)$, carbon dioxide $\left(\mathrm{CO}_{2}\right)$, carbon monoxide (CO), methane $\left(\mathrm{CH}_{4}\right)$, nitric oxide (NO), nitrogen dioxide $\left(\mathrm{NO}_{2}\right)$, ammonia $\left(\mathrm{NH}_{3}\right)$, hydrogen cyanide $(\mathrm{HCN})$, ethene $\left(\mathrm{C}_{2} \mathrm{H}_{4}\right)$, acetylene $\left(\mathrm{C}_{2} \mathrm{H}_{2}\right)$, formaldehyde $(\mathrm{HCHO})$, methanol $\left(\mathrm{CH}_{3} \mathrm{OH}\right)$, acetic acid $\left(\mathrm{CH}_{3} \mathrm{COOH}\right)$, formic acid $(\mathrm{HCOOH})$, and ozone $\left(\mathrm{O}_{3}\right)$.

Ram air was grab-sampled into stainless steel canisters (whole air sampling - WAS) that were later analyzed at the University of Miami by gas chromatography (GC) with a 
flame ionization detector (FID) for $\mathrm{CH}_{4}$, and the following non-methane hydrocarbons (NMHC): ethane, $\mathrm{C}_{2} \mathrm{H}_{4}, \mathrm{C}_{2} \mathrm{H}_{2}$, propane, propene, isobutane, $\mathrm{n}$-butane, $\mathrm{t}-2$ butene, 1-butene, isobutene, c-2-butene, 1,3 butadiene, cyclopentane, isopentane, and n-pentane. $\mathrm{CO}$ was measured in parallel with the $\mathrm{CH}_{4}$ measurement, but utilized GC with a Trace Analytical Reduction Gas Detector (RGD). Canisters were also collected for later analysis at the United States Forest Service (USFS) Fire Sciences Laboratory by GC/FID/RGD for $\mathrm{CO}_{2}, \mathrm{CO}, \mathrm{CH}_{4}, \mathrm{H}_{2}$, and several $\mathrm{C}_{2}-\mathrm{C}_{3}$ hydrocarbons. The canister-filling inlet (large diameter, fast flow) also supplied sample air for a Radiance Research Model 903 integrating nephelometer that measured "dry" (inlet $\mathrm{RH}<20 \%$ ) $\mathrm{b}_{\text {scat }}$ at $530 \mathrm{~nm}$ at $0.5 \mathrm{~Hz}$. The $\mathrm{b}_{\text {scat }}$ measured at the inlet temperature and pressure was converted to $b_{\text {scat }}$ at standard temperature and pressure (STP, $273 \mathrm{~K}, 1 \mathrm{~atm}$ ) and then multiplied by $208800 \pm 11900$ to yield the mass of particles with aerodynamic diameter $<2.5$ microns $\left(\mathrm{PM}_{2.5}\right)$ in $\mu \mathrm{g} / \mathrm{sm}^{3}$ of air, based on a gravimetric "calibration" similar to that described in Trent et al. (2000).

An isokinetic particle inlet sampled fine particles with a diameter cut-off of a few microns. Particles of diameter $<1$ micron account for nearly all the fine particle $\left(\mathrm{PM}_{2.5}\right)$ mass emitted by biomass fires (Radke et al., 1991). This inlet supplied sample air to two particle samplers (MPS-3, California Measurements, Inc.) that were used to collect aerosol particles onto transmission electron microscope (TEM) grids in three size ranges over time intervals of $\sim 1$ to $10 \mathrm{~min}$ for subsequent TEM analyses. Details of the analyses are described in Adachi and Buseck (2008). The same inlet also supplied a LiCor (Model \#7000) measuring $\mathrm{CO}_{2}$ and $\mathrm{H}_{2} \mathrm{O}$ at $5 \mathrm{~Hz}$ and a UHSAS (Ultra High Sensitivity Aerosol Spectrometer, Particle Metrics, Inc.) deployed by the University of Colorado (CU). The UHSAS provided the number of particles in each of 99 user-selectable bins for diameters between 55 and $1000 \mathrm{~nm}$ at $1 \mathrm{~Hz}$. All three Twin Otter inlets were located within $30 \mathrm{~cm}$ of each other. The nephelometer was not available on the 12 March flight so we used the UHSAS particle counting/size data to indirectly determine particle mass. We assumed spherical particles and integrated over the dry size distribution measured by the UHSAS, to obtain an estimate of the volume of particles $\left(\mathrm{PV}_{1}, \mu \mathrm{m}^{3} / \mathrm{cm}^{3}\right)$ in air at $1 \mathrm{~Hz}$. We then noted that on 22 and 29 of March the $\mathrm{PV}_{1}$ (for $\mathrm{PV}_{1}<\sim 30$ ) was related to $\mathrm{b}_{\text {scat }}$ as follows:

$\mathrm{b}_{\text {scat }}=\mathrm{PV}_{1} \times 1.25( \pm 0.25) \times 10^{-5}$

On 12 March, the $\mathrm{PV}_{1}$ did not exceed $30 \mu \mathrm{m}^{3} / \mathrm{cm}^{3}$ in the plume of Fire \#3. We used equation 1 to convert $P V_{1}$ to $b_{\text {scat }}$ and then converted $\mathrm{b}_{\text {scat }}$ to $\mathrm{PM}_{2.5}$ as described above.

\subsection{Measurements on the C-130}

\subsubsection{Continuous measurements}

The continuous measurements are listed in order of their sampling frequency starting with nominal $1 \mathrm{~s}$ resolution. A CO vacuum ultraviolet (VUV) resonance fluorescence instrument, similar to that of Gerbig et al. (1999), was operated on the C-130 through the National Center for Atmospheric Research (NCAR) and NSF. Sulfur dioxide $\left(\mathrm{SO}_{2}\right)$ was measured by the NOAA UV pulsed fluorescence instrument (Thermo Electron model 43C-TL modified for aircraft use). $\mathrm{O}_{3}, \mathrm{NO}, \mathrm{NO}_{2}$, and $\mathrm{NO}_{\mathrm{y}}$ (the sum of all $\mathrm{N}$-containing species minus $\mathrm{HCN}, \mathrm{NH}_{3}$, and $\mathrm{N}_{2}$ ) were measured by the NCAR chemiluminescence instrument (Ridley et al., 2004). Formaldehyde was measured by the NCAR difference frequency generation (DFG) airborne spectrometer (Weibring et al., 2007). The absorption $(530 \mathrm{~nm})$, scattering $(550 \mathrm{~nm})$, number, and size distribution of dry particles was measured at $1-10 \mathrm{~s}$ resolution by a particle soot absorption photometer (PSAP), nephelometer (TSI 3563), and optical particle counter (OPC) all deployed by the University of Hawaii (Clarke et al., 2004). The total $550 \mathrm{~nm}$ scattering was converted to STP scattering and then $\mathrm{PM}_{2.5}\left(\mu \mathrm{g} / \mathrm{sm}^{3}\right)$ using a dry mass scattering efficiency (MSE) of $4.8 \pm 1.0$ obtained for a USFS TSI model 3563 during the gravimetric calibration carried out for the Twin Otter nephelometer. The absorption was used directly with the scattering to calculate single scattering albedo (SSA) or converted to an estimated black carbon in $\mu \mathrm{g} / \mathrm{sm}^{3}$ using a mass absorption efficiency (MAE) of $12 \pm 4$ (Martins et al., 1998). The NCAR Scanning Actinic Flux Spectroradiometers measured $25 \mathrm{~J}$ values at $10 \mathrm{~s}$ resolution (Shetter and Müller, 1999). An NCAR selected ion chemical ionization mass spectrometer (SICIMS) measured the hydroxyl radical $(\mathrm{OH})$, sulfuric acid $\left(\mathrm{H}_{2} \mathrm{SO}_{4}\right)$, and methane sulfonic acid (MSA) at $30 \mathrm{~s}$ time resolution (Mauldin et al., 2003).

\subsubsection{Discrete measurements}

The PAN-CIGARette (PAN-CIMS Instrument by Georgia Tech and NCAR, small version, Slusher et al., 2004) measured compounds collectively referred to as PANs (PAN, peroxyacetyl nitrate; PPN, peroxypropionyl nitrate; PBN, peroxybutyryl nitrates = sum of peroxy-n-butyryl- and peroxyisobutyryl nitrates; MoPAN, Methoxyperoxyacetyl nitrate; APAN, peroxyacryloyl nitrate; MPAN, peroxymethacryloyl nitrate) in turn on a $2 \mathrm{~s}$ cycle. A California Institute of Technology (Caltech) CIMS measured a suite of organic acids (acetic, peroxyacetic, formic, and propanoic acid); and $\mathrm{SO}_{2}$, $\mathrm{HCN}$, hydrogen peroxide $\left(\mathrm{H}_{2} \mathrm{O}_{2}\right)$, nitrous acid (HONO), and nitric acid $\left(\mathrm{HNO}_{3}\right)$. The mixing ratio of each species was measured for $0.5 \mathrm{~s}$, in turn during a multi-species scan, with a period ranging from 4-20 s for each analyte (Crounse et al., 2006). An Aerodyne high-resolution time-of-flight aerosol 
mass spectrometer (HR-ToF-AMS) operated by CU (DeCarlo et al., 2006, 2008; Aiken et al., 2008) measured the organic aerosol mass (OA); the OA to organic carbon (OC) mass ratio; and non-refractory (NR) sulfate, nitrate, ammonium, and chloride $\left(\mu \mathrm{g} / \mathrm{sm}^{3} 1 \mathrm{~atm}, 273 \mathrm{~K}\right)$ for the last $6 \mathrm{~s}$ of each $12 \mathrm{~s}$ measurement cycle. (The first $6 \mathrm{~s}$ of each cycle measured size distributions.) At times continuous $4 \mathrm{~s}$ particle chemistry averages were recorded instead. A proton transfer mass spectrometer (PTR-MS) measured $\mathrm{CH}_{3} \mathrm{OH}$, acetonitrile $\left(\mathrm{CH}_{3} \mathrm{CN}\right)$, acetaldehyde, acetone, methyl ethyl ketone, methyl propanal, hydroxyacetone plus methyl acetate, benzene, and 13 other species in a $35 \mathrm{~s}$ cycle (Karl et al., 2007, 2009).

\subsection{Generalized airborne sampling protocol}

The Twin Otter and C-130 were based in Veracruz with other MILAGRO research aircraft (http://mirage-mex.acd. ucar.edu/). The main goal of the Twin Otter flights was to sample fires and the C-130 also sampled a few fires. On both aircraft, background air (i.e. ambient boundary layer (BL) air not in plumes) was characterized when not sampling BB plumes. The continuous instruments operated in real time in background air. The discrete instruments acquired numerous spot measurements in background air. These spot measurements should be representative since the continuous instruments showed that the background air was well-mixed on the spatial scale corresponding to the discrete sampling intervals.

To measure the initial emissions from the fires, the aircraft usually sampled smoke less than several minutes old by penetrating the column of smoke $150-600 \mathrm{~m}$ above the active flame front. A few "fresh" smoke samples up to 10$30 \mathrm{~min}$ old were acquired at elevations up to $1700 \mathrm{~m}$. The continuous instruments monitored their species while penetrating the plume up to five times per fire. On the Twin Otter, the AFTIR, MPS-3, and WAS were used for spot measurements in the smoke plumes. To allow calculation of excess concentrations in the smoke plume; paired background spot measurements were made just outside the plume. The discrete instruments on the C-130 always acquired at least one sample, and usually several, that were within the fresh smoke plumes. The background for those samples was taken as the average of the discrete measurements in the background air near the plume.

More than a few kilometers downwind from the source, smoke samples are already "photochemically aged" and better for probing post-emission chemistry than estimating initial emissions (Goode et al., 2000; Hobbs et al., 2003). Both aircraft acquired some samples in aged plumes up to $\sim 14 \mathrm{~km}$ downwind and $\sim 1.5$ h old (see Sect. 3.4).

\subsection{Data processing and synthesis}

Grab, or discrete, samples of both a plume and the adjacent background can be used to calculate excess mixing ratios
( $\Delta \mathrm{X}$, the mixing ratio of species " $\mathrm{X}$ " in the plume minus the mixing ratio of " $\mathrm{X}$ " in the background air). $\Delta \mathrm{X}$ reflects the degree of dilution of the plume and the instrument response time. Thus, a useful, derived quantity is the normalized excess mixing ratio (NEMR) where $\Delta \mathrm{X}$ is divided by the "simultaneously" measured excess mixing ratio of another species $(\Delta \mathrm{Y})$; usually a fairly long-lived plume "tracer" such as $\Delta \mathrm{CO}$ or $\Delta \mathrm{CO}_{2}$. The uncertainty in the NEMR includes a contribution due to differences in response times if 2 instruments are involved. A measurement of $\Delta \mathrm{X} / \Delta \mathrm{Y}$ in smoke up to a few minutes old is a molar emission ratio (ER). We computed fire-average molar ER for each individual fire from grab or discrete samples as follows. First, if there is only one sample of a fire then the calculation is trivial and equivalent to the definition of $\Delta \mathrm{X} / \Delta \mathrm{Y}$ given above. For multiple grab (or discrete) samples of a fire, the fire-average, ER was obtained from the slope of the least-squares line (with the intercept forced to zero) in a plot of one set of excess mixing ratios versus another. This method is justified in detail by Yokelson et al. (1999). When the AFTIR and the USFS WAS measured the same pair of compounds on the same fire, their data were combined in the plots as shown in Fig. 1a.

Emission ratios can also be obtained from the continuous instruments by comparing the integrals of $\Delta \mathrm{X}$ and $\Delta \mathrm{Y}$ as the aircraft passes through a nascent smoke plume. Comparing the integrals helps compensate for the different instrument response times (Karl et al., 2007). When only one pass is made thru the plume of a fire (as on the C-130), the ratio of those integrals gives the ER. When more than one pass is made through the plume of a single fire with continuous instruments (e.g. PM and $\mathrm{CO}_{2}$ on the Twin Otter), we plot the integrals versus each other and obtain the ER from the slope; analogous to grab sample plots. For the C-130 we usually compared integrals for various species to the integrals for CO. The exception was the PTR-MS. For the PTR-MS we obtained ER to methanol averaged over the three C-130 fires by comparing the integrated excess for all three fires to the integrated excess amount for methanol. Finally, it is sometimes possible to use a "proxy" to generate continuous data from discrete samples. For example, the ratio of $\mathrm{HCN}$ to $\mathrm{NO}_{\mathrm{y}}$ should not vary much throughout an individual plume. Thus, an estimate of the real-time variation in $\mathrm{HCN}$ can be obtained by multiplying the continuous $\mathrm{NO}_{\mathrm{y}}$ data by the $\mathrm{HCN} / \mathrm{NO}_{\mathrm{y}}$ ratio measured intermittently in the plume. Subsequently, the "continuous" HCN trace can be integrated and compared to integrals from other continuous instruments such as $\mathrm{CO}$. For two species measured discretely by the Caltech CIMS $\left(\mathrm{SO}_{2}\right.$ and $\mathrm{HCN}$ ) it was meaningful to compare the "integral-based" ER to CO to the "plot-based" ER to CO. In comparison to the integral-based ER, the plot-based approach returned individual fire ER that were less than $10 \%$ different when 23 minutes were spent in plume and up to $19 \%$ different for brief sample periods. The ER obtained from the plot-based method did not show significant bias when averaged over all five comparable samples (the plot-based ER was $0.998 \pm 0.14$ 
of the integral based ER).We take this as a rough estimate of the additional uncertainty affecting the study-average ER calculated from discrete samples. The lack of bias makes sense since e.g. a slower-responding $\mathrm{CO}$ instrument could read a little low when entering the plume, but a little high when leaving the plume. Figure 1 illustrates typical analyte levels encountered and gives examples of ER derivations.

It is also possible to estimate ER from measurements that were not made simultaneously, or that were made on different aircraft. For example, the molar ER to $\mathrm{CO}_{2}$ for the NMHC measured by U-Miami WAS on the Twin Otter was derived for each fire as follows. The molar ER to $\mathrm{CO}$ measured by WAS from a fire was multiplied by the molar $\Delta \mathrm{CO} / \Delta \mathrm{CO}_{2}$ ER measured on that same fire by AFTIR. The study-average molar ER to $\mathrm{CO}_{2}$ for species measured on the $\mathrm{C}-130$ (no $\mathrm{CO}_{2}$ data on $\mathrm{C}-130$ ) was estimated by multiplying the $\mathrm{C}-130$ molar emission ratio to $\mathrm{CO}$ or $\mathrm{CH}_{3} \mathrm{OH}$ by the study-average molar emission ratio of these latter species to $\mathrm{CO}_{2}$ measured by AFTIR/WAS on board the Twin Otter (on different fires). CO was measured with high accuracy by AFTIR, the VUV instrument, and WAS. Methanol was measured with high accuracy by the AFTIR and PTR-MS. This facilitated coupling data from various platforms and instruments or for different fires. As a plume ages, the downwind NEMR $(\Delta \mathrm{X} / \Delta \mathrm{Y})$ can vary from the ER that was measured at the source. The accuracy of downwind $\Delta \mathrm{X} / \Delta \mathrm{Y}$ may be reduced by differences in the time response of instruments, but in the dilute plume, the excess mixing ratios tend to vary slower in time and space making timing differences less critical. Section 3.4 discusses uncertainty in the aging plume in detail.

\subsubsection{Estimation of fire-average initial emission factors}

For any carbonaceous fuel, a set of ER to $\mathrm{CO}_{2}$ for the other major carbon emissions (i.e. $\mathrm{CO}, \mathrm{CH}_{4}$, a suite of nonmethane organic compounds (NMOC), particle carbon, etc) can be used to calculate emission factors (EF, g compound emitted/kg dry fuel burned) for all the emissions quantified from the source using the carbon mass-balance method (Yokelson et al., 1996). In this project, EF were calculated for all the individual fires sampled by the Twin Otter from AFTIR measurements of $\mathrm{CO}_{2}, \mathrm{CO}, \mathrm{CH}_{4}$, and NMOC and WAS measurements of $\mathrm{CO}_{2}, \mathrm{CO}, \mathrm{CH}_{4}$, and non-methane hydrocarbons (NMHC, a subset of NMOC consisting of compounds containing only $\mathrm{C}$ and $\mathrm{H}$ and no $\mathrm{O}$ or $\mathrm{N}$ ). The nephelometer $\mathrm{PM}_{2.5}$ and the AMS/PSAP measurements of the mass fraction of $\mathrm{C}$ in the Yucatan BB aerosol $(0.48 \pm 0.08)$ were used to estimate the particulate carbon. We also calculated study-average EF for the species measured on the C-130 by using the study average ER for those species to $\mathrm{CO}_{2}$ calculated using the overlap species with the AFTIR as described above.

The carbon mass balance method assumes that all the volatilized carbon is detected. By ignoring unmeasured
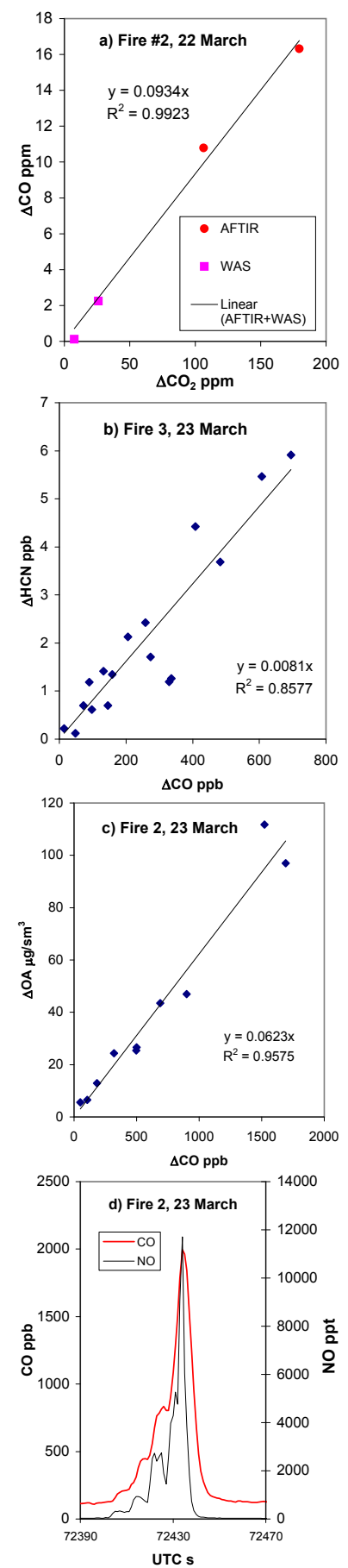

Fig. 1. (a) WAS and AFTIR spot measurements were coupled to determine the ER $\Delta \mathrm{CO} / \Delta \mathrm{CO}_{2}$ on the Twin Otter and they agreed well with each other. This is a key quantity used to synthesize data from the two aircraft. (b) The $\Delta \mathrm{HCN} / \Delta \mathrm{CO}$ ER from plotting discrete CIMS samples vs. the $\mathrm{CO}$ measured at the same time for all data in the fresh and aging plume of Fire \#3. The slope of the plot gives an ER within $10 \%$ of the proxy method (Sect. 2.4). $\Delta \mathrm{HCN} / \Delta \mathrm{CO}$ does not vary greatly in the downwind samples. (c) Four-second averages for $\triangle \mathrm{OA}$ from the AMS plotted versus the 4-s averages of $\triangle \mathrm{CO}$. (d) Continuous NO and CO for same fire as in c). Comparison of the integrated amounts above background yields the ER. 
Table 1. Details of the fires sampled in the Yucatan by the Twin Otter and C-130 during MILAGRO (March 2006).

\begin{tabular}{|c|c|c|c|c|c|c|c|c|}
\hline \multirow{2}{*}{$\begin{array}{l}\text { Date } \\
\mathrm{dd} / \mathrm{mm} / \mathrm{yy}\end{array}$} & \multirow{2}{*}{$\begin{array}{l}\text { Fire } \\
\#\end{array}$} & \multirow{2}{*}{$\begin{array}{l}\text { Lat } \\
\text { dd.dddd }\end{array}$} & \multirow{2}{*}{$\begin{array}{l}\text { Long } \\
\text { dd.dddd }\end{array}$} & \multirow{2}{*}{$\begin{array}{l}\text { Time } \\
\text { LT }\end{array}$} & \multicolumn{2}{|c|}{ Coverage by cloud-free MODIS OP } & \multirow{2}{*}{$\begin{array}{l}\text { Hotspot } \\
\mathbf{Y} / n\end{array}$} & \multirow{2}{*}{$\begin{array}{l}\text { Fuels } \\
\text { observed from aircraft }\end{array}$} \\
\hline & & & & & Terra hhmm LT & Aqua hhmm LT & & \\
\hline $12 / 03 / 06$ & 3 & 19.1834 & -90.7269 & 1405-1409 & 1034 & 1338 & $n$ & crop residue (CR) some small-holdings \\
\hline $12 / 03 / 06$ & 4 & 19.6330 & -90.6758 & $1420-1424$ & 1034 & 1338 & $n$ & CR larger holdings \\
\hline $12 / 03 / 06$ & 5 & 19.5947 & -90.6497 & 1555 & 1034 & 1338 & $n$ & nearly all $\mathrm{CR}$, one spot in forest \\
\hline $22 / 03 / 06$ & 1 & 19.5306 & -90.1063 & $1314-1317$ & 1110 & 1240 & $n$ & $\begin{array}{l}\mathrm{CR} / \text { deforestation (DF) for } \\
\text { mechanized agriculture (MA) }\end{array}$ \\
\hline $22 / 03 / 06$ & 2 & 19.7748 & -89.8675 & $1329-1333$ & 1110 & 1240 & $\mathbf{Y}$ & CR/DF mixed (MA) \\
\hline $22 / 03 / 06$ & 3 & 19.7703 & -89.5177 & $1344-1348$ & 1110 & 1240 & $n$ & deforestation (DF) adjacent to MA \\
\hline $22 / 03 / 06$ & 4 & 19.8158 & -89.4578 & $1353-1356$ & 1110 & 1240 & $n$ & DF adj. MA \\
\hline $22 / 03 / 06$ & 5 & 19.8649 & -89.4717 & $1358-1401$ & 1110 & 1240 & $n$ & DF adj. MA \\
\hline $22 / 03 / 06$ & 6 & 20.3532 & -88.8383 & $1424-1427$ & 1110 & 1240 & $n$ & DF adj. MA \\
\hline $22 / 03 / 06$ & 7 & 20.8525 & -88.4018 & $1447-1450$ & 1110 & 1240 & $n$ & DF adj. MA \\
\hline $22 / 03 / 06$ & 8 & 21.2085 & -89.0345 & $1512-1529$ & 1110 & 1240 & $\mathbf{Y}$ & $\begin{array}{l}\text { CR/DF many small fields; also } \\
\text { burned brush, scrub, and grass }\end{array}$ \\
\hline $23 / 03 / 06$ & 1 & 19.8266 & -89.3825 & 1410 & 1016 & 1321 & $n$ & unknown \\
\hline $23 / 03 / 06$ & 2 & 19.7648 & -89.5220 & 1412 & 1016 & 1321 & $\mathbf{Y}$ & unknown \\
\hline $23 / 03 / 06$ & 3 & 19.8201 & -89.3681 & 1417 & 1016 & 1321 & $n$ & unknown \\
\hline 29/03/06 & 1 & 19.6235 & -90.3815 & $1337-1353$ & 1116 & 1246 & $\mathbf{Y}$ & CR/DF clearing scrub/brush for MA \\
\hline 29/03/06 & 2 & 19.7208 & -90.4108 & 1346 & 1116 & 1246 & $n$ & DF adjacent to mid-sized fields \\
\hline 29/03/06 & 3 & 19.4230 & -90.2315 & 1400 & 1116 & 1246 & $n$ & $\begin{array}{l}\text { CR/DF many small fields; also burned } \\
\text { brush, scrub, and grass }\end{array}$ \\
\hline 29/03/06 & 4 & 19.5128 & -89.8192 & $1412-1416$ & 1116 & 1246 & $n$ & CR MA \\
\hline 29/03/06 & 5 & 20.0371 & -89.8395 & $1435-1448$ & 1116 & 1246 & $n$ & CR MA \\
\hline $29 / 03 / 06$ & 6 & 20.0055 & -89.7808 & $1438-1441$ & 1116 & 1246 & $n$ & CR MA \\
\hline
\end{tabular}

gases, we may overestimate the emission factors by $1-2 \%$ (Andreae and Merlet, 2001). We also assumed all the fires burned in fuels that were $50 \% \mathrm{C}$ by mass on a dry weight basis (Susott et al., 1996), but the actual fuel carbon percentage could vary by $\pm 10 \%$ ( $2 \sigma)$ of our nominal value. EF scale linearly with the assumed fuel carbon fraction. Because much of the $\mathrm{NO}$ is quickly converted to $\mathrm{NO}_{2}$ after emission, we also report an EF for " $\mathrm{NO}_{\mathrm{x}}$ as NO." For any species "X" we abbreviate the EF as EFX.

\subsection{Details of flights}

\subsubsection{Twin Otter flight of 12 March}

Figure 2a shows the Twin Otter flight path over the Yucatan peninsula on 12 March along with the location of the fires that we sampled and the hotspots detected by MODIS. (The MODIS hotspots were obtained from the Mexican Comisión Nacional para el Conocimiento y Uso de la Biodiversidad (CONABIO) website at: http://www.conabio.gob. $\mathrm{mx} /$ conocimiento/puntos_calor/doctos/puntos_calor.html hereinafter cited as "CONABIO"). The fire locations and characteristics and any matches with hotspot locations are also shown in Table 1. Widespread cloud cover over the Yucatan could have obscured some fires during both of the satellite overpasses that covered the Yucatan: 10:34 LT (Terra 1, usually before most burning) and 13:38 LT (Aqua 2) (CONABIO). All three fires were sampled between 14:00 and 16:00 LT and all the fires were located near the coast $S$ of Campeche. The fuel for all these fires was crop residue
(CR) with a minor fraction in adjoining woodlands on Fire \#5. The fire numbers begin with \#3 because two fires were sampled enroute to the Yucatan that will be described elsewhere.

\subsubsection{Twin Otter flight of 22 March}

Figure $2 b$ shows the Twin Otter flight path over the Yucatan peninsula on 22 March along with the locations of the fires sampled and the MODIS hotspots. The fire locations, characteristics, and hotspot matches are also shown in Table 1. Eight fires were sampled between 13:14 and 15:29 LT of which 5 were deforestation fires (DF, burning forest slash) and 3 were "mixed" (CR fires that escaped and burned adjacent forest, or CR/DF). (Sect. 4 gives more detail on the fires.) The sampling was all after the last satellite overpass with coverage of the Yucatan (Aqua 1 12:40 LT). At the time we sampled Fire \#3 it was burning in slash in a small clearing surrounded by intact forest. The fire evidently began burning the adjacent forest by 23 March and was then sampled by the C-130 (see next section). Our Fire \#8 was located near the coast in a patchwork of small fields and differentaged forests suggesting intensive use by small holders. The fire started as a crop residue fire, but spread to adjoining fields and forest. Strong surface winds pushed this fire aggressively towards the southeast. At $600-700 \mathrm{~m}$ altitude, the plume "curled back" and dispersed northwest at higher elevations. Three samples of this fire's plume were obtained below $669 \mathrm{~m}$ (m.s.l.) and then 2 more were acquired at 

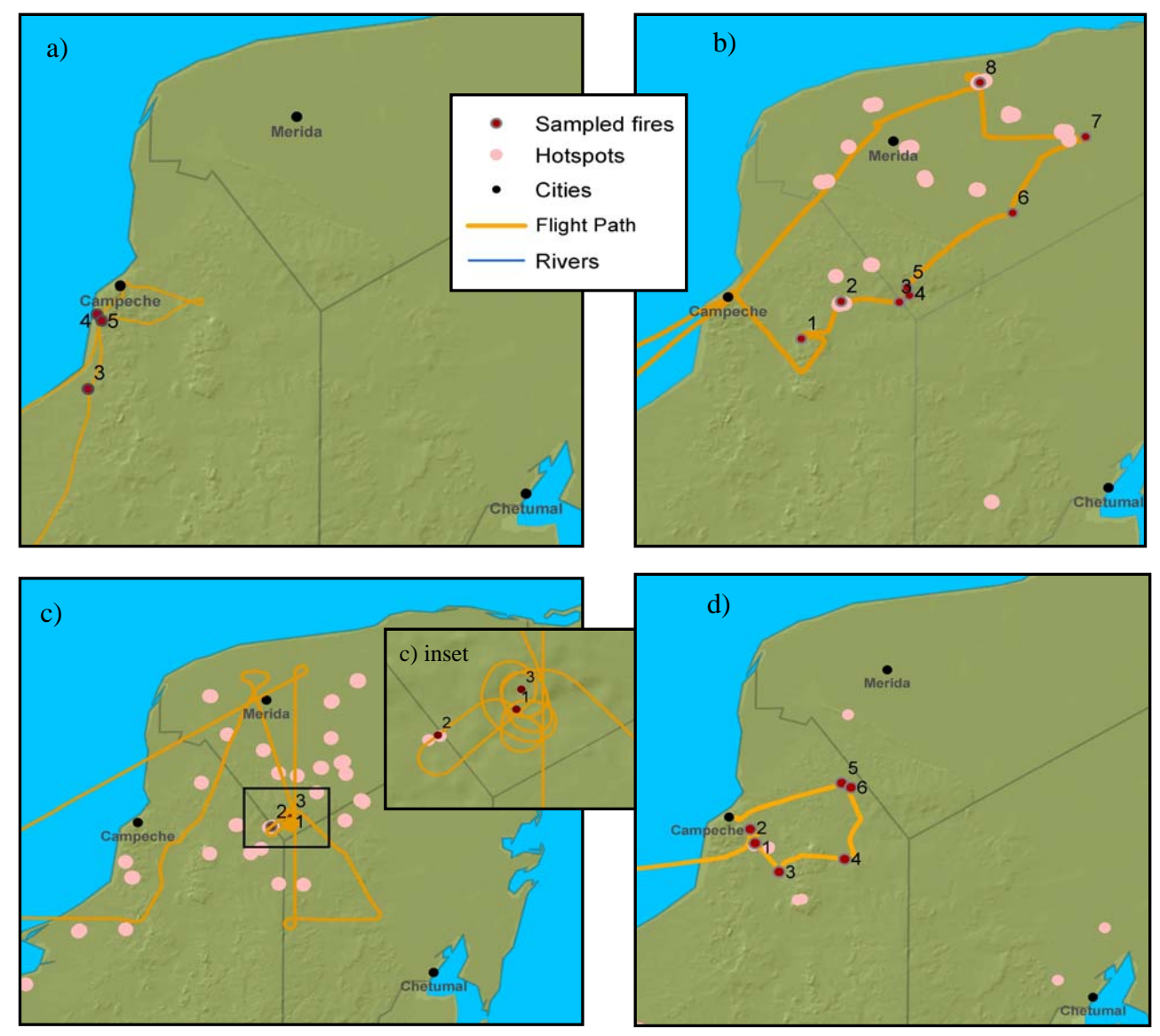

Fig. 2. Fires sampled, hot spots, and flight tracks for: (a) 12 March 2006. (b) 22 March 2006 (c) 23 March 2006. (d) 29 March 2006. Scale varies from plot to plot. For comparison the distance from Campeche to Merida is $155 \mathrm{~km}$.

$\sim 1700 \mathrm{~m}$ where the plume had probably aged $\sim 10-30 \mathrm{~min}$. Fire \#8 was one of several sampled fires that were detected by MODIS and in the case of Fire \#8 this indicates that it had burned for at least $\sim 3 \mathrm{~h}$.

\subsubsection{C-130 flight of 23 March: Yucatan portion}

On 23 March, from 14:05:35-14:06:39LT, the C-130 descended through 3 closely spaced "stacked" smoke layers (with embedded fair-weather cumulus) near the top of the boundary layer (2200-2500 m) over the Yucatan (Fig. 2c; Table 1). The 3 high smoke layers had aged up to several hours and probably experienced some cloud processing (based on the proximity of the clouds and the fact that the RH exceeded $100 \%$ as the C-130 passed through the middle layer). Next, at lower altitude, nascent smoke was sampled from three fires in the area; once per fire (14:09:31-14:16:47 LT). The sample of Fire \#2 acquired by the C-130 on 23 March was located $\sim 750$ meters from the sample acquired by the Twin Otter on 22 March of their "Fire \#3." A photograph of the C-130 Fire \#2 shows a large area of burned forest. Thus, this fire was likely a continuation of the one sampled from the Twin Otter a day earlier. This fire was also the only fire sampled by the C-130 that was detected by MODIS (CONABIO, Table 1).

The last C-130 sample of nascent smoke (from Fire \#3 on $23 \mathrm{March}$ ) was at $1700 \mathrm{~m}$ and thus about 10-30 min old. Immediately after this sample, the aircraft stayed in the plume and followed the smoke in a curving path for about $14 \mathrm{~km}$ down wind probing smoke that had presumably aged an additional $\sim 1.5 \pm 0.7 \mathrm{~h}$ relative to the sample of nascent smoke (14:16:48-14:18:31 LT) (Sect. 3.4). During the nominal aging interval from $1.27-1.47 \mathrm{~h}$ the RH exceeded $100 \%$ indicating possible cloud processing. By 14:19:41 LT, the C-130 had climbed back above the boundary layer and set course for Veracruz.

\subsubsection{Twin Otter flight of 29 March}

Figure $2 \mathrm{~d}$ shows the Twin Otter flight path over the Yucatan peninsula on 29 March, the fires sampled (from 13:37-14:41 LT), and the hotspot locations (from Terra 1 at 11:16 LT and Aqua 1 at 12:46 LT). The fire, fire type, and hotspot matches are also in Table 1 . In contrast to the 22 March flight when most of the fires found were DF, on 29 
March all but one of the fires found were originally CR. Thus, of the six fires found, there was one DF, $3 \mathrm{CR}$, and 2 mixed (CR that escaped and also burned some woodland).

\section{Results and discussion}

\subsection{Fire-average initial emission factors measured on the Twin Otter}

The fire-average emission factors $(\mathrm{EF} \mathrm{g} / \mathrm{kg})$ measured on the Twin Otter are shown in Table 2 along with the study average EF for DF and CR fires. If molar ER are preferred for an application, they can be obtained from the EF in Table 2 with consideration of the difference in molecular mass. The modified combustion efficiency (MCE, $\Delta \mathrm{CO}_{2} /\left(\Delta \mathrm{CO}_{2}+\Delta \mathrm{CO}\right)$ ) for each fire is also shown in Table 2. The MCE indicates the relative amount of flaming and smoldering combustion for biomass burning. Lower MCE indicates more smoldering (Yokelson et al., 2003). Figure 3 shows $\mathrm{EFCH}_{3} \mathrm{OH}$ vs. MCE and demonstrates that much of the large variation in $\mathrm{EFCH}_{3} \mathrm{OH}$ (factor of $\sim 4.5$ ) is correlated with the different MCE that occur naturally on biomass fires. In principle, it would be advantageous to incorporate this variability into emissions estimates. Unfortunately, at this time, MCE cannot be measured from satellites nor can seasonal trends in MCE be confidently assigned (Yokelson et al., 2008). For N and S species EF variability also arises from the variable $\mathrm{N}$ and S components of the fuel (Yokelson et al., 1996, 2003, 2008). We note that the sum of the EF for gas-phase nonmethane organic compounds (NMOC) in Table 2 is 12.8 and $12.0 \mathrm{~g} / \mathrm{kg}$ for CR and DF fires, respectively. However, oxygenated volatile organic compounds (OVOC) normally dominate the gas-phase NMOC emitted by biomass fires and in this study many OVOC common in biomass smoke were not measured on the Twin Otter. In an earlier study of fire emissions with enhanced detection of gas-phase OVOC, the combined instrumentation could not identify about $50 \%$ of the gas-phase NMOC by mass (Yokelson et al., 2008). Therefore, we speculate that $30 \mathrm{~g} / \mathrm{kg}$ is a conservative estimate of the real sum of gas-phase NMOC from these Yucatan fire types (see also Sect. 3.2).

\subsubsection{Comparison to previous work on Yucatan and other deforestation fires}

Cofer et al. (1993) made the only other fire emissions measurements in the Yucatan. They measured $\mathrm{CO}_{2}, \mathrm{CO}, \mathrm{H}_{2}$, $\mathrm{CH}_{4}$, and total NMHC (TNMHC) on two deforestation fires in February of 1990 and 1991. Utilizing all 23 WAS smoke samples and 11 backgrounds they collected yielded an average $\mathrm{CO} / \mathrm{CO}_{2}$ ratio of 0.071 - equivalent to an MCE of 0.934 . Their MCE is a little higher than our DF average (0.927), but well within our range for DF (0.907-0.945). We can not derive EF from their data because the average molecular mass and carbon fraction of their TNMHC is unknown.

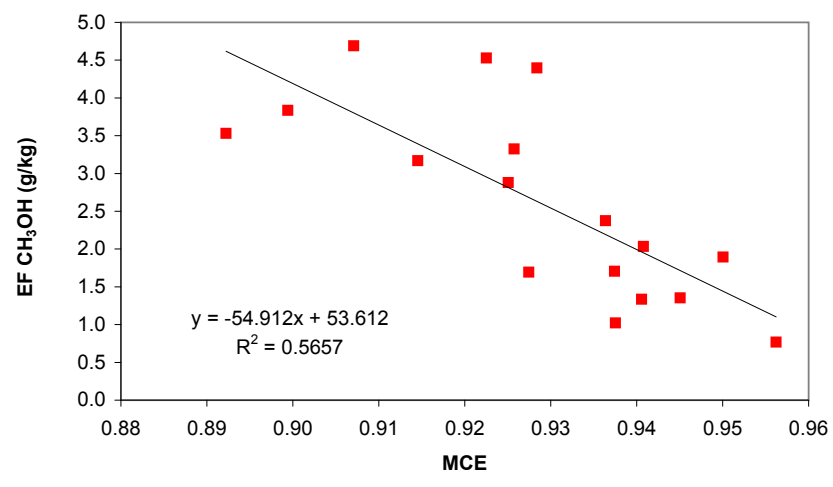

Fig. 3. The variation in the fire-average initial EF for NMOC is typically high and it is usually well correlated with the modified combustion efficiency (MCE). High MCE indicates relatively more flaming combustion and low MCE indicates more smoldering.

We can directly compare to their molar ratios to $\mathrm{CO}$ for $\mathrm{H}_{2}$ $\left(0.35 \pm 0.13 ; 0.44 \pm 0.21\right.$ - Twin Otter) and $\mathrm{CH}_{4}(0.096 \pm 0.03$; $0.125 \pm 0.056$ - Twin Otter). Thus, while there is no statistically significant difference, our measurements imply moderately higher emissions of these smoldering compounds. The response of TNMHC instruments to OVOC is poorly characterized, but their large molar ratio of TNMHC/CO (24\%) agrees with our statement above (and Sect. 3.2) that the Twin Otter total NMOC is too low. The present study does, however, greatly expand the extent of speciation of Yucatan fire emissions.

We compare our DF data to the most recent and extensive measurements of DF in the Amazon, a study which included both airborne measurements of nascent emissions and ground-based measurements of the smoldering emissions that cannot be sampled from an aircraft (Yokelson et al., 2008). A few main features stand out. The largest difference occurs for initial emissions of particles. The EFPM 2.5 for the Twin Otter Yucatan DF is only $4.5 \pm 1.6 \mathrm{~g} / \mathrm{kg}$ compared to $14.8 \pm 3.4 \mathrm{~g} / \mathrm{kg}$ for the Amazon. Both of these values are significantly different from the recommendation of Andreae and Merlet (2001) of $9.1 \pm 1.5 \mathrm{~g} / \mathrm{kg}$, although their recommendation agrees remarkably well with the average of the Yucatan and Amazon values $(9.7 \mathrm{~g} / \mathrm{kg})$. A main factor contributing to the observed difference in $\mathrm{EFPM}_{2.5}$ is probably that the March 2006 early dry season fires that we were able to sample in the Yucatan were much smaller and less "intense" than the late dry season fires sampled in Brazil. As discussed in detail by Yokelson et al. (2007b) and references therein, it is likely that larger more intense fires have much larger particle emission factors. Since a large fraction of annual biomass burning occurs late in the dry season, the late dry season EFPM may better represent the annual particle production. Also, we show in section 3.4 that the $\Delta \mathrm{PM}_{2.5} / \Delta \mathrm{CO}$ ratio could increase by a factor of $\sim 2.6$ in $\sim 1.4 \mathrm{~h}$ after emission. This factor times our initial $\mathrm{EFPM}_{2.5}$ of $4.5 \mathrm{~g} / \mathrm{kg}$ suggests that shortly after emission, about $12 \mathrm{~g} / \mathrm{kg}$ 
Table 2. The date, fire number, fire type (see text), and emission factors $(\mathrm{g} / \mathrm{kg}$ ) sorted by primary technique for fires sampled by the Twin Otter in the Yucatan during March 2006. Blank indicates no data.

\begin{tabular}{|c|c|c|c|c|c|c|c|c|c|c|c|c|c|c|c|c|c|c|c|c|c|}
\hline & $12 / 3$ & $12 / 3$ & $12 / 3$ & $22 / 3$ & $22 / 3$ & $22 / 3$ & $22 / 3$ & $22 / 3$ & $22 / 3$ & $22 / 3$ & $22 / 3$ & $29 / 3$ & $29 / 3$ & $29 / 3$ & $29 / 3$ & $29 / 3$ & $29 / 3$ & & & & \\
\hline Species & 3 & 4 & 5 & 1 & 2 & 3 & 4 & 5 & 6 & 7 & 8 & 1 & 2 & 3 & 4 & 5 & 6 & $\mathrm{CR}$ & & DF & \\
\hline AFTIR & $\mathrm{CR}$ & $\mathrm{CR}$ & $\mathrm{CR}$ & MIX & MIX & $\mathrm{DF}$ & $\mathrm{DF}$ & $\mathrm{DF}$ & $\mathrm{DF}$ & $\mathrm{DF}$ & MIX & MIX & $\mathrm{DF}$ & MIX & $\mathrm{CR}$ & $\mathrm{CR}$ & $\mathrm{CR}$ & Avg & Stdev & Avg & Stdev \\
\hline $\mathrm{CO}_{2}$ & 1631 & 1722 & 1729 & 1607 & 1627 & 1644 & 1651 & 1711 & 1600 & 1651 & 1671 & 1656 & 1682 & 1695 & 1603 & 1679 & 1689 & 1676 & 50 & 1656 & 38 \\
\hline $\mathrm{CO}$ & 80.04 & 57.63 & 50.38 & 114.4 & 96.76 & 84.71 & 88.22 & 63.27 & 104.3 & 84.26 & 72.25 & 82.44 & 71.35 & 68.13 & 123.2 & 67.25 & 71.74 & 75.04 & 25.81 & 82.68 & 14.21 \\
\hline MCE & 0.928 & 0.950 & 0.956 & 0.899 & 0.915 & 0.925 & 0.923 & 0.945 & 0.907 & 0.926 & 0.936 & 0.927 & 0.938 & 0.941 & 0.892 & 0.941 & 0.937 & 0.934 & 0.023 & 0.927 & 0.013 \\
\hline NO & & & & 4.780 & 1.620 & 2.688 & 3.866 & 1.275 & 1.496 & 0.877 & 5.386 & 2.412 & 3.909 & 6.345 & 3.206 & 1.960 & 1.322 & 2.163 & 0.958 & 2.352 & 1.334 \\
\hline $\mathrm{NO}_{2}$ & 4.457 & 7.077 & 4.550 & 11.51 & 2.360 & 2.049 & 3.559 & 1.248 & 4.598 & 3.858 & 12.43 & 4.818 & 6.253 & 9.669 & 4.753 & 1.253 & 1.275 & 3.894 & 2.256 & 3.594 & 1.791 \\
\hline $\mathrm{NO}_{\mathrm{x}}$ as $\mathrm{NO}$ & 2.907 & 4.615 & 2.968 & 12.29 & 3.159 & 4.025 & 6.187 & 2.089 & 4.495 & 3.394 & 13.49 & 4.568 & 7.987 & 12.65 & 5.673 & 2.777 & 2.154 & 3.516 & 1.337 & 4.696 & 2.099 \\
\hline $\mathrm{CH}_{4}$ & 9.648 & 1.471 & 2.067 & 7.349 & 6.302 & 6.055 & 7.326 & 2.557 & 9.213 & 6.595 & 4.151 & 3.517 & 3.718 & 4.883 & 5.131 & 4.402 & 2.709 & 4.238 & 2.993 & 5.911 & 2.427 \\
\hline $\mathrm{HCHO}$ & & & & & 3.136 & 6.661 & & 0.886 & 0.879 & 2.613 & & & & & & & & & & 2.760 & 2.726 \\
\hline $\mathrm{CH}_{3} \mathrm{OH}$ & 4.397 & 1.892 & 0.766 & 3.834 & 3.168 & 2.879 & 4.527 & 1.354 & 4.689 & 3.325 & 2.376 & 1.694 & 1.021 & 1.336 & 3.530 & 2.034 & 1.704 & 2.387 & 1.327 & 2.966 & 1.544 \\
\hline $\mathrm{CH}_{3} \mathrm{COOH}$ & 4.643 & 6.476 & 7.070 & & 3.544 & 2.534 & 2.412 & 1.431 & 4.678 & 3.416 & & 6.359 & & & & 3.250 & 2.388 & 4.765 & 2.013 & 2.894 & 1.220 \\
\hline $\mathrm{HCOOH}$ & 3.859 & 0.618 & 3.739 & & & & & & & & & & & & & & & 2.738 & 1.838 & & \\
\hline $\mathrm{NH}_{3}$ & 0.910 & 3.902 & 1.393 & 0.626 & 0.080 & 1.869 & & 0.539 & 0.309 & 0.366 & 1.675 & & & & & 0.350 & 0.339 & 1.379 & 1.477 & 0.771 & 0.739 \\
\hline $\mathrm{HCN}$ & & & & & 0.102 & 0.302 & & 0.225 & & 0.172 & 0.449 & & & 0.250 & & 0.277 & & 0.277 & & 0.233 & 0.065 \\
\hline \multicolumn{22}{|l|}{ WAS } \\
\hline ethane & 1.476 & 0.153 & 0.190 & & & 1.187 & & 0.490 & 1.611 & 1.065 & 0.668 & 0.866 & 0.992 & & & 0.897 & 0.662 & 0.676 & 0.548 & 1.069 & 0.403 \\
\hline ethene & 1.465 & 0.526 & 0.594 & & & 0.992 & & 0.742 & 1.452 & 1.127 & 1.065 & 0.813 & 0.925 & 0.433 & 0.962 & 0.761 & 0.746 & 0.842 & 0.341 & 1.048 & 0.265 \\
\hline propane & 0.436 & 0.040 & 0.054 & & & & & & & & & & & & & 0.256 & 0.184 & 0.194 & 0.163 & & \\
\hline propene & 0.942 & 0.173 & 0.205 & & & 0.521 & & 0.423 & 1.215 & 0.669 & 0.845 & 1.386 & 3.924 & & & 0.630 & 0.634 & 0.517 & 0.325 & 1.350 & 1.471 \\
\hline isobutane & 0.032 & 0.003 & 0.004 & & & & & & & & & & & & & 0.020 & 0.012 & 0.014 & 0.012 & & \\
\hline n-butane & 0.097 & 0.009 & 0.014 & & & & & & & & & & & & & 0.045 & 0.048 & 0.042 & 0.035 & & \\
\hline ethyne & 0.292 & 0.144 & 0.139 & & & & & & & & & 0.295 & & & & 0.234 & 0.202 & 0.202 & 0.064 & & \\
\hline $\mathrm{t}-2$ butene & 0.089 & 0.011 & 0.012 & & & & & & & & & & & & & 0.057 & 0.034 & 0.041 & 0.033 & & \\
\hline 1-butene & 0.195 & 0.041 & 0.044 & & & & & & & & & & & & & 0.127 & 0.080 & 0.097 & 0.065 & & \\
\hline isobutene & 0.176 & 0.022 & 0.031 & & & & & & & & & & & & & 0.117 & 0.064 & 0.082 & 0.064 & & \\
\hline c-2-butene & 0.067 & 0.008 & 0.009 & & & & & & & & & & & & & 0.043 & 0.025 & 0.031 & 0.025 & & \\
\hline cyclopentane & $3 \mathrm{E}-3$ & $1 \mathrm{E}-4$ & $4 \mathrm{E}-4$ & & & & & & & & & & & & & $2 \mathrm{E}-3$ & $1 \mathrm{E}-3$ & $1 \mathrm{E}-3$ & $1 \mathrm{E}-3$ & & \\
\hline isopentane & 0.014 & 0.001 & & & & & & & & & & & & & & 0.010 & 0.010 & 0.009 & 0.006 & & \\
\hline n-pentane & 0.030 & 0.003 & 0.005 & & & & & & & & & & & & & 0.020 & 0.014 & 0.014 & 0.011 & & \\
\hline 1,3 butadiene & 0.214 & 0.033 & 0.057 & & & & & & & & & & & & & 0.130 & 0.072 & 0.101 & 0.073 & & \\
\hline $\mathrm{H}_{2}$ & & & & & & 3.00 & & 2.16 & 4.32 & 2.27 & 2.37 & 1.44 & 1.29 & & 4.76 & 1.66 & 1.68 & 2.70 & 1.79 & 2.61 & 1.13 \\
\hline \multicolumn{22}{|l|}{ Neph/UHSAS } \\
\hline $\mathrm{PM}_{2.5}$ & 6.52 & & & 8.29 & 8.83 & 5.48 & 5.49 & 2.12 & 6.59 & 3.73 & 10.06 & 6.21 & 3.56 & 5.69 & 5.78 & 7.06 & 3.87 & 5.81 & 1.39 & 4.50 & 1.64 \\
\hline
\end{tabular}

of $\mathrm{PM}_{2.5}$ have been produced even by the small Yucatan fires considered here.

The Yucatan fires had higher mean $\mathrm{EFCO}_{2}(1656 \pm 38$; 1601 Amazon) and lower mean EFCO (83 \pm 14 ; 108 Amazon). This is indicative of relatively more flaming combustion, which is also reflected in the higher MCE (0.927; 0.904 Amazon). The higher MCE and a possible tendency for the biomass to be higher in nitrogen content may explain the higher mean $\mathrm{EFNO}_{\mathrm{x}}(4.7 ; 1.7$ Amazon). Propene was also emitted in higher amounts from Yucatan fires (1.36; 0.5 Amazon).

Most of the compounds that were measured in both studies had average EF that were not statistically different between the two forest environments. The means (in $\mathrm{g} / \mathrm{kg}$ ) for these compounds are: $\mathrm{CH}_{4}$ (5.9 Yucatan, 6.3 Amazon); HCHO (2.6 Yucatan, 1.7 Amazon); $\mathrm{CH}_{3} \mathrm{OH}$ (2.98 Yucatan, 2.95 Amazon); $\mathrm{NH}_{3}$ (0.78 Yucatan, 1.1 Amazon); ethane (1.08 Yucatan, 1.01 Amazon); ethene (1.05 Yucatan, 0.98 Amazon) and HCN (0.23 Yucatan, $0.66 \pm 0.56$ Amazon). Two compounds had significantly lower emissions from the $\mathrm{Yu}-$ catan deforestation fires: $\mathrm{CH}_{3} \mathrm{COOH}$ (2.9 Yucatan, 4.3 Amazon) and $\mathrm{HCOOH}$ (below detection limit in Yucatan, 0.57 Amazon).

The EF measured for a single understory fire in a tropical dry forest in Africa were all within the range of EF we mea- sured for the Yucatan DF, except that the EF for total PM for the African understory fire was $13 \mathrm{~g} / \mathrm{kg}$ (Sinha et al., 2004). There are not enough measurements of understory fires to determine if their EF are significantly different from the EF for DF. For species not measured in this study, the EF measured for deforestation fires in Brazil are probably the best estimate for these, and global tropical forest fires (Yokelson et al., 2008). By extension, the EF values measured in this work, but not in Brazil (Sect. 3.2) are likely the best estimate for global tropical forest fires.

\subsubsection{Comparison of Yucatan deforestation and crop residue fires}

We also compare the EF from the two main types of fires we observed in the Yucatan. Despite the fuel differences, the EF overlap within one standard deviation for most species. However, the tendency towards higher emissions of organic acids and ammonia from crop residue fires is clear $\left(\mathrm{CH}_{3} \mathrm{COOH}\right.$ (4.8 CR, 2.9 DF); $\mathrm{HCOOH} \mathrm{(2.7} \mathrm{CR,} \mathrm{below} \mathrm{detection} \mathrm{limit}$ $\mathrm{DF})$; and $\mathrm{NH}_{3}$ (1.38 CR, $\left.0.775 \mathrm{DF}\right)$ ). "Higher than normal" emissions of these species were also observed from burning rice straw by Christian et al. (2003) in a lab study.

The Yucatan DF emitted more HCHO than the CR fires we sampled (below detection limit CR, 2.6 DF). However, 
the rice straw fires sampled by Christian et al. (2003) had very high $\mathrm{HCHO}$ emissions. Thus, low $\mathrm{HCHO}$ emissions are not likely a universal feature of CR fires. In summary, since the EF were about equal for most species, this suggests that the overall average trace gas speciation of the emissions from the region may not be very sensitive to a shift in the relative amount of these two main fire types for most species.

\subsection{Fire initial emissions measured on the C-130}

No $\mathrm{CO}_{2}$ data was collected on the $\mathrm{C}-130$ so we present $\mathrm{ER}$ to $\mathrm{CO}$ in Table 3. Also the fuels were not positively identified so the C-130 data was not included in the "fire-type specific" comparison above. However, the extensive instrumentation on the C-130, and the well-designed flight path, provided a large amount of valuable data.

The initial fire emissions of several species were measured for the first time in the field by the Caltech CIMS. These include $\mathrm{H}_{2} \mathrm{O}_{2}$, peroxyacetic acid, and propanoic acid. All these reactive compounds were present in significant amounts in the youngest smoke samples. The presence of the peroxide species in the nascent smoke may partially reflect fast initial photochemistry (e.g. recombination of peroxy radicals $\left(\mathrm{RO}_{2}\right.$, $\left.\mathrm{HO}_{2}\right)$ ). There was no increase with altitude in the ratio of peroxide species to $\mathrm{CO}$ when comparing the freshest sample of each fire, but we cannot rule out a photochemical contribution to our reported initial emissions since even the freshest smoke (from Fire \#2) could have been $\sim 3-10$ min old and photochemical production of $\mathrm{H}_{2} \mathrm{O}_{2}$ was observed in the aging plume from Fire \#3 (Sect. 3.4). They are important as a $\mathrm{HO}_{\mathrm{x}}$ reservoir and the $\mathrm{H}_{2} \mathrm{O}_{2}$ plays an important role (along with $\mathrm{HCHO}$ ) in the oxidation of sulfur in clouds (FinlaysonPitts and Pitts, 2000).

The NCAR SICIMS detected traces of $\mathrm{H}_{2} \mathrm{SO}_{4}$ $\left(\Delta \mathrm{H}_{2} \mathrm{SO}_{4} / \Delta \mathrm{CO}, \quad 5.4 \times 10^{-7} \pm 5.2 \times 10^{-7}\right) \quad$ and $\mathrm{MSA}$ ( $\triangle \mathrm{MSA} / \Delta \mathrm{CO} \sim 8.4 \times 10^{-8} \pm 1.3 \times 10^{-7}$ ) in the young fire emissions also for the first time. The initial amount of these species varies greatly potentially due to differences in fuel S and plume reactivity. To "normalize" for fuel $S$ variation and highlight any altitude dependence, which could indicate fast initial chemistry, we computed the initial ratios of $\mathrm{H}_{2} \mathrm{SO}_{4}$ or MSA to $\mathrm{SO}_{2}$. No trend was observed with altitude in these ratios, but due to the high variability and uncertain formation process we do not report initial emissions for these species in the Tables.

The combination of PTR-MS and the Caltech CIMS made it possible to detect many gas-phase NMOC that have been measured from fires before, but not on the Twin Otter in this study. In Table 4 where the results from the two aircraft are combined (as detailed in Sect. 3.3) the sum of identified gas-phase NMOC is $22 \mathrm{~g} / \mathrm{kg}$. This value is close to the sum of identified gas-phase NMOC for Brazilian deforestation fires $(25.8 \mathrm{~g} / \mathrm{kg})$ reported by Yokelson et al. (2008). However, both of these values are only $\sim 50 \%$ of the true sum of gas-phase NMOC, which includes detected, but unidenti- fied species that are mostly high molecular weight OVOC (Yokelson et al., 2008). The sum of the molar ratios to CO (Table 4 data) for the OVOC that could be measured was 0.1295 . The sum of the molar ER to $\mathrm{CO}$ for measurable NMHC was 0.0393. Thus, the OVOC/NMHC ratio in the initial gas-phase emissions was about 3.3 - or OVOC accounted for $77 \%$ of measured, emitted NMOC on a molar basis. The dominance of NMOC by OVOC in BB plumes causes significant photochemistry differences compared to fossil fuel burning plumes, where NMOC are dominated by NMHC (Singh et al 1995; Mason et al., 2001).

An important species detected by PTR-MS was acetonitrile, which is thought to be produced almost exclusively by biomass burning (de Gouw et al., 2003) and thus has value as a BB tracer with relatively long (few months) atmospheric lifetime. The ER to $\mathrm{CO}$ for this species averaged over the $3 \mathrm{C}-130$ fires was 0.0043 . The recommended acetonitrile to CO ER for 18 Brazilian DF was 0.0026 \pm 0.0007 (Yokelson et al., 2008). Without better information on the variability of this ratio in the Yucatan we cannot say it is different from the ER for Brazilian DF. HCN is another compound produced mainly by biomass burning and used as a tracer ( $\mathrm{Li}$ et al., 2000). The $\Delta \mathrm{HCN} / \Delta \mathrm{CO}$ ER measured on the C-130 was $0.0100 \pm 0.0044(n=3)$ and the Twin Otter $\Delta \mathrm{HCN} / \Delta \mathrm{CO}$ ER for all fires was $0.0032 \pm 0.0014(n=7)$. The combined average for both aircraft is about $0.0066 \pm 0.0041$, which is not significantly higher than the $\Delta \mathrm{HCN} / \triangle \mathrm{CO}$ ER obtained for Brazilian DF $(0.0063 \pm 0.0054)$. The $\Delta \mathrm{CH}_{3} \mathrm{CN} / \Delta \mathrm{HCN}$ molar ER is fairly consistent for several recent field studies: 0.39 MC-area (Crounse et al., 2009), 0.41 Brazil DF (Yokelson et al., 2008) and $\sim 0.43$ in the Yucatan if we only consider the fires where both species were measured. The $\Delta \mathrm{CH}_{3} \mathrm{CN} / \Delta \mathrm{HCN}$ molar ER for laboratory fires in six different tropical fuels was 0.56 \pm 0.31 (Christian et al., 2003).

As noted in section 3.1.1, the Yucatan DF emitted more $\mathrm{NO}_{\mathrm{x}}$ than Brazilian DF, which could suggest a higher fuel $\mathrm{N}$ content in the Yucatan and the hypothesis that $\mathrm{NO}_{\mathrm{x}}$ is produced by oxidation of most of the $\mathrm{N}$-containing compounds in the fuel. The fact that $\mathrm{HCN}$ and acetonitrile emissions are highly variable in both locations, but not larger (on average) from the Yucatan fires suggests that these species may arise from the pyrolysis of only specific, $\mathrm{N}$-containing precursor compounds in the fuel that vary in concentration, but on average are about the same in Brazil as in the Yucatan. In any case, potential, total fuel $\mathrm{N}$ differences do not provide a simple rationale for all our observations (Yokelson et al., 2008).

Nitrous acid (HONO) is known to be a direct initial emission from fossil fuel combustion (Finlayson-Pitts and Pitts, 2000) and Keene et al. (2006) and Yokelson et al. (2007b) observed direct emission of HONO from biomass burning in the lab and field, respectively. Photolysis with unit quantum yield to $\mathrm{OH}$ and $\mathrm{NO}$ is the only important daytime loss for HONO and occurs within 10-20 min (Finlayson-Pitts and Pitts, 2000). Thus we expect the lower altitude samples of the Yucatan BB plumes to have higher $\Delta \mathrm{HONO} / \Delta \mathrm{NO}_{\mathrm{y}}$ values 
Table 3. Initial emission ratios to $\mathrm{CO}^{1}$ measured in nascent smoke and normalized excess mixing ratios (to $\mathrm{CO}$ ) measured in aged smoke layers on the C-130 on 23 March 2006.

\begin{tabular}{|c|c|c|c|c|c|c|c|c|c|c|}
\hline \multirow[b]{2}{*}{ Species } & \multirow[b]{2}{*}{ Instrument } & \multirow[b]{2}{*}{1} & \multicolumn{3}{|c|}{ Fire number and averages } & \multirow[b]{2}{*}{ Stdev } & \multicolumn{3}{|c|}{ Altitude of aged smoke layers } & \multirow[b]{2}{*}{ Avg 3 layers ${ }^{2}$} \\
\hline & & & 2 & 3 & Avg & & $2476 \mathrm{~m}$ & $2292 \mathrm{~m}$ & $2166 \mathrm{~m}$ & \\
\hline $\mathrm{SO}_{2}$ & NOAA UV & 0.0243 & & 0.0264 & 0.0254 & 0.0015 & 0.0090 & 0.0186 & 0.0188 & 0.0155 \\
\hline $\mathrm{SO}_{2}$ & Cal Tech CIMS slope & 0.0257 & 0.0048 & 0.0213 & 0.0173 & 0.0110 & & & & \\
\hline $\mathrm{SO}_{2}$ & Ratio 2 methods & 1.06 & & 0.81 & 0.93 & 0.18 & & & & \\
\hline NO & NCAR Chemiluminescence & 0.0080 & 0.0032 & 0.0085 & 0.0066 & 0.0029 & 0.0069 & 0.0011 & 0.0008 & 0.0030 \\
\hline $\mathrm{NO}_{2}$ & NCAR Chemiluminescence & 0.0270 & 0.0147 & 0.0377 & 0.0265 & 0.0115 & 0.0088 & 0.0012 & 0.0017 & 0.0039 \\
\hline $\mathrm{NO}_{\mathrm{X}} / \mathrm{CO}$ & NCAR Chemiluminescence & 0.0350 & 0.0179 & 0.0462 & 0.0330 & 0.0142 & 0.0157 & 0.0023 & 0.0025 & 0.0068 \\
\hline $\mathrm{NO}_{\mathrm{y}} / \mathrm{CO}$ & NCAR Chemiluminescence & 0.0471 & 0.0282 & 0.0607 & 0.0453 & 0.0163 & 0.0424 & 0.0108 & 0.0070 & 0.0201 \\
\hline $\mathrm{NO}_{\mathrm{x}} / \mathrm{NO}_{\mathrm{y}}$ & NCAR Chemiluminescence & 0.7423 & 0.6369 & 0.7606 & 0.7133 & 0.0668 & 0.3708 & 0.2103 & 0.3625 & 0.3145 \\
\hline $\mathrm{O}_{3}$ & NCAR Chemiluminescence & & & & & & 0.1700 & 0.0458 & 0.0189 & 0.0782 \\
\hline PANs/Noy & NCAR spectrometer & & & & & & 0.1130 & 0.1350 & 0.3030 & 0.1837 \\
\hline $\mathrm{HCHO}$ & NCAR diode laser & & & 0.0252 & 0.0252 & & 0.0344 & & 0.0164 & 0.0254 \\
\hline $\mathrm{HCN}$ & CIMS NOy proxy & 0.0148 & 0.0063 & 0.0088 & 0.0100 & 0.0044 & & & & \\
\hline $\mathrm{HCN}$ & CIMS slope & 0.0152 & 0.0074 & 0.0081 & 0.0102 & 0.0043 & & & & 0.0022 \\
\hline $\mathrm{HCN}$ & Ratio 2 methods & 1.03 & 1.17 & 0.92 & 1.04 & 0.13 & & & & \\
\hline HONO & CIMS $\mathrm{NO}_{\mathrm{y}}$ proxy & 0.0023 & 0.0031 & 0.0029 & 0.00277 & 0.00042 & & & & \\
\hline HONO & CIMS slope & 0.0022 & 0.0075 & 0.0028 & 0.00417 & 0.00290 & 0.00033 & & 0.00008 & \\
\hline $\mathrm{CH}_{3} \mathrm{COOH}$ & CIMS slope & 0.0093 & 0.0466 & 0.0158 & 0.0239 & 0.0199 & & & & 0.0240 \\
\hline $\mathrm{HCOOH}$ & CIMS slope & 0.0023 & 0.0034 & 0.0025 & 0.0027 & 0.0006 & & & & 0.0055 \\
\hline $\mathrm{H}_{2} \mathrm{O}_{2}$ & CIMS slope & 0.0018 & 0.0013 & 0.0013 & 0.00147 & 0.0003 & & & & \\
\hline Peroxyacetic Acid & CIMS slope & 0.00013 & 0.00026 & 0.00017 & 0.00019 & 0.0001 & & & & 0.0011 \\
\hline Propanoic Acid & CIMS slope & 0.00098 & 0.00280 & 0.00086 & 0.00155 & 0.0011 & & & & 0.0007 \\
\hline Acetonitrile & NCAR PTR-MS & & & & 0.0043 & & & & & \\
\hline Acetaldehyde & NCAR PTR-MS & & & & 0.0187 & & & & & \\
\hline Acetone & NCAR PTR-MS & & & & 0.0066 & & & & & \\
\hline Methanol & NCAR PTR-MS & & & & 0.0254 & & & & & \\
\hline Methylethylketone & NCAR PTR-MS & & & & 0.0030 & & & & & \\
\hline Methylpropanal & NCAR PTR-MS & & & & 0.0011 & & & & & \\
\hline$\sum$ Hydroxyacetone, Methylacetate & NCAR PTR-MS & & & & 0.0070 & & & & & \\
\hline Benzene & NCAR PTR-MS & & & & 0.0034 & & & & & \\
\hline Ammonium $\left(\mathrm{PM}_{1}\right)$ & CU HR-ToF-AMS & 0.0034 & 0.0005 & 0.0033 & 0.0024 & 0.0017 & 0.0141 & & & 0.0062 \\
\hline Chloride $\left(\mathrm{PM}_{1}\right)$ & CU HR-ToF-AMS & 0.0090 & 0.0009 & 0.0092 & 0.0063 & 0.0047 & 0.0122 & & & 0.0025 \\
\hline Nitrate $\left(\mathrm{PM}_{1}\right)$ & CU HR-ToF-AMS & 0.0031 & 0.0022 & 0.0034 & 0.0029 & 0.0007 & 0.0257 & & & 0.0057 \\
\hline Sulfate $\left(\mathrm{PM}_{1}\right)$ & CU HR-ToF-AMS & 0.0004 & 0.0004 & 0.0010 & 0.0006 & 0.0003 & 0.0196 & & & 0.0022 \\
\hline Organic Aerosol $\left(\mathrm{PM}_{1}\right)$ & CU HR-ToF-AMS & 0.0330 & 0.0498 & 0.0390 & 0.0406 & 0.0086 & 0.1714 & & & 0.0751 \\
\hline Organic Carbon $\left(\mathrm{PM}_{1}\right)$ & CU HR-ToF-AMS & 0.0203 & 0.0342 & 0.0248 & 0.0264 & 0.0071 & & & & \\
\hline $\mathrm{PM}_{1}$ Species & CU HR-ToF-AMS & 0.0489 & 0.0538 & 0.0558 & 0.0528 & 0.0036 & 0.2429 & & & 0.0917 \\
\hline Black Carbon $\left(\mathrm{PM}_{2.5}\right)$ & UH PSAP & 0.0066 & 0.0043 & 0.0081 & 0.0063 & 0.0019 & & & & 0.0039 \\
\hline Total $\mathrm{PM}_{2.5}$ & UH Nephelometer & 0.0698 & 0.0730 & 0.0624 & 0.0684 & 0.0054 & 0.2185 & & & 0.1151 \\
\hline$\% \mathrm{PM}_{2.5}$ speciated & AMS, PSAP, Nephelometer & 79 & 80 & 102 & 87.1 & 13.3 & 111 & & & 83 \\
\hline Particle surface area ${ }^{3}$ & UH OPC and FMPS & 50.7 & 52.3 & 41.1 & 48.0 & 6.1 & 29.5 & & & 34.6 \\
\hline
\end{tabular}

${ }^{1}$ Trace gas ratios to $\mathrm{CO}$ are molar ratios and particle species ratios to $\mathrm{CO}$ are mass ratios $\left(273^{\circ} \mathrm{K}, 1 \mathrm{~atm}\right)$.

2 Computed as average of individual layers when available or as single value for all layers.

${ }^{3}$ Dry $\mathrm{PM}_{3.0}$ surface area in $\mathrm{m}^{2} / \mathrm{gPM}_{2.5}$

(where this ratio should normalize for fuel $\mathrm{N}$ differences to some extent). This trend is evidenced in our samples since $\Delta \mathrm{HONO} / \triangle \mathrm{NO}_{\mathrm{y}}$ was the highest for Fire \#2 $(\sim 0.11$, sampled at $390 \mathrm{~m})$ and decreased for Fires $1(\sim 0.05,1110 \mathrm{~m})$ and $3(\sim 0.044,1730 \mathrm{~m})$. Since $\mathrm{NO}_{\mathrm{y}}$ is about $75 \% \mathrm{NO}_{\mathrm{x}}$ (Table 3), a comparable value for $\Delta \mathrm{HONO} / \Delta \mathrm{NO}_{\mathrm{x}}$ of 0.14 was measured at lower altitudes (predominantly $\sim 580 \mathrm{~m}$ ) in Brazil by Yokelson et al. (2007b). The lab BB study of Keene et al. (2006) reported a $\Delta \mathrm{HONO} / \Delta \mathrm{NO}_{\mathrm{x}}$ molar ratio of $0.13 \pm 0.097$. In the aging Fire \#3 plume (Sect. 3.4) the $\Delta \mathrm{HONO} / \triangle \mathrm{CO}$ dropped to about one-tenth of the initially observed value within $\sim 20 \mathrm{~min}$ and $\Delta \mathrm{HONO} / \Delta \mathrm{CO}$ was even lower in the aged haze layers (Table 3, Sect. 3.5). Thus, we conclude that HONO accounts for about $10 \%$ of initial BB
$\mathrm{NO}_{\mathrm{y}}$ and that it makes a major contribution to both $\mathrm{OH}$ and $\mathrm{NO}$ in fresh BB plumes.

Both the Caltech CIMS and NOAA UV instruments confirmed higher than average emission of $\mathrm{SO}_{2}$ from these fires. The average $\mathrm{SO}_{2} / \mathrm{CO}$ ER from the CIMS instrument reflects one more fire than sampled by the NOAA UV instrument. The CIMS average molar ER of 0.0173 is approximately 7 times larger than the average for tropical forest fires $(0.0024)$ quoted by Andreae and Merlet (2001). The reason for this could involve the fuel $\mathrm{S}$ content, which could be high in the Yucatan because of soil S; manure used as fertilizer; or deposition of marine sulfur. There are some very large $\mathrm{SO}_{2}$ sources in central Mexico including volcanoes and petrochemical refineries (de Foy et al., 2007; Grutter et al., 2008). 
Table 4. Initial $\mathrm{ER}^{1}$ to $\mathrm{CO}$ and $\mathrm{EF}$ ( $\mathrm{g} / \mathrm{kg}$ ) for Yucatan Fires as measured by both Twin Otter (Seventeen fires) and C-130 (Three fires).

\begin{tabular}{|c|c|c|c|c|c|c|c|}
\hline \multirow[b]{3}{*}{ Compound } & \multirow{2}{*}{\multicolumn{2}{|c|}{$\begin{array}{l}\text { Twin Otter } \\
\text { ER to CO }\end{array}$}} & \multirow{2}{*}{\multicolumn{2}{|c|}{$\begin{array}{l}\text { C-130 } \\
\text { ER to CO }\end{array}$}} & \multicolumn{3}{|c|}{ Yucatan Average Initial ${ }^{2}$} \\
\hline & & & & & \multirow{2}{*}{$\frac{\text { ER to } \mathrm{CO}}{\text { avg }}$} & \multirow{2}{*}{$\frac{\mathrm{EF}}{\mathrm{g} / \mathrm{kg}}$} & \multirow{2}{*}{$\frac{\mathrm{EF}}{\mathrm{stdev}}$} \\
\hline & avg & stdev & avg & stdev & & & \\
\hline $\mathrm{CO}_{2}$ & 13.024 & 0.321 & & & 13.024 & 1641 & 40 \\
\hline $\mathrm{CO}$ & 1.0000 & & 1.0000 & & 1.0000 & 80.18 & 19.40 \\
\hline NO & 0.0338 & 0.0196 & 0.0066 & 0.0029 & 0.0202 & 1.733 & 1.264 \\
\hline $\mathrm{NO}_{2}$ & 0.0378 & 0.0256 & 0.0265 & 0.0115 & 0.0321 & 4.235 & 3. 406 \\
\hline $\mathrm{NO}_{\mathrm{x}}$ as $\mathrm{NO}$ & 0.0645 & 0.0431 & 0.0330 & 0.0142 & 0.0488 & 4.188 & 3.328 \\
\hline $\mathrm{NO}_{\mathrm{y}}$ & & & 0.0453 & 0.0163 & 0.0453 & & \\
\hline $\mathrm{HONO}^{3}$ & & & 0.0028 & 0.0004 & 0.0063 & 0.853 & 0.636 \\
\hline $\mathrm{SO}_{2}$ (Caltech CIMS three fires) & & & 0.0173 & 0.0110 & 0.0173 & 3.164 & 2.016 \\
\hline $\mathrm{CH}_{4}$ & 0.1104 & 0.0517 & & & 0.1104 & 5.059 & 2.369 \\
\hline $\mathrm{HCHO}$ & 0.0326 & 0.0275 & 0.0252 & & 0.0289 & 2.482 & 2.095 \\
\hline $\mathrm{CH}_{3} \mathrm{OH}$ & 0.0282 & 0.0138 & 0.0254 & & 0.0282 & 2.586 & 1.264 \\
\hline $\mathrm{CH}_{3} \mathrm{COOH}$ & 0.0231 & 0.0105 & 0.0239 & 0.0199 & 0.0235 & 4.036 & 3.829 \\
\hline $\mathrm{HCOOH}$ & 0.0205 & 0.0141 & 0.0027 & 0.0006 & 0.0116 & 1.532 & 1.105 \\
\hline $\mathrm{NH}_{3}$ & 0.0209 & 0.0219 & & & 0.0209 & 1.017 & 1.066 \\
\hline $\mathrm{HCN}$ & 0.0032 & 0.0014 & 0.0100 & 0.0044 & 0.0066 & 0.512 & 0.316 \\
\hline Acetonitrile & & & 0.0043 & & 0.0043 & 0.500 & \\
\hline Acetaldehyde & & & 0.0187 & & 0.0187 & 2.355 & \\
\hline Acetone & & & 0.0066 & & 0.0066 & 1.103 & \\
\hline Methylethylketone & & & 0.0030 & & 0.0030 & 0.624 & \\
\hline Methylpropanal & & & 0.0011 & & 0.0011 & 0.219 & \\
\hline Hydroxyacetone plus Methylacetate & & & 0.0070 & & 0.0070 & 1.475 & \\
\hline Benzene & & & 0.0034 & & 0.0034 & 0.759 & \\
\hline $\mathrm{H}_{2} \mathrm{O}_{2}$ & & & 0.0015 & 0.0003 & 0.0015 & 0.143 & 0.029 \\
\hline Peroxyacetic Acid & & & 0.0002 & 0.0001 & 0.0002 & 0.040 & 0.022 \\
\hline Propanoic Acid & & & 0.0015 & 0.0011 & 0.0015 & 0.328 & 0.233 \\
\hline Ethane & 0.0098 & 0.0052 & & & 0.0098 & 0.844 & 0.449 \\
\hline Ethene & 0.0111 & 0.0038 & & & 0.0111 & 0.889 & 0.305 \\
\hline Propane & 0.0015 & 0.0013 & & & 0.0015 & 0.192 & 0.161 \\
\hline Propene & 0.0079 & 0.0082 & & & 0.0079 & 0.952 & 0.988 \\
\hline Isobutane & 0.00009 & 0.00007 & & & $8.6 \mathrm{E}-05$ & 0.014 & 0.012 \\
\hline n-Butane & 0.00025 & 0.00021 & & & $2.5 \mathrm{E}-04$ & 0.042 & 0.035 \\
\hline Ethyne & 0.00289 & 0.00091 & & & 0.0029 & 0.215 & 0.068 \\
\hline $\mathrm{t}-2$ Butene & 0.00025 & 0.00020 & & & $2.5 \mathrm{E}-04$ & 0.040 & 0.033 \\
\hline 1-Butene & 0.00060 & 0.00040 & & & $6.0 \mathrm{E}-04$ & 0.096 & 0.064 \\
\hline Isobutene & 0.00051 & 0.00040 & & & $5.1 \mathrm{E}-04$ & 0.081 & 0.064 \\
\hline c-2-Butene & 0.00019 & 0.00015 & & & $1.9 \mathrm{E}-04$ & 0.030 & 0.025 \\
\hline Cyclopentane & $5.8 \mathrm{E}-06$ & $4.8 \mathrm{E}-06$ & & & $5.8 \mathrm{E}-06$ & 0.0012 & 0.0010 \\
\hline Isopentane & $3.4 \mathrm{E}-05$ & $3.0 \mathrm{E}-05$ & & & $3.4 \mathrm{E}-05$ & 0.007 & 0.006 \\
\hline n-Pentane & $6.9 \mathrm{E}-05$ & $5.4 \mathrm{E}-05$ & & & $6.9 \mathrm{E}-05$ & 0.014 & 0.011 \\
\hline 1,3 Butadiene & 0.00065 & 0.00046 & & & $6.5 \mathrm{E}-04$ & 0.100 & 0.072 \\
\hline $\mathrm{H}_{2}$ & 0.4301 & 0.2060 & & & 0.4301 & 2.463 & 1.180 \\
\hline $\mathrm{PM}_{2.5}$ & 0.0733 & 0.0261 & 0.0684 & 0.0054 & 0.0709 & 5.877 & 2.142 \\
\hline Ammonium $\left(\mathrm{PM}_{1}\right)$ & & & 0.0024 & 0.0017 & 0.0024 & 0.192 & 0.136 \\
\hline Chloride $\left(\mathrm{PM}_{1}\right)$ & & & 0.0063 & 0.0047 & 0.0063 & 0.509 & 0.377 \\
\hline Nitrate $\left(\mathrm{PM}_{1}\right)$ & & & 0.0029 & 0.0007 & 0.0029 & 0.233 & 0.056 \\
\hline Sulfate $\left(\mathrm{PM}_{1}\right)$ & & & 0.0006 & 0.0003 & 0.0006 & 0.047 & 0.024 \\
\hline Organic aerosol mass $(\mathrm{OA})\left(\mathrm{PM}_{1}\right)$ & & & 0.0406 & 0.0086 & 0.0406 & 3.254 & 0.690 \\
\hline Organic carbon $(\mathrm{OC})\left(\mathrm{PM}_{1}\right)$ & & & 0.0264 & 0.0071 & 0.0264 & 2.117 & 0.569 \\
\hline Black carbon $(\mathrm{BC})\left(\mathrm{PM}_{2.5}\right)$ & & & 0.0063 & 0.0019 & 0.0063 & 0.541 & 0.163 \\
\hline
\end{tabular}

${ }^{1}$ Molar ratio to $\mathrm{CO}$ for gases and mass ratio to $\mathrm{CO}(273 \mathrm{~K}, 1 \mathrm{~atm})$ for particle species.

2 Straight average of Twin Otter and C-130 data when species measured from both aircraft.

${ }^{3}$ Yucatan initial values calculated assuming that initial $\mathrm{HONO}$ is about $13 \%$ of $\mathrm{NO}_{\mathrm{x}}$. Uncertainty from Keene et al. (2006) (see text). 
These sources are normally downwind of the Yucatan, but there may be occasional meteorological circumstances where they contribute to sulfate deposition in the Yucatan.

The mean $\mathrm{PM}_{2.5}$ mass ratio to $\mathrm{CO}(0.0684 \pm 0.0054$, Table 3) obtained by coupling the UH nephelometer with the NCAR CO for the $3 \mathrm{C}-130$ fires was very similar to the average ratio obtained for all 17 fires on the Twin Otter $(0.073 \pm 0.026)$. This suggests that the two aircraft sampled a similar mix of biomass burning and confirms that the PM emissions were below the literature average for tropical forest fires. The UH PSAP allowed a rough measurement of black carbon (BC) based on light absorption. Martins et al. (1998) compared BC measurements by light absorption to those made by thermal evolution techniques. They found significant variation in the MAE with mixing state, size distribution etc, and obtained an average MAE for fresh-aged Brazilian BB smoke of $12 \pm 4 \mathrm{~m}^{2} / \mathrm{g}$. Using this MAE we obtained an average initial mass fraction of $\mathrm{BC}$ to $\mathrm{PM}_{2.5}$ of $0.095 \pm 0.036$, which is a little higher than the average initial mass fraction obtained for Brazilian fires by Ferek et al. (1998) (0.071 \pm 0.012$)$. Black carbon is the main component of smoke that lowers the single scattering albedo (SSA). Christian et al. (2003) showed that EFBC increase with MCE (BC is a flaming combustion product) while $\mathrm{CO}$ correlates with smoldering combustion, which also tends to emit a "white" reflective smoke high in organic mass (Yokelson et al., 1997). Fires 1 and 3 sampled by the C-130 had updraft cores that directly rose to high altitudes in the boundary layer due to vigorous flaming, while Fire \#2 had a lower buoyancy plume (C-130 flight video, http://data.eol.ucar.edu/). The plume dynamics are consistent with the $\mathrm{BC}$ and SSA data as Fires 1 and 3 had low SSA (0.67 and 0.73) and high BC/CO mass ratios (0.066 and 0.081) compared to Fire 2 (SSA 0.84, $\mathrm{BC} / \mathrm{CO}$ 0.043).

From the OPC data, assuming spherical particles, we calculated the dry surface area of particles $0.15-3$ microns in diameter, which should account for most of the particle surface emitted (Table 3). The average value was $48 \pm 6.1 \mathrm{~m}^{2} / \mathrm{gPM}_{2.5}$. The lowest individual value was obtained for Fire \#3 $\left(41.1 \mathrm{~m}^{2} / \mathrm{gPM}_{2.5}\right)$, which was sampled at the highest altitude $(1700 \mathrm{~m})$ and likely reflected fast initial coagulation. The more aged upper haze layers had values near $30 \mathrm{~m}^{2} / \mathrm{gPM}_{2.5}$, and this is likely a good estimate of the dry surface area after most of the coagulation is complete. Ambient RH in the upper boundary layer ranged from $70-100 \%$ so the ambient particles would have been significantly larger due to addition of water. Measurements of the growth of BB particles as they hydrate typically show an exponential increase in total scattering to about a factor of 2 near $80 \% \mathrm{RH}$, which is usually the cut-off for the measurement (Magi and Hobbs, 2003). Thus, the particle surface area could certainly double as "dry smoke" becomes "wet smoke." Assuming an aged smoke layer dry $\mathrm{PM}_{2.5}$ of $100 \mu \mathrm{g} / \mathrm{sm}^{3}$ we obtain a dry particle surface area concentration of $\sim 3 \times 10^{-3} \mathrm{~m}^{2} / \mathrm{sm}^{3}$. Multiplying by a typical number of active sites per $\mathrm{m}^{2}\left(10^{19}\right.$, Bertram et al., 2001) suggests a "few ppbv" of active surface sites are available for heterogeneous chemistry in a typical wet or dry smoke plume. This is a significant available surface area, but much smaller than the droplet surface area within clouds (up to $0.5 \mathrm{~m}^{2} / \mathrm{sm}^{3}$ ). The tendency of smoke-impacted clouds to have more, but smaller droplets (Kaufman and Nakajima, 1993) can cause the surface area in smoky clouds to be 2-7 times larger than in clean clouds. Depending on the extent of smoke-cloud interaction this could be the most important influence of BB on available surface area.

The AMS coupled with the VUV-CO provided the mass ratio to $\mathrm{CO}$ for a suite of particle constituents: NR sulfate, nitrate, ammonium, chloride, and organic mass (Tables 3 and 4). Coupling the AMS with the UH nephelometer allowed an estimate of the mass fraction of each AMS species to the total $\mathrm{PM}_{2.5}$ (Tables 3-5). These ratios can be compared to measurements in plume penetrations of nascent smoke from Brazilian fires by Ferek et al. (1998). (Since these ratios change rapidly after emission, it is best to compare initial ratios from similarly aged, very fresh samples.) Since Ferek et al. (1998) report a higher average ratio of $\mathrm{PM}_{4}$ to $\mathrm{CO}(0.10)$ this could bias a comparison of ratios to $\mathrm{CO}$ between the two studies. Thus we compare our mass fractions of total $\mathrm{PM}_{2.5}$ to the mass fractions of total $\mathrm{PM}_{4}$ that they obtained for the average of four fire types shown in their Table 3. The average MCE for their data treated in this manner is 0.924; close to the average MCE (0.929) measured on the Twin Otter for all Yucatan biomass burning.

Fire \#2, which may have been a forest fire (based on the video and photos) had the highest $\mathrm{OA}$ and lowest $\mathrm{BC}$ and is the $\mathrm{C}-130$ fire that is most like the Brazil fires (Table 5). Fires 1 and 3 have much higher initial NR chloride, nitrate, and ammonium than Fire 2 or the Brazilian fires. This could indicate that these fires were burning crop residue and that the emissions were impacted by fertilizers. However, the high average $\mathrm{EFCl}^{-}$in the Yucatan could also reflect wet deposition of marine aerosol on the fuels (McKenzie et al., 1996). The lower $\mathrm{EFCl}^{-}$for Fire \#2 might indicate that it was not burning hot enough to volatilize the fuel chlorine efficiently. Despite the high $\mathrm{SO}_{2}$ emissions from the Yucatan fires the initial $\mathrm{PM}_{2.5}$ is not elevated in sulfate, which makes sense since the atmospheric oxidation of $\mathrm{SO}_{2}$ to sulfate typically requires about a week. The sum of species characterized by Ferek et al. (1998) on their filters was about $77 \%$ of their $\mathrm{PM}_{4}$. The main species they did not measure is non-carbon organic mass since they analyzed for organic carbon (OC) only. Adding their residue to their OC suggests a $\triangle \mathrm{OA} / \triangle \mathrm{OC}$ ratio of $\sim 1.34 \pm 0.11$, which is a little lower than the $\Delta \mathrm{OA} / \triangle \mathrm{OC}$ of $1.55 \pm 0.08$ measured by the AMS for the Yucatan fires. The average Yucatan OC was $39 \pm 9 \%$ of the $\mathrm{PM}_{2.5}$ on a mass basis, which is below the average of $\sim 62 \pm 6 \%$ obtained by Ferek et al. (1998) in Brazil. However, the OA for Yucatan fires may be a little higher. Clarke et al. (2007) and Hoffer et al. (2006) suggested that a small 
Table 5. Estimated speciation of the total $\mathrm{PM}_{2.5}$ as a percentage of the mass for fires 1-3 on 23 March 2006 (sampled by C-130).

\begin{tabular}{|c|c|c|c|c|c|c|c|c|}
\hline \multirow[b]{2}{*}{ Species } & \multicolumn{5}{|c|}{ Yucatan This Work } & \multicolumn{2}{|c|}{ Amazon ${ }^{1}$} & \multirow{2}{*}{$\begin{array}{l}\text { Yucatan/ } \\
\text { Amazon }\end{array}$} \\
\hline & Fire1 & Fire2 & Fire3 & Avg & Stdev & Avg & Stdev & \\
\hline Sulfate $\left(\mathrm{PM}_{1}\right)$ & 0.57 & 0.55 & 1.54 & 0.89 & 0.56 & 1.95 & 0.83 & 0.45 \\
\hline Nitrate $\left(\mathrm{PM}_{1}\right)$ & 4.47 & 2.96 & 5.51 & 4.31 & 1.28 & 0.96 & 0.33 & 4.49 \\
\hline Organic Aerosol Mass $\left(\mathrm{PM}_{1}\right)$ & 47.19 & 68.26 & 62.42 & 59.29 & 10.88 & & & \\
\hline Organic Carbon $\left(\mathrm{PM}_{1}\right)$ & 29.09 & 46.80 & 39.82 & 38.57 & 8.92 & 61.8 & 6.4 & 0.62 \\
\hline Ammonium $\left(\mathrm{PM}_{1}\right)$ & 4.93 & 0.66 & 5.26 & 3.61 & 2.56 & 0.09 & 0.08 & 40.14 \\
\hline Chloride $\left(\mathrm{PM}_{1}\right)$ & 12.83 & 1.21 & 14.74 & 9.59 & 7.33 & 1.8 & 1.1 & 5.33 \\
\hline$\Sigma$ AMS-PM $_{1}$ Species & 69.99 & 73.63 & 89.46 & 77.70 & 10.35 & & & \\
\hline $\mathrm{BC}\left(\mathrm{PM}_{2.5}\right)$ & 9.45 & 5.87 & 13.02 & 9.45 & 3.58 & 7.1 & 1.2 & 1.33 \\
\hline $\mathrm{K}$ & & & & & & & 3.7 & 2.7 \\
\hline $\mathrm{PM}_{4} \%$ speciated (Amazon) & & & & & & 77.4 & 4.4 & \\
\hline $\mathrm{PM}_{2.5} \%$ speciated Yucatan & 79.44 & 79.50 & 102.48 & 87.14 & 13.29 & & & \\
\hline
\end{tabular}

${ }^{1}$ Source: mass percent of $\mathrm{PM}_{4}$ from Ferek et al. (1998).

fraction of BBOA (up to $\sim 20 \%$ ) is refractory. The classification as "refractory" depends on the technique so some BBOA defined as "refractory" in other studies may be detected by the AMS. Finally, one African tropical dry forest fire emitted "total" PM that was only 23\% OC (Sinha et al., 2004). The sum of the species analyzed on the C-130 accounted for $87 \pm 13 \%$ of the total $\mathrm{PM}_{2.5}$ as calculated from our MSE-based approach. Other methods of computing total $\mathrm{PM}_{2.5}$ on the $\mathrm{C}-130$ could be used such as the size distribution coupled with the particle number and an assumed density. But the agreement obtained from the MSE-based approach is adequate as each technique only claims accuracy of $\sim 25 \%$. The main aerosol species not quantified on the $\mathrm{C}-130$ is potassium $(\mathrm{K})$. The $\mathrm{K}^{+}$signal in the AMS can reflect both surface and electron impact ionization making it difficult to quantify the amount of $\mathrm{K}$ in ambient particles. $\mathrm{K}$ was about $3.7 \%$ of particle mass in Ferek et al. (1998) but its incorporation into particles depends strongly on the amount of flaming combustion (Ward and Hardy et al., 1991) as may also be the case for chloride.

\subsection{Overall combined initial emissions from Yucatan biomass burning}

In this study we simply take the average of all the Twin Otter data and weight it equally to the average of all the C-130 data. As discussed in Sect. 4, this approach may weight the emissions from CR fires too heavily to be a true regional average, but it allows us to use the valid measurements from mixed or unknown fire types. Since, we have also presented the emissions data in the original stratified form (Tables 2 and 3), this allows alternate coupling schemes for future applications. In any case, as noted above, the fire type may not affect the smoke chemistry dramatically except for organic acids, $\mathrm{NH}_{3}$, and some PM species. In addition, the smoke transported away from the Yucatan will not have the same composition as the initial emissions due to rapid photochemistry detailed in Sect. 3.4.

To couple data from both aircraft in our estimate we proceed as follows. Both molar ER to $\mathrm{CO}$ and EF are useful for regional estimates and only the former was measured on the C-130. Thus, in Table 4, Column 2, we have converted the average EF for all the species and all the fires measured from the Twin Otter (DF, CR, and mixed) to molar ER to CO. Column 4 shows the average ER to $\mathrm{CO}$ measured for all the species for all fires sampled by the C-130. In Column 6 the combined average ER to $\mathrm{CO}$ is shown for all species. When a species was measured on both aircraft or by two instruments we took the straight average of the two values as our preliminary estimate of the study average regional value (except for $\mathrm{SO}_{2}$ as detailed above). Finally, in Column 7, the study-average initial ER from Column 6 have been converted to EF using the Twin Otter average $\mathrm{CO} / \mathrm{CO}_{2}$ and the carbon mass balance method (Sect. 2.4.1).

It is worth noting briefly that, on average, similar fires were sampled by each aircraft. The $\mathrm{PM}_{2.5} / \mathrm{CO}$ ratios are close as noted above. A best calculation of the methanol to $\mathrm{CO}$ ratio measured on the $\mathrm{C}-130$ (allowing for sampling rate differences) gives an average value for the three $\mathrm{C}-130$ fires of 0.0254 , which is within $10 \%$ of the average measured by AFTIR for the 17 fires sampled on the Twin Otter (0.0282). The $\Delta \mathrm{CH}_{3} \mathrm{COOH} / \Delta \mathrm{CO}$ and $\Delta \mathrm{HCHO} / \Delta \mathrm{CO} \mathrm{ER}$ measured on the two different aircraft were also very similar (Table 4). The means were not as close for $\mathrm{NO}_{\mathrm{x}}$ and $\mathrm{HCN}$, but the standard deviation about the mean was large for both species on both aircraft. We do note that, the $\Delta \mathrm{HCN} / \Delta \mathrm{CO}$ ER measured on Fire \#3 by the AFTIR on 22 March was 0.0037 , which is not far from the value measured by the Caltech CIMS (0.0047) on the continuation of that fire the next day, though perhaps burning partly different fuels. 

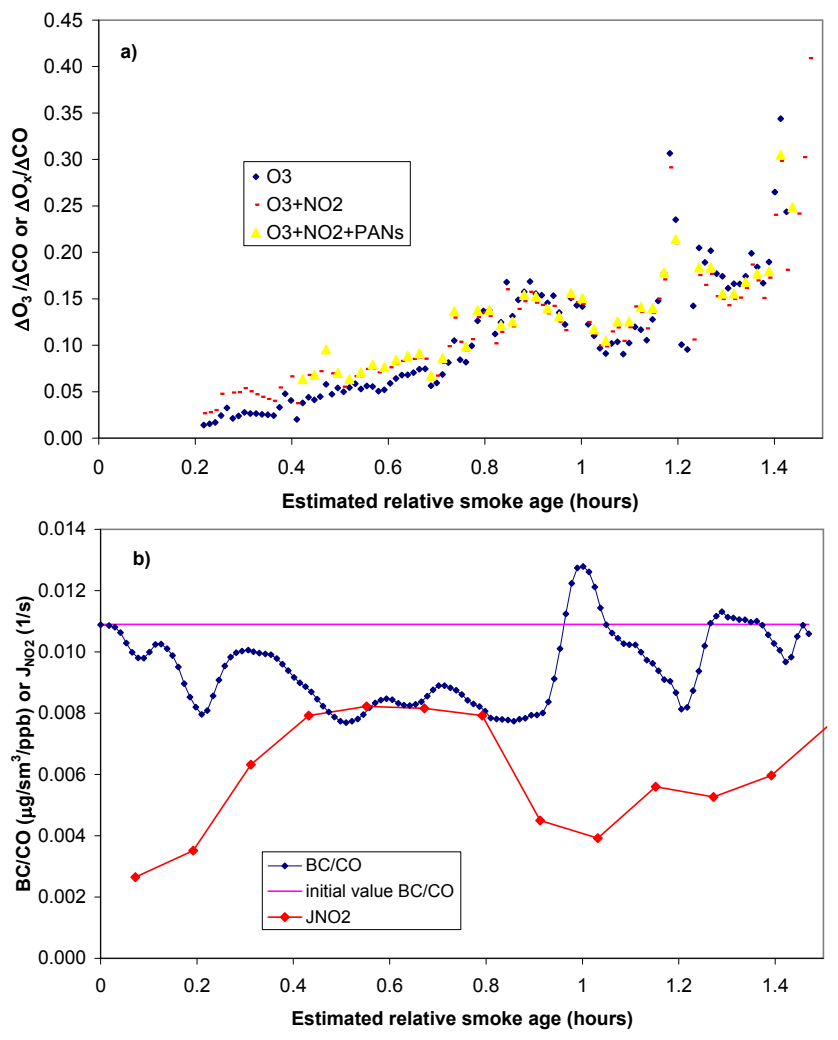

Fig. 4. (a) Rapid increase in $\Delta \mathrm{O}_{3} / \Delta \mathrm{CO}$ and $\Delta \mathrm{O}_{\mathrm{X}} / \Delta \mathrm{CO}$ in the aging plume of the C-130 Fire \#3 discussed in Sect. 3.4. (b) The plot of $\Delta \mathrm{BC} / \triangle \mathrm{CO}$ in the same plume shows that the flaming to smoldering ratio at the source, and the initial emissions, were probably similar for the beginning and end of the aging sequence shown. The $\mathrm{J}_{\mathrm{NO}_{2}}$ trace shows that the rate of photochemistry can vary within the same plume (Sect. 3.4).

\subsection{Photochemical aging of smoke (first $1.5 \mathrm{~h}$ )}

Post-emission chemistry determines much of the atmospheric impact of smoke from fires. In this study, the C130 first sampled Fire \#3 at $1700 \mathrm{~m}$ where the smoke would have been $\sim 10-30 \mathrm{~min}$ old and then immediately followed the plume downwind. About $14 \mathrm{~km}$ downwind, $\triangle \mathrm{CO}$ in the plume suddenly decreased from values that were $\geq 10-20$ times the variation in the background ( $\sim 5 \mathrm{ppbv} \mathrm{CO})$ to only 2-3 times the background variation. The measurements continued beyond this point, but we do not discuss them since the excess values are highly uncertain. The average windspeed measured in the aging plume was $9.6 \pm 4.2 \mathrm{~km} / \mathrm{h}$. Assuming the average winds were the same when the downwind smoke was originally emitted implies that the downwind smoke had aged up to an additional $\sim 1.5 \pm 0.7 \mathrm{~h}$.

In Fig. $4 \mathrm{a}, \Delta \mathrm{O}_{3} / \Delta \mathrm{CO}$ is plotted versus the estimated change in smoke age. A rapid increase in this ratio to $\sim 15 \%$ occurs in $<1 \mathrm{~h}$. Figure $4 \mathrm{a}$ also shows $\Delta \mathrm{O}_{\mathrm{x}} / \Delta \mathrm{CO}$ versus time where " $\mathrm{O}_{\mathrm{x}}$ " approximates the total odd oxygen. In this work the sum of $\mathrm{O}_{3}, \mathrm{NO}_{2}$, and PANs account for nearly all the odd oxygen. The rise in $\Delta \mathrm{O}_{\mathrm{x}} / \Delta \mathrm{CO}$ is very similar to that in $\Delta \mathrm{O}_{3} / \Delta \mathrm{CO}$ confirming that $\mathrm{O}_{3}$ is being produced through photochemical oxidation of NMOC (Crutzen et al., 1999). Yokelson et al. (2003) measured a rise in $\Delta \mathrm{O}_{3} / \Delta \mathrm{CO}$ to $\sim 9 \%$ in $\sim 0.7 \mathrm{~h}$ on 3 isolated $\mathrm{BB}$ plumes in Africa and the $\Delta \mathrm{O}_{3} / \Delta \mathrm{CO}$ observed in this work after $\sim 0.7 \mathrm{~h}$ of smoke aging $(\sim 8 \%)$ is close to the value observed in the African plumes. The chemical evolution of one of the above-mentioned African plumes was measured in great detail (Hobbs et al., 2003) and Trentmann et al. (2005) constructed a comprehensive photochemical model for comparison with those measurements. The model agreed with the measured rate of increase in $\Delta \mathrm{O}_{3} / \Delta \mathrm{CO}$ only if plausible, but unconfirmed, heterogeneous reactions were added; or if the measured initial emissions of NMOC were increased by $30 \%$ (on a molar basis) as a surrogate for unmeasured NMOC. The latter assumption is consistent with our earlier statement that $\sim 50 \%$ of the NMOC emitted by BB are unidentified on a mass basis and this should perhaps be a standard assumption in the modeling of $\mathrm{BB}$ plumes. The rate of increase in $\Delta \mathrm{O}_{3} / \Delta \mathrm{CO}$ seen in the Yucatan and Africa is faster than observed in some BB plumes; especially at high latitudes (Goode et al., 2000; De Gouw et al., 2006), but most BB occurs in the tropics. In any case, from southern Africa to Alaska it has been shown that large-scale chemical changes can occur in BB plumes in an initial photochemical regime that is different from the ambient boundary layer and at a spatial scale that could challenge regional-global models.

In Fig. 4a, and some of the Figures that follow, there is some non-monotonic structure and/or "scatter" in the downwind normalized excess mixing ratios (NEMR). This is expected due to several factors including: (1) Different parts of the plume can age at different rates. An aircraft cannot fly exactly down the plume center-line and instead goes in and out of regions where the smoke is more concentrated and there is less light. Also, the combustion rate at the source can fluctuate leading to a non-monotonic decay in total smoke concentration downwind. (2) The fuels and initial emissions can vary over the course of a fire. When a fire burns freely into homogeneous fuels, the flaming/smoldering ratio and the initial emission ratios may be fairly constant (Hobbs et al., 2003), but this is not always the case. (3) Mixing with fresh or aging plumes from other fires is possible. $\Delta \mathrm{HCN} / \Delta \mathrm{CO}$ is one of the ER that varies the most from fire to fire and this NEMR was fairly constant for the $1.5 \mathrm{~h}$ of Fire \#3 data we show. (Figure $1 \mathrm{~b}$ shows all the $\mathrm{HCN}$ and $\mathrm{CO}$ values in the aging Fire \#3 plume.) However, some degree of mixing with other plumes cannot be completely ruled out.

A rigorous error estimate is not possible for each of the above terms or the assumption of a similar windspeed before our sampling. Thus we point out obvious trends in the data and, in some cases, we fit a line to the data and compare the slope to the standard error in the slope to determine if there is a statistically significant trend. The plume chemistry 
is not expected to be linear: the linear fit is employed as a simple test of whether the values at the beginning and end of the aging sequence are significantly different from each other. Below, we show that the initial emissions were likely very similar for the samples probed at the beginning and the end of the sequence and so significant differences between these points are then evidence for a net change due mostly to photochemistry. The fractional uncertainty in the effective "rate" of any process that might be derived from the fit would be larger than the standard error divided by the slope due to the additional uncertainty in the sample ages. Probably all the samples have experienced more aging, or all the samples have experienced less aging, than estimated. The real uncertainty in the rate is probably about a factor of two.

Figure $4 \mathrm{~b}$ suggests that there were likely some gradual changes in the initial emissions of Fire \#3 and the postemission processing environment that help interpret our data in the aging plume. Figure $4 \mathrm{~b}$ shows $\triangle \mathrm{BC} / \triangle \mathrm{CO}$ at the $5 \mathrm{~s}$ time resolution of the PSAP. $\mathrm{BC}$ is a flaming product and $\mathrm{CO}$ is a smoldering product. As the $\mathrm{C}-130$ flew downwind in the plume, the gradual $20 \%$ decrease in $\Delta \mathrm{BC} / \Delta \mathrm{CO}$ until about $0.9 \mathrm{~h}$ suggests the instruments were sampling smoke originally produced at a gradually decreasing flaming/smoldering (F/S) ratio. The peak in $\mathrm{BC} / \mathrm{CO}$ at $\sim 1 \mathrm{~h}$ could reflect a temporary increase in the $\mathrm{F} / \mathrm{S}$ ratio at the source about an hour before the sampling started. For the older samples, the F/S ratio was again close to the $\mathrm{F} / \mathrm{S}$ ratio at the time of the first $\mathrm{C}-130$ sample. Thus a comparison of the beginning and end NEMRs may best reflect post-emission chemistry. The variation in $\mathrm{J}_{\mathrm{NO}_{2}}$ is also shown in Fig. 4b. $\mathrm{J}_{\mathrm{NO}_{2}}$ first increases by about a factor of 3 as the smoke dilutes. Near the one-hour aging mark $\mathrm{J}_{\mathrm{NO}_{2}}$ decreases by $\sim 2, \Delta \mathrm{O}_{3} / \Delta \mathrm{CO}$ decreases slightly, and $\mathrm{CO}$ increases. The aircraft is evidently entering a region of the plume with greater total smoke concentration. After one hour, both $\Delta \mathrm{O}_{3} / \Delta \mathrm{CO}$ and $\mathrm{J}_{\mathrm{NO}_{2}}$ increase, the smoke concentration decreases, and minimal cloud-processing may occur.

A key driver for photochemistry besides $\mathrm{UV}$ is $\mathrm{OH}$. In Hobbs et al. (2003) the rate of decrease of numerous NMHC in one African biomass burning plume was used to estimate an average plume $\mathrm{OH}$ over the first $40 \mathrm{~min}$ of aging of $\sim 1.7 \times 10^{7}$ molecules $/ \mathrm{cm}^{3}$. On our Fire \#3, no NMHC were measured within the aging plume, but an $\mathrm{OH}$ instrument was on board. The first $\mathrm{OH}$ value in the aging plume (averaged over $29 \mathrm{~s}$ of flight time and a calculated range of smoke aging of $22-43 \mathrm{~min}$ ) is $1.14 \times 10^{7}$ molecules $/ \mathrm{cm}^{3}$. This is $5-$ 20 times larger than the $\mathrm{OH}$ values in nearby background air. The plume $\mathrm{OH}$ levels thereafter decreased to about twice the average $\mathrm{OH}$ in the boundary layer. To our knowledge this is the first in-situ measurement of $\mathrm{OH}$ in a $\mathrm{BB}$ plume and it confirms the potential for very high initial $\mathrm{OH}$ in $\mathrm{BB}$ plumes. The measurements imply a major shortening of reactive species "lifetimes" in comparison to ambient air as predicted earlier (Mason et al., 2001). $\mathrm{HO}_{2}$ and $\mathrm{RO}_{2}$ would likely be elevated along with $\mathrm{OH}$ (Mason et al., 2001). How-

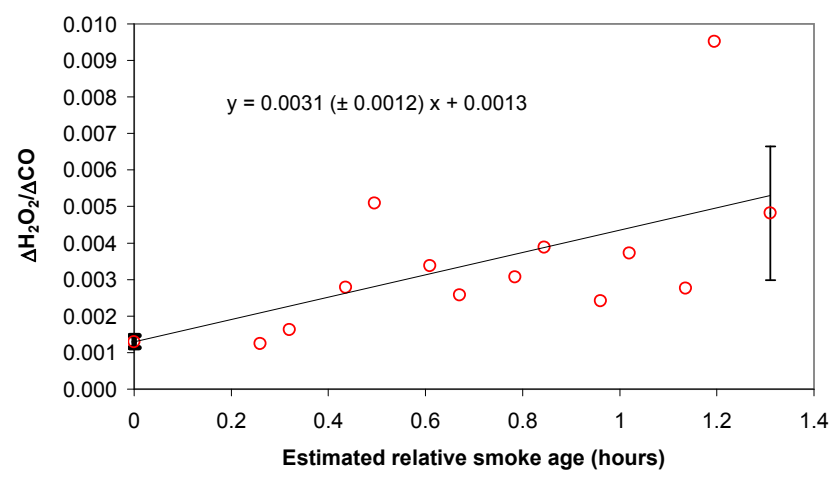

Fig. 5. The plot and comparison of the standard error in the slope to the slope indicates that there is a statistically significant increase in $\Delta \mathrm{H}_{2} \mathrm{O}_{2} / \Delta \mathrm{CO}$ with aging. The uncertainty in the rate of increase is probably about a factor of two when uncertainty in the age of the samples is considered (Sect. 3.4).

ever, the one minute time resolution of the $\mathrm{HO}_{2}$ instrument and some missing data make it difficult to determine the levels of this species in the $3 \mathrm{BB}$ plumes sampled on the C-130.

Trace gases other than $\mathrm{O}_{3}$ also increased. The initial $\triangle \mathrm{HCHO} / \triangle \mathrm{CO}$ from the NCAR DFG spectrometer was $0.025 \pm 0.01$ and it increased to $0.038 \pm 0.01$ at $0.8 \pm 0.1 \mathrm{~h}$. Similar increases in this NEMR were also seen in an African plume in samples acquired near the top of the plume (Hobbs et al., 2003). The $\Delta \mathrm{HCHO} / \Delta \mathrm{CO}$ increased dramatically when smoke entered a cloud in Africa (Tabazadeh et al., 2004) and may have also increased strongly in the Fire \#3 plume for the points that may be cloud impacted $(\sim 0.065 \pm 0.025)$.

The ratio $\Delta \mathrm{H}_{2} \mathrm{O}_{2} / \Delta \mathrm{CO}$ was 0.0013 in the nascent smoke from Fire \#3 and then increased by $\sim 4$ to 0.0054 after $\sim 1.3 \mathrm{~h}$ of aging (Fig. 5). In Fig. 5, the intercept is forced to the initial $\Delta \mathrm{H}_{2} \mathrm{O}_{2} / \Delta \mathrm{CO}$ value that was determined by plotting $\Delta \mathrm{H}_{2} \mathrm{O}_{2}$ versus $\Delta \mathrm{CO}$ for all the samples in the nascent smoke of Fire \#3. We force the intercept because it is based on more samples (with higher S:N) and it has lower uncertainty than the individual downwind NEMRs. With additional aging, the $\Delta \mathrm{H}_{2} \mathrm{O}_{2} / \Delta \mathrm{CO}$ ratio would likely increase significantly beyond the ratio measured at $1.3 \mathrm{~h}$ due to lower $\mathrm{NO}_{\mathrm{x}}$ and entrainment of the $\mathrm{BL}$ air which had an absolute $\mathrm{H}_{2} \mathrm{O}_{2} / \mathrm{CO}$ ratio of 0.0125. Lee et al. (1997) observed $\Delta \mathrm{H}_{2} \mathrm{O}_{2} / \Delta \mathrm{CO}$ ratios of 0.01-0.046 in BB-impacted SH BL air.

Figure 6 shows post-emission growth in peroxyacyl nitrates both as $\Delta \mathrm{PAN} / \Delta \mathrm{CO}$ and $\Delta \Sigma \mathrm{PANs} / \Delta \mathrm{NO}_{\mathrm{y}}$. An initial value for $\triangle \mathrm{PAN}$ or $\triangle \Sigma \mathrm{PAN}$ may not be meaningful (as for $\mathrm{O}_{3}$ ) and was not measured due to interference in the nascent smoke. However, Figure 6a shows that the $\triangle \mathrm{PAN} / \triangle \mathrm{CO}$ ratio increases rapidly from $\sim 0.0025$ (at $\sim 0.4 \mathrm{~h}$ ) to $\sim 0.006$ (at $\sim 1.4 \mathrm{~h}$ ). The NEMR reached in $\sim 1.4 \mathrm{~h}$ is as large as the NEMR observed in smoke from Canada that was $\sim 8$ days old during NEAQS (F. Flocke, personal communication, 2008). This demonstrates that large variability in initial 

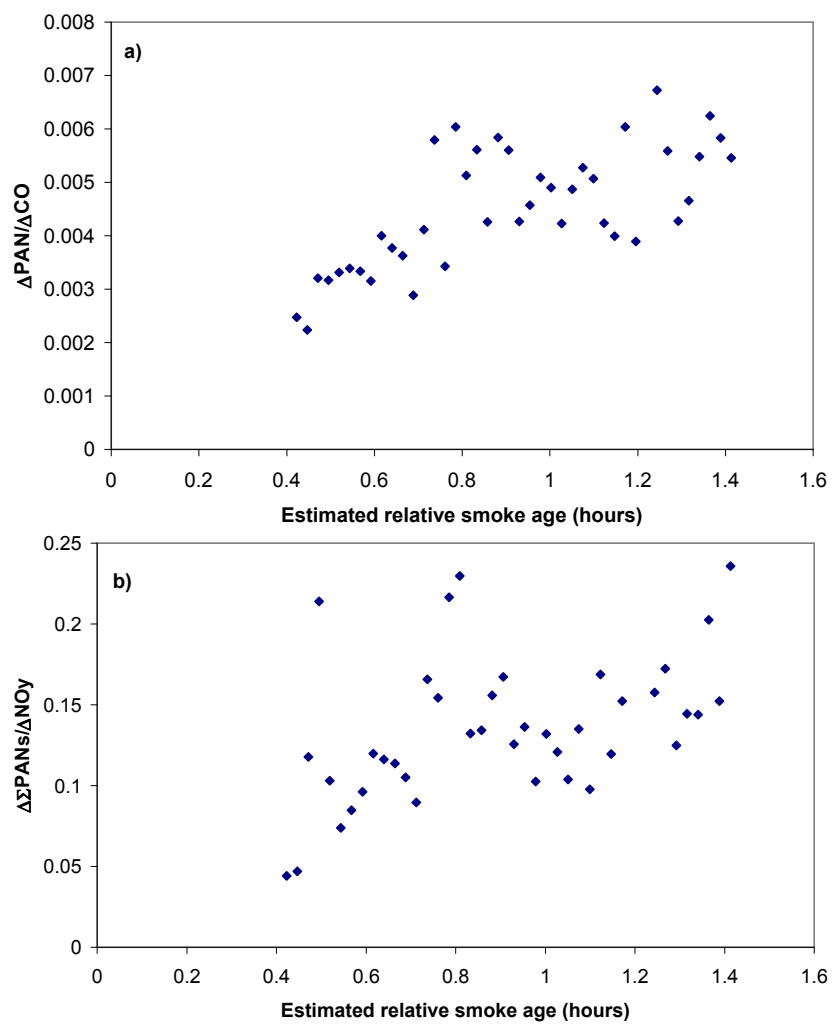

Fig. 6. (a) $\triangle \mathrm{PAN} / \triangle \mathrm{CO}$ increases quickly. (b) The increase in PANs accounts for $\sim 31 \%$ of the loss in $\mathrm{NO}_{\mathrm{X}}$ (Sect. 3.4).

emissions and/or photochemical processing can be associated with BB plumes. Figure $6 \mathrm{~b}$ shows the $\Delta \Sigma \mathrm{PANs} / \Delta \mathrm{NO}_{\mathrm{y}}$ with aging in the Fire \#3 plume. In the $\sim 1.2-1.4 \mathrm{~h}$ aging interval, $\triangle \mathrm{PAN} / \triangle \mathrm{NO}_{\mathrm{y}}$ alone has increased to about $13 \%$. The other PAN-like species showed similar trends, but were present in smaller amounts. The sum of the most abundant other PAN-like species (APAN and PPN) was about $20 \%$ of $\mathrm{PAN}$ in the $1.2-1.4 \mathrm{~h}$ interval and the $\triangle \Sigma \mathrm{PANs} / \Delta \mathrm{NO}_{\mathrm{y}} \mathrm{had}$ increased to $0.167 \pm 0.036$ in this interval. In the initial Fire \#3 plume $\Delta \mathrm{NO}_{\mathrm{x}} / \Delta \mathrm{NO}_{\mathrm{y}}$ was 0.76 (based on comparing integrals) and in the 1.2-1.4 $\mathrm{h}$ aging interval $\Delta \mathrm{NO}_{\mathrm{x}} / \Delta \mathrm{NO}_{\mathrm{y}}$ was $0.41 \pm 0.1$. This implies a $\mathrm{NO}_{\mathrm{x}}$ loss of $46 \pm 11 \%$. A second estimate of the percentage of $\mathrm{NO}_{\mathrm{x}}$ loss based on the decrease in $\Delta \mathrm{NO}_{\mathrm{X}} / \Delta \mathrm{CO}$ is $62 \pm 16 \%$. Averaging these estimates of the $\mathrm{NO}_{\mathrm{x}}$ loss gives $54 \pm 19 \%$ implying that PANs accounted for $31 \pm 13 \%$ of the loss of $\mathrm{NO}_{\mathrm{x}}$. Similar trends were not observed for $\mathrm{HNO}_{3}$. Modestly elevated mixing ratios of $\mathrm{HNO}_{3}$ occurred in some parts of the BL, but were not correlated with the obvious presence of fresh or aged smoke (i.e. elevated $\mathrm{CO}$ ). The $\mathrm{NH}_{3} / \mathrm{NO}_{\mathrm{x}}$ molar ER measured by AFTIR on Yucatan fires was as high as 1.5 and averaged $0.46 \pm 0.42$. Thus, much of the $\mathrm{HNO}_{3}$ formed may have reacted quickly with $\mathrm{NH}_{3}$ to form particle nitrate as also discussed later.

The post-emission fate of organic acids in BB plumes is variable. Goode et al. (2000) observed secondary increases
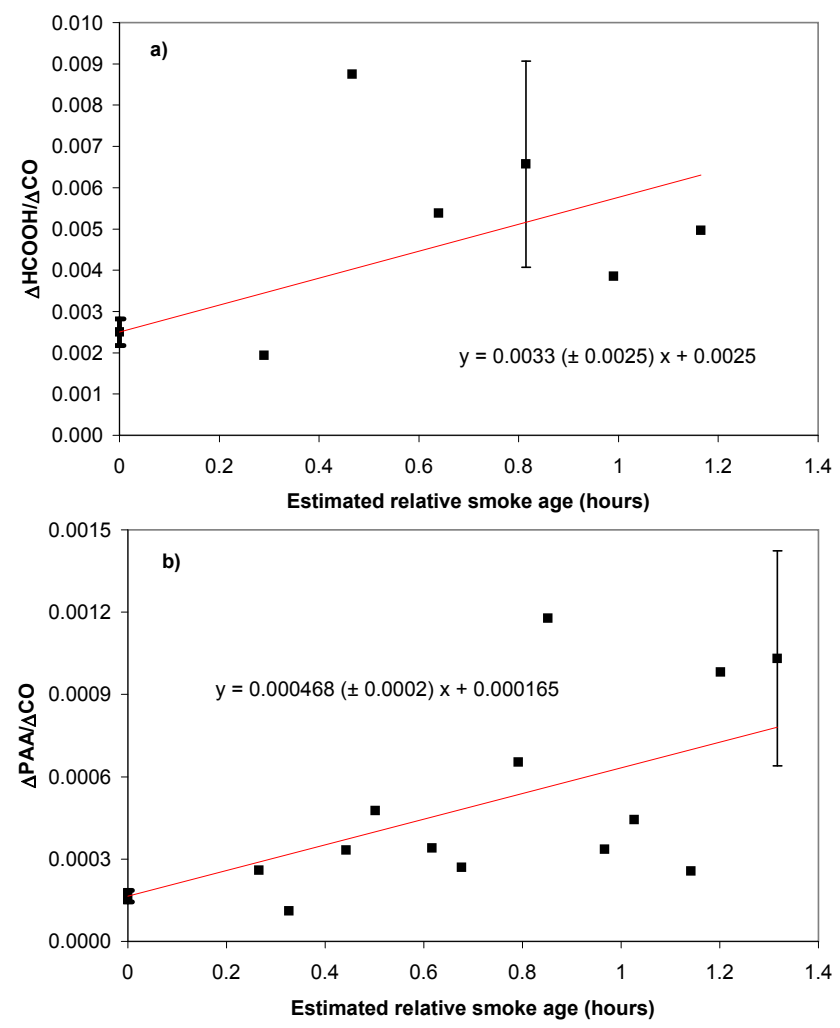

Fig. 7. Net production of both formic acid (a) and peroxyacetic acid (PAA) (b) in the aging smoke from the C-130 Fire \# 3 (Sect. 3.4).

in both excess formic acid $(\triangle \mathrm{FAc})$ and excess acetic acid $(\triangle \mathrm{HAc})$ ratioed to $\triangle \mathrm{CO}$ for one Alaskan fire, but only in $\triangle \mathrm{FAc} / \triangle \mathrm{CO}$ for another Alaskan fire. In 3 different African BB plumes, Yokelson et al. (2003) observed $\Delta \mathrm{HAc} / \Delta \mathrm{CO}$ increase to $6-9 \%$ in $<1 \mathrm{~h}$, but saw no post-emission increase in $\triangle \mathrm{FAc} / \triangle \mathrm{CO}$. A huge regional plume emanating from the Brazilian Amazon had much higher $\triangle \mathrm{FAc} / \triangle \mathrm{CO}(\sim 1.6 \%)$ and $\triangle \mathrm{HAc} / \triangle \mathrm{CO}(\sim 5 \%)$ than the initial values measured for Amazonian fires (Yokelson et al., 2007b). Within the aged Fire \#3 plume, we measured more organic acids than previously possible. The excess mixing ratios of FAc and peroxyacetic acid normalized to $\triangle \mathrm{CO}$ both increased (Fig. 7) while the excess mixing ratios of HAc and propanoic acid normalized to $\triangle \mathrm{CO}$ did not show significant trends. In general, the ratio of excess carbon contained in organic acids to excess carbon contained in $\mathrm{CO}$ is large in fresh smoke and very large in slightly aged smoke $(4-18 \%$ in the Yucatan, Brazil, and Africa). Thus, in many BB plumes organic acids are the third most important carbon reservoir behind $\mathrm{CO}_{2}$ and $\mathrm{CO}$ and ahead of $\mathrm{CH}_{4}$. The observed growth in organic acids is often much larger than the amount of known precursors. There may be currently unidentified high molecular weight precursors that are emitted in quite variable amounts.

The total $\mathrm{NO}_{\mathrm{x}}$ loss for the 1.2-1.4h aging interval was $54 \pm 19 \%$ with the formation of PANs accounting for a 


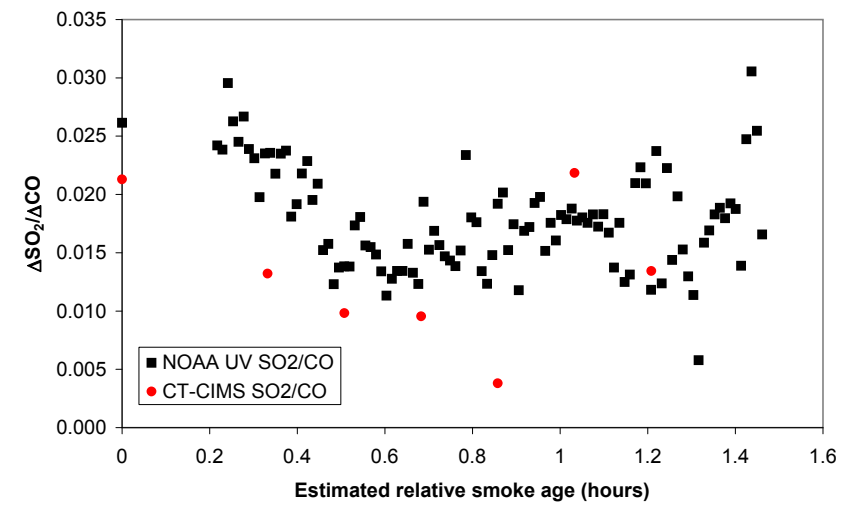

Fig. 8. Continuous and discrete measurements of $\Delta \mathrm{SO}_{2} / \Delta \mathrm{CO}$ in the aging $\mathrm{C}-130$ Fire \#3 plume. Much of the initial drop in $\Delta \mathrm{SO}_{2} / \Delta \mathrm{CO}$ is likely due to the gradually decreasing ratio of flaming to smoldering combustion (F/S) at the source (Sect. 3.4). The $\mathrm{F} / \mathrm{S}$ for the beginning and end of the aging sequence shown is about the same and the average $\Delta \mathrm{SO}_{2} / \Delta \mathrm{CO}$ value in the $1.2-1.4 \mathrm{~h}$ aging interval is $\sim 23 \%$ lower than the initial ratio.

$\mathrm{NO}_{\mathrm{x}}$ loss of $\sim 17 \%$ as shown earlier. The measured $\mathrm{OH}$ (starting at $1.1 \times 10^{7}$ and dropping to $4.1 \times 10^{6}$ ) coupled with the pseudo-second order rate constant for $\mathrm{OH}+\mathrm{NO}_{2}$ $\left(1.02 \times 10^{-11} \mathrm{~cm}^{3} / \mathrm{molecule} / \mathrm{s}\right)$ at the temperature and pressure of the plume $\left(288^{\circ} \mathrm{K}, 815 \mathrm{hPa}\right)$ predicts an additional $30 \%$ loss (Sander et al., 2006). The additive loss from these two channels $(47 \%)$ is close to the total loss considering the uncertainty in the sample ages (a factor of two) and the rate constant $(\sim 30 \%)$, but other loss processes are not excluded. For the 22 March Twin Otter Fire \#8, $\Delta \mathrm{NO}_{\mathrm{x}} / \Delta \mathrm{CO}$ decreased $\sim 75 \%$ between the young and aged samples. This larger decrease could be partly due to changes in this ratio at the source, but may also reflect the fact that the Twin Otter sampled initial smoke at lower altitude (300-600 m) than the $\mathrm{C}-130(\sim 1700 \mathrm{~m})$. OH may be higher in the fresher smoke (Hobbs et al., 2003).

Figure 8 shows $\Delta \mathrm{SO}_{2} / \Delta \mathrm{CO}$ from both the NOAA UV and the Caltech CIMS in the C-130 Fire \#3 plume. The ratio drops from the initial average of 0.0239 to $\sim 0.015$ by $\sim 0.7 \mathrm{~h}$. A decrease this fast is not likely to be due only to gas-phase or heterogeneous processes in the aging plume. The fact that $\mathrm{SO}_{2}$ is produced by flaming combustion and $\mathrm{CO}$ is mainly from smoldering combustion probably explains much of the observed drop. As shown in Fig. 4b, the samples with nominal aging times up to almost $1 \mathrm{~h}$ reflected relatively more smoldering at the source. For the $1.2-1.4 \mathrm{~h}$ aging interval, the $\mathrm{F} / \mathrm{S}$ was about the same as the initial value and $\Delta \mathrm{SO}_{2} / \Delta \mathrm{CO}$ was $0.0186 \pm 0.006$ on the continuous instrument (no CIMS samples). This could imply an $\mathrm{SO}_{2}$ loss of $23 \pm 8 \%$ due mainly to plume processes. The expected loss by $\mathrm{OH}$ oxidation is only $\sim 3 \%$ at $1.3 \pm 0.1 \mathrm{~h}$. According to Seinfeld and Pandis (2006), $\mathrm{SO}_{2}$ loss is very fast in cloud droplets and also significant on particles at $\mathrm{RH}>90 \%$ or near $\mathrm{NH}_{3}$ sources,
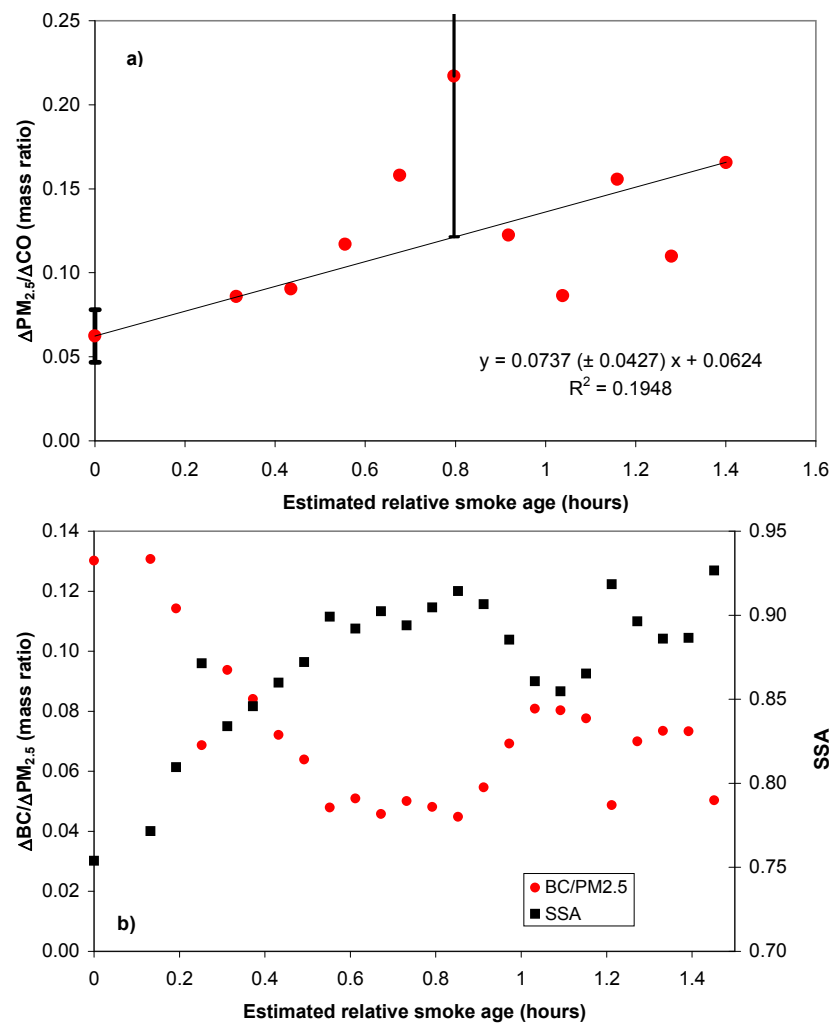

Fig. 9. (a) The mass ratio of $\Delta \mathrm{PM}_{2.5} / \Delta \mathrm{CO}$ increases by 2.6 as the smoke from the $\mathrm{C}$-130 Fire \#3 ages $1.4 \mathrm{~h}$ using the endpoint of the fit line. (The apparent faster initial increase may reflect the higher particle emissions for smoldering combustion.) (b) As the particles age, $\mathrm{BC}$ is conserved $\left(\triangle \mathrm{BC} / \Delta \mathrm{PM}_{2.5}\right.$ decreases by 2.6$)$, non-absorbing components are added, and SSA increases.

conditions which are met for much of the Fire \#3 plume. The expected and observed changes in sulfur species over the relatively short time monitored in the Fire \#3 plume are small and uncertain, but heterogeneous processes may well have contributed.

A large increase in $\Delta \mathrm{PM}_{2.5} / \Delta \mathrm{CO}$ was observed in the aging Fire 3 plume. Figure $9 \mathrm{a}$ shows a rapid initial rise in $\Delta \mathrm{PM}_{2.5} / \Delta \mathrm{CO}$, which may partly reflect decreased $\mathrm{F} / \mathrm{S}$ at the source combined with the higher EFPM normally observed for smoldering (Yokelson et al., 2007a). At $\sim 1.4 \mathrm{~h}$ of aging the $\Delta \mathrm{PM}_{2.5} / \Delta \mathrm{CO}$ had increased by a factor of $2.6 \pm 1.5$, which is independent of the choice of a fixed MSE. Figure $9 \mathrm{~b}$ shows the mass fraction $\triangle \mathrm{BC} / \Delta \mathrm{PM}_{2.5}$, which decreased by 2.6 over the same aging period. This decrease is independent of the choice of fixed MAE. Since BC is made only by flaming combustion at the source and $\triangle \mathrm{BC} / \triangle \mathrm{CO}$ is similar at the source and the end of the aging period, the complementary change in the above ratios confirms that the overall change in $\triangle \mathrm{PM}_{2.5} / \Delta \mathrm{CO}$ is due to secondary aerosol formation. Also shown in Fig. $9 \mathrm{~b}$ is the increase in SSA from $\sim 0.75$ to $\sim 0.93$ as the mass fraction of BC decreases in the $\mathrm{PM}_{2.5}$. This is analogous to the increase in SSA from 0.84 
to 0.885 measured by Abel et al. (2003) over $\sim 2.4$ hours of aging in an African BB plume. In this work, we also quantified the secondary formation of the individual non-absorbing constituents using the AMS as described next.

Figure 10 shows the Fire \#3 aging results for all the particle species measured by the AMS except for NR chloride. The excess amounts of all the particle species shown are normalized to excess $\mathrm{CO}$ and all these ratios increased significantly. ( $\Delta$ chloride/ $\Delta \mathrm{CO}$ remained constant over $\sim 1.4 \mathrm{~h}$ ). Summing the ER to CO (on a mass basis) in the fresh smoke of Fire \#3 gives a total of $5.6 \%$. We derived a "final" mass ER to CO from the fit shown at 1.4 hours and then summed these ratios to obtain $13.3 \%$. Thus, the excess mass of all AMS species ratioed to excess $\mathrm{CO}$ increases by a factor of 2.4 over this time period - in good agreement with the factor of 2.6 implied by the light scattering.

The changes in the mass percentage of the $\Delta \mathrm{PM}_{2.5}$ were also computed for each species yielding complementary results since the particles were adding mass. For instance, the $\Delta$ sulfate/ $\Delta \mathrm{CO}$ ratio increased by a factor of $8.6 \pm 2.7(95 \%$ CI) from its initial value to its value at $1.4 \mathrm{~h}$. This was larger than the overall $\mathrm{PM}_{2.5}$ growth factor of $\sim 2.6$ so the mass percentage of the particles accounted for by sulfate increased from $\sim 1.5$ to $\sim 5 \%$. The growth factor measured for $\Delta \mathrm{OA} / \triangle \mathrm{CO}$ was $2.3 \pm 0.85$, which is slightly smaller than the overall $\mathrm{PM}_{2.5}$ growth of $\sim 2.6$ so the calculated mass fraction of $\mathrm{OA}$ in the $\mathrm{PM}_{2.5}$ decreased slightly from 62 to $53 \%$. Disregarding uncertainty, the calculation suggests that the particles could be adding organic mass, but adding inorganic mass at an even higher rate. The growth factor for $\Delta \mathrm{NO}_{3}^{-} / \Delta \mathrm{CO}$ was $5.4 \pm 1.2$ and the mass percentage of nitrate increased from 5.5 to $11 \%$. The ratio $\Delta \mathrm{NH}_{4}^{+} / \Delta \mathrm{CO}$ increased by $2.7 \pm 2.0$ and so the computed mass percentage of ammonium was nearly unchanged (5.3\% initial to $5.4 \%$ final). Since $\Delta \mathrm{Cl}^{-} / \Delta \mathrm{CO}$ (final) divided by $\Delta \mathrm{Cl}^{-} / \Delta \mathrm{CO}$ (initial) was 1.02 , the calculated mass percentage of $\mathrm{Cl}^{-}$decreased by 2.6 (from $14.7 \%$ to $5.7 \%$ ); the inverse of the overall particle growth. Note in this case $\mathrm{Cl}^{-}$was not lost from the particles; it simply represented a decreasing fraction of the PM. The AMS spectra showed that the $\triangle \mathrm{OA} / \triangle \mathrm{OC}$ ratio increased with aging (Fig. 10). This is consistent with an increasing contribution of oxygenated secondary OA (Zhang et al., 2005) since heterogeneous chemistry with $\mathrm{OH}$ is too slow to add so much oxygen on this time scale (DeCarlo et al., 2008).

On a molar basis, as the plume from Fire \#3 ages, the increase in $\Delta$ nitrate/ $\Delta C O$ accounts for $49 \pm 16 \%$ of the decrease in $\Delta \mathrm{NO}_{\mathrm{x}} / \Delta \mathrm{CO}$ expected due to $\mathrm{OH}$ reaction. The molar increase in $\Delta$ sulfate/ $\Delta \mathrm{CO}$ accounts for $39 \pm 16 \%$ of the total observed $\Delta \mathrm{SO}_{2} / \Delta \mathrm{CO}$ decrease. Similar calculations for ammonium are not possible since $\mathrm{NH}_{3}$ was not measured on the C-130. However, on a molar basis, the ammonium formation is nearly equal to the sum of the sulfate and nitrate formation. A balance between the loss of gas phase organic precursors emitted by $\mathrm{BB}$ and the secondary formation of BBOA is complex for several reasons. The
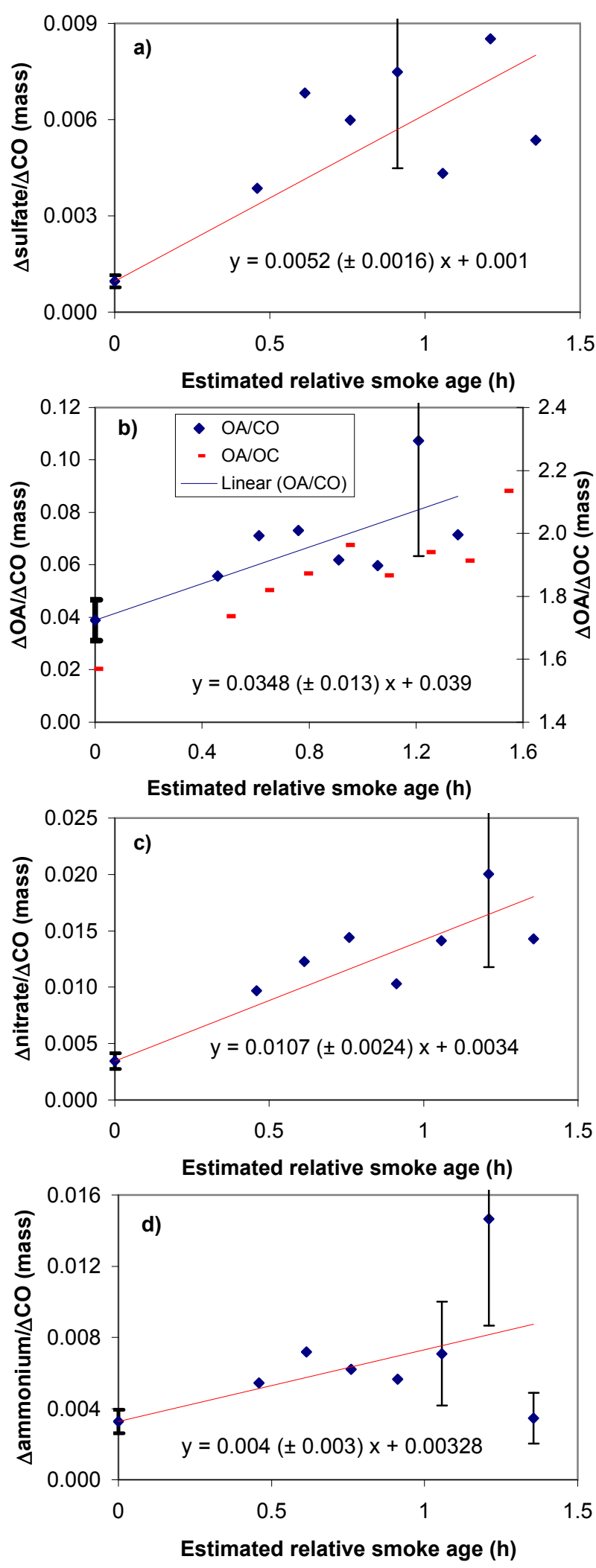

Fig. 10. Secondary formation of organic and inorganic aerosol in the aging plume of C-130 Fire \#3 (see Sect. 3.4). 
condensed phase species comprising BBOA are mostly unknown and they likely added mass during gas-phase oxidation. In addition, only $\sim 50 \%$ of the total gas-phase NMOC emitted by BB have been identified. Grieshop et al. (2008) recently found that the loss of known secondary OA (SOA) precursors in wood stove smoke only accounted for $\sim 20 \%$ of the measured SOA formation in a smog chamber experiment. They also developed a model that accounted for all the observed SOA formation by assuming that unspecified low volatility organic compounds were present in significant amounts; an assumption that is not included in other current SOA models. Finally, in real BB plumes some of the secondary aerosol formation can occur due to condensation of trace gases from other sources. However, we get a rough idea of the magnitude of the conversion process as follows. We estimate the growth for each AMS particle species by applying the measured growth factor from Fire \#3 to the average initial EF for that species shown in Table 4. We then divide by the average initial EF in Table 4 for the trace gas precursor to get an upper limit for the fractional precursor conversion. With these assumptions, the mass of the PM species formed in $\sim 1.4 \mathrm{~h}$ divided by the mass of the co-emitted gasphase precursor is: sulfate $/ \mathrm{SO}_{2}(0.11), \mathrm{OA} / \Sigma \mathrm{NMOC}(0.19)$, $\mathrm{NO}_{3}^{-} / \mathrm{NO}_{\mathrm{x}}(0.25)$, and $\mathrm{NH}_{4}^{+} / \mathrm{NH}_{3}(0.32)$. The OA/NMOC fraction is overestimated as explained above: i.e. the projected mass yield of OA at $1.4 \mathrm{~h}$ is 0.10 compared to estimated total NMOC (including unmeasured species). However, the growth factors observed in this work, coupled with the TEM results presented next may be the most comprehensive evidence available for rapid secondary formation of both organic and inorganic aerosol in a BB plume. The large amount of secondary formation observed in this work has important implications for air quality, radiative transfer, and visibility. This is especially true because biomass burning is the second largest global source of NMOC $(\sim 500 \mathrm{Tg} / \mathrm{yr})$ after biogenic emissions ( $\sim 1000 \mathrm{Tg} / \mathrm{yr})$ (Yokelson et al., 2008). Finally, large formation of SOA may not always occur in BB plumes (Capes et al., 2008) so this subject deserves significant further research.

TEM analysis of individual aerosol particles shows that their composition and structure in the smoke changed within 30 minutes of emission, presumably through condensation, heterogeneous reactions, or both (Fig. 11). We compared TEM samples that were collected at two altitudes $(\sim 600 \mathrm{~m}$ and $\sim 1700 \mathrm{~m}$ ) on the Twin Otter from the 22 March Fire \#8. The younger sample was collected within a few minutes of emission. The older sample had aged between 10 and $30 \mathrm{~min}$ since emission.

The younger sample contains many particles with a large fraction of $\mathrm{KCl}$, whereas the older one has particles that contain $\mathrm{K}, \mathrm{S}$, and $\mathrm{Na}$ and that presumably consist of $\mathrm{K}_{2} \mathrm{SO}_{4}$, $\mathrm{Na}_{2} \mathrm{SO}_{4}$, and their mixtures. The older sample also includes spherical organic aerosol particles (tar balls; indicated with a "T" in Fig. 11c) like those reported by Pósfai et al. (2004) and Hand et al. (2005).
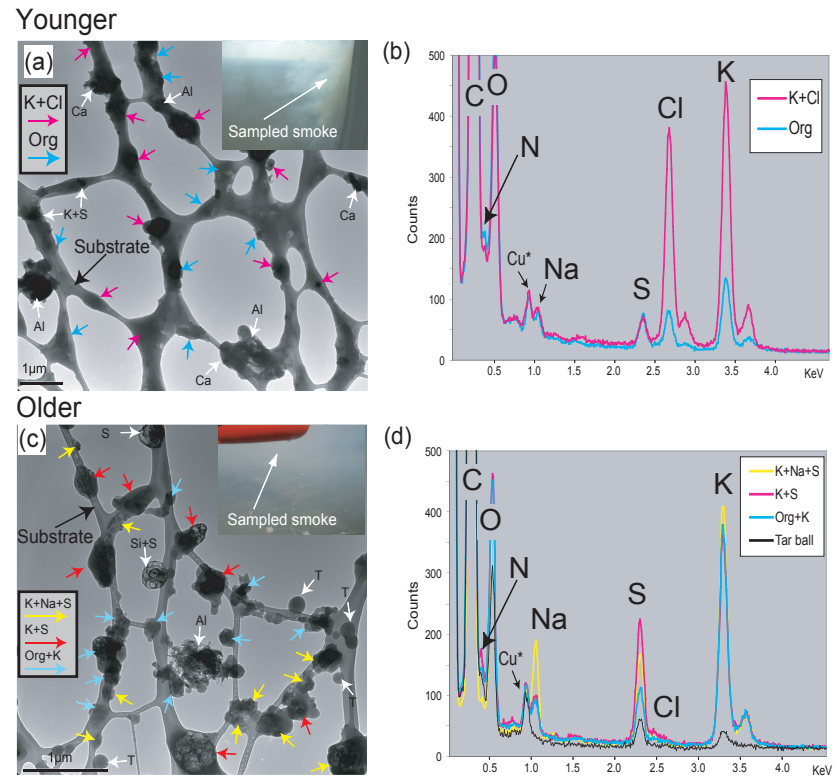

Fig. 11. Morphologies and compositions of individual particles from young (a few minutes old) and older ( $\sim 10$ to $30 \mathrm{~min}$ ) biomassburning samples collected on 22 March from fire \#8. (a) TEM image of the younger aerosol particles. The thin black linear features are the lacy-carbon substrate on which the samples were collected. The white arrows plus chemical symbols indicate particles that are rich in $\mathrm{Ca}, \mathrm{Al}$, or $\mathrm{K}+\mathrm{S}$. (b) Energy-dispersive X-ray spectrometer (EDS) spectra of typical particles in image (a). (c) TEM image of the older aerosol particles. The white arrows plus chemical symbols indicate particles that are rich in $\mathrm{S}, \mathrm{Si}+\mathrm{S}$, or $\mathrm{Al}$. T indicates tar ball particles. (d) EDS spectra of typical particles in image (c). We used an electron beam $\sim 0.2 \mu \mathrm{m}$ in diameter and 30 -second counting times for the EDS analyses. The spectra were averaged across the particles indicated by arrows in the images. Almost all particles included strong $\mathrm{C}$ and $\mathrm{O}$ signals from organic material and the lacey-carbon filter. $\mathrm{N}$-bearing species such as nitrates and ammonium were not well measured using EDS because $\mathrm{N}$ signals are generally weak plus these species decompose rapidly in the TEM beam. The $\mathrm{Cu}$ peak is marked with an asterisk because it is from the TEM grid. Sample collection times were less than a minute for both samples. Scale bars in both images indicate $1 \mu \mathrm{m}$. Org indicates organic material.

The increases in $\mathrm{S}$ and organic $\mathrm{C}$ with aging measured by using the TEM are consistent with the increases for the same species measured using the AMS on the C-130 Fire \#3. One possible difference between the two fires is that the TEM data show that there is almost no $\mathrm{Cl}$ in the 10-30 minute old sample whereas measurements with the AMS revealed a decrease in the mass percentage of chlorine, but a constant chlorine/CO ratio with aging. Chlorine could decrease with age as the result of reactions in the atmosphere. Similar $\mathrm{Cl}$ loss was also observed in African biomass burning plumes (Pósfai et al., 2003; Li et al., 2003). KCl reacts with sulfuric acid and forms $\mathrm{K}_{2} \mathrm{SO}_{4}$, releasing $\mathrm{Cl}$ as $\mathrm{HCl}$. A possible reason for the difference in the results for the two fires could 
be that $\mathrm{Cl}$ loss is a fast initial process and the youngest AMS sample was at the same altitude as the oldest TEM sample. If most of the $\mathrm{KCl}$ particles reacted within 10-30 min of emission, no further $\mathrm{Cl}$ decrease would have been detected with AMS in their biomass burning plume. Another possibility is that as the sulfate is replacing the chloride in $\mathrm{KCl}$, the chloride is recondensing as $\mathrm{NH}_{4} \mathrm{Cl}$, which is detectable with the AMS but is likely lost in the vacuum of the TEM (Johnson et al., 2008). In any case, to our knowledge, $\mathrm{Cl}^{-}$has been observed to decrease or be conserved as BB plumes age, but not to increase.

\subsection{Chemistry of aged smoke layers at top of boundary layer}

Unlike the case for the C-130 Fire \#3, we don't know the initial ER for the fires that contributed to the aged, and potentially cloud-processed, smoke layers that were penetrated at the top of the BL on 23 March. However, we can compare the normalized excess mixing ratios in these high-altitude, aged smoke layers to our study-average initial ER measured in nascent smoke and the trends observed in the aging of the Fire \#3 plume to gain some additional insight into the likely nature of smoke aging. The general observation is that these layers tend to have normalized excess mixing ratios similar to those in the aged Fire \#3 plume or exhibit a continuation of the aging trends noted in the plume downwind of Fire \#3. But some caveats are noted.

The $\Delta \mathrm{O}_{3} / \Delta \mathrm{CO}$ ratio in these layers increases with altitude from $\sim 0.02$ to $\sim 0.05$ to 0.17 (Table 3 ) suggesting that the highest layer is the oldest and $\sim 1.5 \mathrm{~h}$ old. On the other hand the $\triangle \mathrm{OA} / \triangle \mathrm{CO}(\sim 0.17)$ and $\Delta$ sulfate/ $\triangle \mathrm{CO}(\sim 0.02)$ ratios in the highest layer are about twice the value in the Fire 3 plume at $\sim 1.4 \mathrm{~h}$. This would suggest an age of about $3 \mathrm{~h}$ if a linear aging rate and similar initial emissions are assumed. The largest gas-phase $\mathrm{H}_{2} \mathrm{O}_{2}$ mixing ratios occurred just above the highest smoke layer. Thus the aqueous $\mathrm{H}_{2} \mathrm{O}_{2}$ in clouds is likely also largest for the highest smoke layer, which may contribute to the high degree of sulfate formation and the low $\Delta \mathrm{SO}_{2} / \Delta \mathrm{CO}$ ratio of this layer. On the other hand, the $\Delta \mathrm{NO}_{\mathrm{y}} / \Delta \mathrm{CO}$ ratio varies greatly between the 3 high smoke layers and it is much larger in the highest layer, which strongly suggests that the initial emissions are not identical for each layer. This complicates the comparison of layers. Also illustrating variability, the $\Delta \mathrm{HCN} / \triangle \mathrm{CO}$ average over all three layers $(0.0022)$ is closer to the Twin Otter average $(0.0032 \pm 0.0014)$ than the $\mathrm{C}-130$ average $(0.0100 \pm 0.0044)$.

In the smoke layers at the top of the BL $\Delta \mathrm{NO}_{\mathrm{x}} / \Delta \mathrm{NO}_{\mathrm{y}}$ ranged from 0.21 to 0.37 , which are all values lower than the average $(0.46)$ in the Fire \#3 plume at $\sim 1.4 \mathrm{~h}$. This suggests that the smoke had aged for more than $\sim 2$ hours. However, the lowest value (indicating the oldest layer) was in the middle layer rather than the top layer, which $\Delta \mathrm{O}_{3} / \Delta \mathrm{CO}$ indicated was the oldest. $\triangle \Sigma \mathrm{PANs} / \Delta \mathrm{NO}_{\mathrm{y}}$ was the highest in the bottom layer $(\sim 0.3)$ and $<0.15$ in the other layers. This would imply that the bottom layer is the oldest. Thus, several normalized excess mixing ratios that can be used as "photochemical clocks" do not all indicate the same average age or relative ages - possibly due to varying initial emissions, mixing of different aged plumes, and different processing environments. An important point of this discussion is that given fire to fire variability (Fig. 3) and the high uncertainty in mean EF (Table 2) it could be misleading to compare aged and fresh smoke from different fires even when they occur or originate in the same region (Capes et al., 2008). Conversely, a non-representative characterization of the average initial $\mathrm{BB}$ emissions from a region, even if coupled with adequate knowledge of the post-emission transformations (which is unlikely), could cause erroneous calculations of the speciation of the $\mathrm{BB}$ emissions exported from a region. We discuss the representativeness of our initial emissions measurements and the topic of scaling to regional emissions next.

\section{Implications and impact on the regional environment}

\subsection{Fire characteristics and estimates of regional emis- sions}

It is important to characterize the fires we sampled, consider how well they represented the regional biomass burning, and help guide reasonable estimates of regional emissions from our spot measurements. In this effort, we rely on notes and photographs from the sampling aircraft, the literature, and remote-sensing data. Based on visual observations from the Twin Otter, nearly all the fires fit into a simple classification scheme: (1) Deforestation fires (DF) - enclaves in the forest where heavy slash was burning to initiate or expand agricultural areas. (2) Burning of crop residue (CR) or "agricultural waste" in fields. (3) DF or CR fires which had "escaped" into nearby un-slashed forest where they consumed mostly understory fuels. If the unintended burned area was $<\sim 10 \%$ of the planned burn, the fire was classified as DF or CR in Tables 1 and 2. If the planned and unplanned areas were comparable the fire was classified as "mixed." Surface windspeeds were high throughout southern Mexico in March of 2006 and at least one-third of the fires we observed from the Twin Otter had escaped their apparent intended boundaries. The fact that much of the Yucatan forest canopy is leafless in the dry season also promotes large amounts of unintended burning; in contrast to evergreen forests where the intact canopy maintains a moist microclimate during the shorter "dry"/fire season.

During our flights a total of $6 \mathrm{DF}, 6 \mathrm{CR}, 5$ mixed, and three fires of unknown type were observed. This suggested that the clearing of new areas and the disposal of crop waste were responsible for a roughly equal number of fires. In addition, we estimated the area burned and fuel consumption for the whole Yucatan region using a model developed at NCAR by Wiedinmyer et al. (2006). Briefly, MODIS 
thermal anomalies were used to identify the daily time and location of fires. The area burned at each fire was assumed to be $1 \mathrm{~km}^{2}$ (100 ha), scaled to the amount of vegetated area at the same location (determined by the MODIS Vegetation Continuous Fields product, Hansen et al., 2003). The fuel loading at each site was dependent on the ecosystem at each fire location (based on the GLC200 dataset; Latifovic et al., 2003). Finally, the fuel consumption was assumed to be a function of both the fuel loading and the vegetation coverage at each site. On average the model fuel consumption per unit area for the two main fires types was $4.5 \mathrm{Mg} / \mathrm{ha}(\mathrm{CR})$ and $52 \mathrm{Mg} / \mathrm{ha}$ (DF).

The average modeled fuel consumption values are in reasonable agreement with field measurements of fuel consumption in tropical dry forest and crop waste fires. Kauffman et al. (2003) measured late dry season fuel consumption on five fires in slashed dry forest in western Mexico and northeastern Brazil ranging from $57-108 \mathrm{Mg} / \mathrm{ha}$. Fuel consumption values near $10 \mathrm{Mg} / \mathrm{ha}$ were measured when only understory fuels were burning in tropical dry forests in Brazil and Africa (Ward et al. 1992; Shea et al., 1996; Hoffa et al., 1999). For crop waste fires total biomass and the percentage that constitutes residue varies considerably by crop. Further, the percentage of residue that decomposes before burning varies with climate and drying time and use of residue as fertilizer, animal feed, or household fuel also varies (Yevich and Logan, 2003). We could not identify the plant material that was burned in this study. However, cereals are the most common crop worldwide and data from Zárate et al. (2004) suggests a range of fuel consumption of $0.36-4.2 \mathrm{Mg} / \mathrm{ha}$ for cereal crop residue burning. Higher values have been measured for other crops that are important in Mexico with the largest values typically being reported for sugar cane $(20 \mathrm{Mg} / \mathrm{ha}$, Lara et al., 2005). Thus, the NCAR model averages lie well within the rather large range of values that occur for these fire types.

The uncertainty in the MODIS-based area burned has two chief components: detection efficiency and the estimation of burned area from counts of fire pixels. The MODIS hotspots show daily trends in fire frequency and the spatial distribution of biomass burning, but not all fires are detected. The timing of the Terra and Aqua MODIS overpasses (at $20^{\circ} \mathrm{N}$ ) results in close spacing $(\sim 100 \mathrm{~min})$ of the midday observations and leads to omission errors for short-lived fires or fire activity initiated following the last daytime pass. There are also times when clouds preclude fire detection or overpasses do not cover an area of interest. Additionally, the detection rate decreases with burn size, Hawbaker et al. (2006) found the MODIS detection rate crossed the $50 \%$ mark at a fire size of $\sim 100$ ha. In fact, only a small fraction (4/20) of the fires we sampled were detected by MODIS (Table 1). Most of the "missed fires" were sampled after the last MODIS overpass and all of the fires we photographed were $<100$ ha. Missing fires would cause the model to underestimate burned area. On the other hand, all the fires that we could roughly size were significantly smaller than the $\sim 100$ ha size assumed in the model. In addition, Giglio et al. (2006) estimated that, on average, a MODIS fire pixel represented $\sim 0.4 \mathrm{~km}^{2}$ (40 ha) of burned area in southern Mexico and Central America. Thus, it's likely that the area burned is overestimated for some of the individual Yucatan fires. The two main sources of error in area burned tend to offset. In light of the above-discussed challenges, the overall model uncertainty in the total amount of emissions is estimated at a factor of two (Wiedinmyer et al., 2006).

The results of applying the NCAR model to the Yucatan peninsula $(\sim 18-22 \mathrm{~N}$ by $87-91 \mathrm{~W})$ for March through May of 2006 are shown in Table 6. The ratio of area burned in forest to croplands is about 6:1 for March 2006 and 7.5:1 for the entire March-May 2006 biomass burning season. This contrasts with our airborne observation that the two fire types occurred in roughly equal numbers. Because of the higher fuel consumption per unit area for forest burning, forest fires account for nearly all the modeled fuel consumption on a mass basis. We compared the NCAR model result for March 2006 with a separate analysis using a different vegetation map (CONABIO, 1999) and the ratio of MODIS active fire detections in forested areas to agricultural areas was in rough agreement at 4:1. The predominance of fire in forested areas in the MODIS based analyses compared to the airborne sampling may reflect several factors. 1) The airborne sampling was concentrated nearer the coast (Fig. 2) while the fraction of forested area (and probably the relative amount of deforestation) increases inland (CONABIO, 1999). 2) The vegetation maps $\left(1 \mathrm{~km}^{2}\right.$ resolution) may classify smaller fields surrounded by forest, which appeared common in the Twin Otter photographs, as forest and neither vegetation map accounts for the deforestation since 2001. 3) The heavier fuel loads of deforestation fires support longer duration fires compared to croplands increasing the likelihood of detection as a thermal anomaly by one of the four daily MODIS overpasses. 4) If DF fires tended to be initiated earlier in the day this would favor their detection by MODIS and enhance the forest to crop fire ratio relative to the airborne observations due to the different sampling periods (13:00-16:00 LT for airborne sampling vs. 10:00-13:30 LT for MODIS overpasses). Giglio et al. (2007) observed that Brazilian fire activity associated with deforestation occurred earlier in the day compared with cropland burning, while Smith et al. (2007) attributed the low MODIS detection rate (13\%) for crop residue fires in Australia to the tendency of farmers to burn later in the day after MODIS overpasses. In reality a 1:1 burned area ratio for DF/CR may be an upper limit as it represents approximately doubling the area under agriculture annually. This upper limit would imply an approximately 11:1 ratio in fuel consumption, which suggests our simple average of all ER presented in Table 4 might ultimately be improved upon. 
Table 6. Estimation of area burned and biomass burned in the Yucatan in 2006 and comparison with MCMAEI ${ }^{1}$.

\begin{tabular}{|c|c|c|c|c|c|c|c|c|c|}
\hline \multirow[b]{2}{*}{ Land cover } & \multicolumn{3}{|c|}{ Area Burned (ha) } & \multicolumn{3}{|c|}{ Biomass Burned (Metric Tons) } & March-May Area & \multirow{2}{*}{$\begin{array}{r}\text { March-May Mass } \\
\text { Tg }\end{array}$} & \multirow[t]{2}{*}{ Percent of March-May Mass } \\
\hline & March & April & May & March & April & May & ha & & \\
\hline Forest & 53395 & 401073 & 383286 & 2587590 & 20652195 & 20133816 & 837755 & 43 & 98.8 \\
\hline Grasslands & 100 & 1180 & 1200 & 992 & 15288 & 11746 & 2480 & 0.03 & 0.1 \\
\hline Croplands & 8599 & 57197 & 45298 & 38513 & 255178 & 202126 & 111094 & 0.50 & 1.1 \\
\hline sum & 62094 & 459450 & 429784 & 2627096 & 20922660 & 20347688 & 951329 & 44 & 100 \\
\hline
\end{tabular}

\begin{tabular}{|c|c|c|c|c|c|c|c|c|c|}
\hline \multirow[b]{2}{*}{ Species $^{2}$} & \multirow[b]{2}{*}{$\begin{array}{r}\text { Fire EF } \\
\mathrm{g} / \mathrm{kg}\end{array}$} & \multicolumn{6}{|c|}{2006 Speciated Emissions (Metric Tons) } & \multirow[b]{2}{*}{$\begin{array}{r}\text { Yucatan/MCMA } \\
\text { annual }\end{array}$} & \multirow[b]{2}{*}{$\begin{array}{r}\text { Yucatan/MCMA } \\
\text { March } 2006\end{array}$} \\
\hline & & Yucatan March & MCMA March & Yucatan April & Yucatan May & Yucatan annual $^{3}$ & $\begin{array}{r}\text { MCMA } \\
\text { annual }\end{array}$ & & \\
\hline $\mathrm{PM}_{10}$ & 7.42 & 19489 & 1724 & 155213 & 150947 & 339021 & 20686 & 16.4 & 11.3 \\
\hline $\mathrm{PM}_{2.5}$ & 6.18 & 16241 & 552 & 129344 & 125789 & 282517 & 6622 & 42.7 & 29.4 \\
\hline $\mathrm{CO}$ & 80.47 & 211402 & 149340 & 1683646 & 1637378 & 3677479 & 1792081 & 2.1 & 1.4 \\
\hline VOC & 22.08 & 58006 & 44347 & 461972 & 449277 & 1009056 & 532168 & 1.9 & 1.3 \\
\hline $\mathrm{CH}_{4}$ & 5.08 & 13343 & 19589 & 106266 & 103346 & 232110 & 235065 & 1.0 & 0.7 \\
\hline $\mathrm{SO}_{2}$ & 3.18 & 8344 & 554 & 66450 & 64624 & 145143 & 6646 & 21.8 & 15.1 \\
\hline $\mathrm{NO}_{\mathrm{X}}$ & 3.68 & 9673 & 15000 & 77037 & 74920 & 168267 & 179996 & 0.9 & 0.6 \\
\hline $\mathrm{NH}_{3}$ & 1.02 & 2677 & 1460 & 21320 & 20734 & 46568 & 17514 & 2.7 & 1.8 \\
\hline
\end{tabular}

${ }^{1}$ MCMAEI = Mexico City metropolitan area emissions inventory (2004), March 2006 estimated as annual/12. ${ }^{2}$ Primary PM only, fire PM 10 approximated as $1.2^{*} \mathrm{PM}_{2.5}$, fire EF from Table 4 this work, VOC are identified VOC only. ${ }^{3}$ Yucatan speciated emissions for 2006 based on 45.7 Tg biomass burned in 2006 .

\subsection{Regional transport and estimated total production of emissions}

As discussed above, the fuels and the mix of flaming and smoldering impact the initial emissions from fires, which can then evolve rapidly. The post-emission transport dictates what areas of the atmosphere are impacted by the emissions and the photochemical processing environment. Figure 12 shows 5-day HYSPLIT forward trajectories from 3 starting altitudes from each fire we sampled (Draxler and Rolph, 2003). Similar forward trajectories were confirmed for multiple days in April and May of 2006, which are the peak biomass burning months. About one-half of the emissions tend to disperse northwesterly and remain at altitudes that are likely within the boundary layer. These trajectories tend to cross under NE trending trajectories from MC over the Gulf of Mexico. There is potential for the Yucatan and MC plumes to eventually mix (after some evolution of each plume) over the US. Forward trajectories that start in the early evening (not shown) can disperse directly to the west towards Mexico City. Much of that transport will happen at night. In any case, it's possible for Yucatan emissions to reach Mexico City, other areas in Mexico, or a large area of the Midwestern and Eastern US as has been documented in detail elsewhere (Lyons et al., 1998; Kreidenweis et al., 2001; Rogers and Bowman, 2001; Bravo et al., 2002; Lee et al., 2006; Massie et al., 2006).

Because a large area is impacted by Yucatan BB emissions we next discuss the amount of these emissions as calculated by the NCAR model described above (Table 6 ). To help place the estimated amount of Yucatan emissions in perspective we compare to the emissions from the Mexico City Metropolitan Area (MCMA). Specifically, we start by comparing the annual and March 2006 Yucatan BB emissions directly to

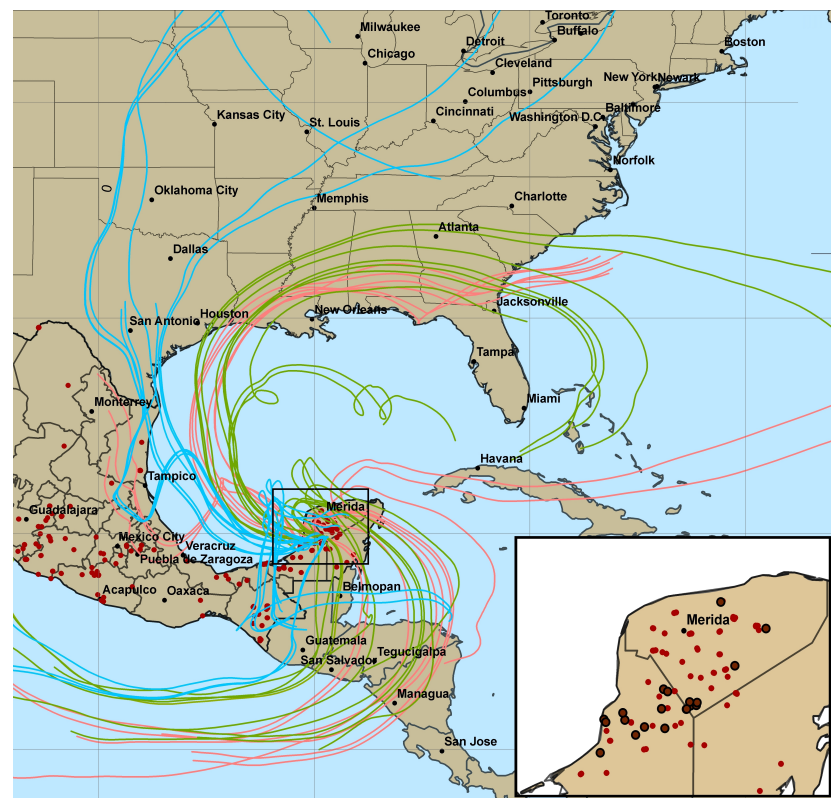

Fig. 12. Three 5-day forward trajectories starting from each fire sampled (red dots with black border). The starting time is the sampling time shown in Table 1. The starting altitudes above ground level are blue $(250 \mathrm{~m})$, green $(1000 \mathrm{~m})$, and red $(2500 \mathrm{~m})$. The projected altitudes stay mainly within the boundary layer. The hotspots (red dots, no border) due to biomass burning throughout Mexico are shown for the dates sampling was conducted in this work.

speciated data from the 2004 MCMA Emissions Inventory (EI) in the bottom half of Table 6 (http://www.sma.df.gob. $\mathrm{mx} / \mathrm{sma} / \mathrm{index}$.php?opcion=26\&id=392). Based on this simple first step, the Yucatan fires appear to emit 20-40 times more $\mathrm{SO}_{2}$ and primary $\mathrm{PM}_{2.5}$ on an annual basis than the 
MCMA. Since biomass burning peaks in April-May, our initial comparison for the March 2006 MILAGRO performance period indicates that the Yucatan fires emitted 15-30 times more $\mathrm{SO}_{2}$ and primary $\mathrm{PM}_{2.5}$ and about equal amounts of other trace gases as the MCMA. However, the $\mathrm{PM}_{2.5}$ in the MCMAEI could be more than a factor of 2 low (calculated from Salcedo et al., 2006). In addition, the simple comparison in Table 6 does not include secondary aerosol formation, which could increase the amount of $\mathrm{PM}_{2.5}$ tenfold in the MCMA emissions (Kleinman et al., 2008) and a factor of two or more in the BB emissions (Sect. 3.4). Adjusting for the above factors implies that the Yucatan $\mathrm{SO}_{2}$ and $\mathrm{PM}_{2.5}$ sources are likely about 2 and 4 times larger, respectively, than MCMA on an annual basis. Additional important pollution sources are located in the region including fires in other parts of Mexico and Central America and large $\mathrm{SO}_{2}$ emissions from the Popocatépetl volcano $\left(894000 \mathrm{t} \mathrm{yr}^{-1}\right.$, Grutter et al., 2008), the Tula refinery (158000 $\mathrm{tyr}^{-1}$, de Foy et al., 2007), and other volcanoes and refinery complexes. Notably, both the Popocatépetl and Tula $\mathrm{SO}_{2}$ sources are estimated to be larger than the Yucatan $\mathrm{BB}$ or MCMA $\mathrm{SO}_{2}$ source. Clearly though, our BB estimates for the Yucatan establish it as one of the major regional sources of trace gases and particles.

\subsection{Distribution of biomass burning in the global North- ern Hemisphere}

Inspection of the TOMS ozone monitoring instrument global aerosol index (AI) images for March-May 2006 is instructive (http://jwocky.gsfc.nasa.gov/aerosols/aerosols_v8.html). Even though we know significant biomass burning is occurring in the Yucatan during this time, no enhancements of the AI are depicted in the global images. However, other areas of the NH tropics show frequent, very strong AI enhancements during the same time period. This suggests that these other areas (Indochina, India, Sahel, etc.) experience a much larger amount of biomass burning. Most of these areas are also heavily populated and suffer from severe air quality problems (Ramanathan et al., 2001).

\section{Conclusions}

This study increased both the total number of fires sampled (from 2 to 22) and the total number of plume species quantified (from 4 to 51) for biomass burning (BB) in the Yucatan. These are the first detailed measurements of $\mathrm{NH}$ tropical $\mathrm{BB}$ and they include some species measured for the first time in young plumes $(\mathrm{OH}$, peroxyacetic acid, propanoic acid, hydrogen peroxide, etc). The $\mathrm{OH}$ measurement in an aging BB plume confirmed the possibility of very high early $\mathrm{OH}$ $\left(1.14 \times 10^{7}\right.$ molecules $\left./ \mathrm{cm}^{3}\right)$ likely caused in part by high initial HONO $\left(\sim 10 \%\right.$ of $\left.\mathrm{NO}_{\mathrm{y}}\right)$. Rapid net production of $\mathrm{O}_{3}$ was observed with $\Delta \mathrm{O}_{3} / \Delta \mathrm{CO}$ reaching $15 \%$ in about one hour of aging in one plume. Significant post-emission increases in $\mathrm{HCHO}, \mathrm{H}_{2} \mathrm{O}_{2}, \mathrm{HCOOH}$, PANs, and other gases were also observed. The most detailed observations to date of secondary aerosol formation in a BB plume showed that the $\Delta \mathrm{PM}_{2.5} / \Delta \mathrm{CO}$ can more than double in less than several hours. Growth in nitrate, ammonium, sulfate and organic mass accounted for nearly all of the secondary formation. Currently unidentified high molecular weight NMOC may contribute significantly to the above observed changes. It was shown that comparing aged and fresh smoke from different fires can be misleading due to high fire-fire variability. The two main types of BB were deforestation and crop residue fires, but determining the regional average mix of these types is difficult. BB in the Yucatan is a major source of trace gases and particles in the region.

Acknowledgements. The authors thank Eric Hintsa and AnneMarie Schmoltner of NSF for supplemental funding for ASU and $\mathrm{U}$ Miami, and travel funds for CU to conduct measurements on the Twin Otter. We thank the Twin Otter and C-130 pilots. Thanks go to Sasha Madronich, Luisa Molina, and Jose Meitin for coordinating the overall MILAGRO campaign. The University of Montana and the Twin Otter were supported mostly by NSF grant ATM-0513055. Yokelson was also supported by the Strategic Environmental Research and Development Program (SERDP) of DoD. Support for the USFS and Twin Otter was provided by the NASA North American Carbon Plan (NNHO5AA86I). P. F. DeCarlo and J. L. Jimenez were supported by NSF ATM-0513116 and ATM-0449815, NASA NNG06GB03G, and EPA Graduate Fellowship FP-91650801. Participation by Arizona State University was supported by NSF grant ATM-0531926. We gratefully acknowledge the use of TEMs within the LeRoy Eyring Center for Solid State Science at Arizona State University. Support to the University of Miami was provided by NSF (ATM 0511820). $\mathrm{X}$. Zhu and L. Pope provided excellent technical support for the canister trace gas analyses. Support for operation of the Caltech CIMS instrument was provided by NASA (NNG04GA59G) and by EPA-STAR support for J. Crounse. The C-130 forward looking video was provided by NCAR/EOL under sponsorship of the National Science Foundation. http://data.eol.ucar.edu/.

Edited by: J. Gaffney

\section{References}

Abel, S. J., Haywood, J. M., Highwood, E. J., Li, J., and Buseck, P. R.: Evolution of biomass burning aerosol properties from an agricultural fire in southern Africa, Geophys. Res. Lett., 30(15), 1783, doi:10.1029/2003GL017342, 2003.

Adachi, K. and Buseck, P. R.: Internally mixed soot, sulfates, and organic matter in aerosol particles from Mexico City, Atmos. Chem. Phys. Discuss., 8, 6469-6481, 2008, http://www.atmos-chem-phys-discuss.net/8/6469/2008/.

Aiken, A., DeCarlo, P. F., Kroll, J. H., et al.: O/C and OM/OC ratios of primary, secondary, and ambient aerosols with high-resolution time of flight aerosol mass spectrometry, Environ. Sci. Technol., 42, 4478-4485, doi:10.1021/es703009q, 2008. 
Alvarado, M. J., and Prinn, R. G.: Formation of ozone and growth of aerosols in young smoke plumes from biomass burning: 1. Lagrangian parcel studies, J. Geophys. Res., 114, D09306, doi:10.1029/2008JD011144, 2009.

Andreae, M. O. and Merlet, P.: Emission of trace gases and aerosols from biomass burning, Global Biogeochem. Cycles, 15(4), 955966, doi:10.1029/2000GB001382, 2001.

Bertram, A. K., Ivanov, A. V., Hunter, M., Molina, L. T., and Molina, M. J.: The reaction probability of $\mathrm{OH}$ on organic surfaces of tropospheric interest, J. Phys. Chem., 105, 9415-9421, 2001.

Bravo, A. H., Sosa, E. R., Sanchez, A. P., Jaimes, P. M., and Saavedra, R. M. I.: Impact of wildfires on the air quality of Mexico City, 1992-1999, Environ. Poll., 117, 243-253, 2002.

Capes, G., Johnson, B., McFiggans, G., Williams, P. I., Haywood, J., and Coe, H.: Aging of biomass burning aerosols over West Africa: Aircraft measurements of chemical composition, microphysical properties, and emission ratios, J. Geophys. Res., 113, D00C15, doi:10.1029/2008JD009845, 2008.

Christian, T., Kleiss, B., Yokelson, R. J., Holzinger, R., Crutzen, P. J., Hao, W. M., Saharjo, B. H., and Ward, D. E.: Comprehensive laboratory measurements of biomass-burning emissions: 1 . Emissions from Indonesian, African, and other fuels, J. Geophys. Res., 108(D23), 4719, doi:10.1029/2003JD003704, 2003.

Clarke, A. D., Shinozuka, Y., Kapustin, V. N., et al.: Size distributions and mixtures of dust and black carbon aerosol in Asian outflow: Physiochemistry and optical properties, J. Geophys. Res., 109, D15S09, doi:10.1029/2003JD004378, 2004.

Clarke, A., McNaughton, C., Kapustin, V., et al.: Biomass burning and pollution aerosol over North America: Organic components and their influence on spectral optical properties and humidification response, J. Geophys. Res., 112, D12S18, doi:10.1029/2006JD007777, 2007.

Cofer III, W. R.,, Levine, J. S., Winstead, E. L., Stocks, B. J., Cahoon, D. R., and Pinto, J. P.: Trace gas emissions from tropical biomass fires: Yucatan peninsula, Mexico, Atmos. Environ., 27a, 1903-1907, 1993.

Comisión Nacional para el Conocimiento y Uso de la Biodiversidad (CONABIO): Uso de suelo y vegetación modificado por CONABIO, Escala 1: 1000 000, Comisión Nacional para el Conocimiento y Uso de la Biodiversidad, Mexico City, Mexico, 1999.

Crounse, J. D., McKinney, K. A., Kwan, A. J., and Wennberg, P. O.: Measurement of gas-phase hydroperoxides by chemical ionization mass spectrometry, Anal. Chem., 78(19), 6726-6732, 2006.

Crounse, J. D., DeCarlo, P. F., Blake, D. R., Emmons, L. K., Campos, T. L., Apel, E. C., Clarke, A. D., Weinheimer, A. J., McCabe, D. C., Yokelson, R. J., Jimenez, J. L., and Wennberg, P. O.: Biomass burning and urban air pollution over the Central Mexican Plateau, Atmos. Chem. Phys., 9, 4929-4944, 2009, http://www.atmos-chem-phys.net/9/4929/2009/.

Crutzen, P. J., Lawrence, M. G., and Pöschl, U.: On the background photochemistry of tropospheric ozone, Tellus, Ser. B, 51, 123146, 1999.

DeCarlo, P. F., Kimmel, J. R., Trimborn, A., et al.: FieldDeployable, High-Resolution, Time-of-Flight Aerosol Mass Spectrometer, Anal. Chem., 78, 8281-8289, 2006.

DeCarlo, P. F., Dunlea, E. J., Kimmel, J. R., et al.: Fast airborne aerosol size and chemistry measurements above Mexico City and
Central Mexico during the MILAGRO campaign, Atmos. Chem. Phys., 8, 4027-4048, 2008,

http://www.atmos-chem-phys.net/8/4027/2008/.

de Foy, B., Lei, W., Zavala, M., Volkamer, R., Samuelsson, J., Mellqvist, J., Galle, B., Martínez, A.-P., Grutter, M., Retama, A., and Molina, L. T.: Modelling constraints on the emission inventory and on vertical dispersion for $\mathrm{CO}$ and $\mathrm{SO}_{2}$ in the Mexico City Metropolitan Area using Solar FTIR and zenith sky UV spectroscopy, Atmos. Chem. Phys., 7, 781-801, 2007,

http://www.atmos-chem-phys.net/7/781/2007/.

de Gouw, J. A., Warneke, C., Parrish, D. D., Holloway, J. S., Trainer, M., and Fehsenfeld, F. C.: Emission sources and ocean uptake of acetonitrile $\left(\mathrm{CH}_{3} \mathrm{CN}\right)$ in the atmosphere, J. Geophys. Res., 108(D11), 4329, doi:10.1029/2002JD002897, 2003.

de Gouw, J. A., Warneke, C., Stohl, A., et al.: Volatile organic compounds composition of merged and aged forest fire plumes from Alaska and western Canada, J. Geophys. Res., 111, D10303, doi:10.1029/2005JD006175, 2006.

Draxler, R. R. and Rolph, G. D.: HYSPLIT (HYbrid Single-Particle Lagrangian Integrated Trajectory) Model access via NOAA ARL READY Website (http://www.arl.noaa.gov/ready/hysplit4.html), NOAA Air Resources Laboratory, Silver Spring, MD, USA, 2003.

Fast, J. D., de Foy, B., Acevedo Rosas, F., et al.: A meteorological overview of the MILAGRO field campaigns, Atmos. Chem. Phys., 7, 2233-2257, 2007, http://www.atmos-chem-phys.net/7/2233/2007/.

Ferek, R. J., Reid, J. S., Hobbs, P. V., Blake, D. R., and Liousse, C.: Emission factors of hydrocarbons, halocarbons, trace gases, and particles from biomass burning in Brazil, J. Geophys. Res., 103(D24), 32107-32118, doi:10.1029/98JD00692, 1998.

Finlayson-Pitts, B. J. and Pitts Jr., J. N.: Chemistry of the upper and lower atmosphere, 969 pp., Academic Press., San Diego, CA, USA, 2000.

Flocke, F., Herman, R. L., Salawitch, R. J., et al.: An examination of the chemistry and transport processes in the tropical lower stratosphere using observations of long-lived and shortlived compounds obtained during STRAT and POLARIS, J. Geophys. Res., 104, 26625-26642, 1999.

Gerbig, C., Schmitgen, S., Kley, D., Volz-Thomas, A., Dewey, K., and Haaks, D.: An improved fast-response vacuum-UV resonance fluorescence CO instrument, J. Geophys. Res., 104, 16991704, 1999.

Giglio, L.: Characterization of the tropical diurnal fire cycle using VIRS and MODIS observations, Remote Sens. Environ., 108(4), 407-421, 2007.

Giglio, L., van der Werf, G. R., Randerson, J. T., Collatz, G. J., and Kasibhatla, P.: Global estimation of burned area using MODIS active fire observations, Atmos. Chem. Phys., 6, 957-974, 2006, http://www.atmos-chem-phys.net/6/957/2006/.

Giglio, L., Descloitres, J., Justice, C. O., and Kaufman, Y. J.: An enhanced contextual fire detection algorithm for MODIS, Remote Sens. Environ., 87(2-3), 273-282, 2003.

Goode, J. G., Yokelson, R. J., Ward, D. E., Susott, R. A., Babbitt, R. E., Davies, M. A., and Hao, W. M.: Measurements of excess $\mathrm{O}_{3}, \mathrm{CO}_{2}, \mathrm{CO}, \mathrm{CH}_{4}, \mathrm{C}_{2} \mathrm{H}_{4}, \mathrm{C}_{2} \mathrm{H}_{2}, \mathrm{HCN}, \mathrm{NO}, \mathrm{NH}_{3}$, $\mathrm{HCOOH}, \mathrm{CH}_{3} \mathrm{COOH}, \mathrm{HCHO}$, and $\mathrm{CH}_{3} \mathrm{OH}$ in 1997 Alaskan biomass burning plumes by airborne Fourier transform infrared spectroscopy (AFTIR), J. Geophys. Res., 105(D17), 22147- 
22166, doi:10.1029/2000JD900287, 2000.

Grieshop, A. P., Logue, J. M., Donahue, N. M., and Robinson, A. L.: Laboratory investigation of photochemical oxidation of organic aerosol from wood fires - Part 1: Measurement and simulation of organic aerosol evolution, Atmos. Chem. Phys., 9, 12631277, 2009, http://www.atmos-chem-phys.net/9/1263/2009/.

Grutter, M., Basaldud, R., Rivera, C., Harig, R., Junkerman, W., Caetano, E., and Delgado-Granados, $\mathrm{H} .: \mathrm{SO}_{2}$ emissions from Popocatépetl volcano: emission rates and plume imaging using optical remote sensing techniques, Atmos. Chem. Phys., 8, 6655-6663, 2008,

http://www.atmos-chem-phys.net/8/6655/2008/.

Hand, J. L., Malm, W. C., Laskin, A., et al.: Optical, physical, and chemical properties of tar balls observed during the Yosemite Aerosol Characterization Study, J. Geophys. Res., 110, D21210, doi:10.1029/2004JD005728, 2005.

Hansen, M. C., DeFries, R. S., Townshend, J. R. G., Carroll, M., Dimiceli, C., and Sohlberg, R.: Global percent tree cover at a spatial resolution of 500 meters: First results of the MODIS vegetation continuous fields algorithm, Earth Interactions, 7(10), 115, doi:10.117/1087-3562, 2003.

Hawbaker, T. J., Radeloff, V. C., Syphard, A. D. Zhu, Z., and Stewart, S. I.: Detection rates of the MODIS active fire product in the United States, Remote Sens. Environ., 112(5), 2656-2664, 2008.

Hobbs, P.V., Sinha, P., Yokelson, R. J., Christian, T. J., Blake, D. R., Gao, S., Kirchstetter, T. W., Novakov, T., and Pilewskie, P.: Evolution of gases and particles from a savanna fire in South Africa, J. Geophys. Res., 108(D13), 8485 doi:10.1029/2002JD002352, 2003.

Hoffa, E. A., Ward, D. E., Hao, W. M., Susott, R. A., and Wakimoto, R. H.: Seasonality of carbon emissions from biomass burning in a Zambian savanna, J. Geophys. Res., 104, 13841-13853, 1999.

Hoffer, A., Gelencsér, A., Blazsó, M., Guyon, P., Artaxo, P., and Andreae, M. O.: Diel and seasonal variations in the chemical composition of biomass burning aerosol, Atmos. Chem. Phys., 6, 3505-3515, 2006, http://www.atmos-chem-phys.net/6/3505/2006/.

IGBP: The miombo network: Framework for a terrestrial transect study of land-use and landcover change in the miombo ecosystems of central Africa, edited by: Desanker, P. V., Frost, P. G. H., Justice, C. O., et al., IGBP Rep. 41, Stockholm, Sweden, 1997.

Johnson, K. S., Laskin, A., Jimenez, J. L., Shutthanandan, V., Molina, L. T., Salcedo, D., Dzepina, K., and Molina. M. J.: Comparative analysis of urban atmospheric aerosol by particleinduced X-ray emission (PIXE), proton elastic scattering analysis (PESA), and aerosol mass spectrometry (AMS)., Environ. Sci. Technol., 42, 6619-6642, 2008.

Jost, C., Trentmann, J., Sprung, D., Andreae, M. O., McQuaid, J. B., and Barjat, H.: Trace gas chemistry in a young biomass burning plume over Namibia: Observations and model simulations, J. Geophys. Res., 108(D13), 8482, doi:10.1029/2002JD002431, 2003.

Justice, C. O., Giglio, L., Korontzi, S., Owens, J., Morisette, J. T., Roy, D., Descloitres, J., Alleaume, S., Petitcolin, F., and Kaufman, Y.: The MODIS fire products, Remote Sens. Environ., 83, 244-262, 2002.

Karl, T. G., Christian, T. J., Yokelson, R. J., Artaxo, P., Hao, W. M., and Guenther, A.: The tropical forest and fire emissions experiment: Method evaluation of volatile organic compound emissions measured by PTR-MS, FTIR, and GC from tropical biomass burning, Atmos. Chem. Phys., 7, 5883-5897, 2007, http://www.atmos-chem-phys.net/7/5883/2007/.

Karl, T., Apel, E., Hodzic, A., Riemer, D. D., Blake, D. R., and Wiedinmyer, C.: Emissions of volatile organic compounds inferred from airborne flux measurements over a megacity, Atmos. Chem. Phys., 9, 271-285, 2009,

http://www.atmos-chem-phys.net/9/271/2009/.

Kauffman, J. B., Steele, M. D., Cummings, D. L., and Jaramillo, V. J: Biomass dynamics associated with deforestation, fire, and conversion to cattle pasture in a Mexican tropical dry forest, For. Ecol. Manage., 176, 1-12, 2003.

Kaufman, Y. J. and Nakajima, T.: Effect of Amazon smoke on cloud microphysics and albedo - Analysis from satellite imagery, J. Appl. Meteor., 32, 729-744, 1993.

Keene, W. C., Aslam, M., Khalil, K., et al.: Composite global emissions of reactive chlorine from anthropogenic and natural sources: Reactive Chlorine Emissions Inventory, J. Geophys. Res., 104(D7), 8429-8440, 1999.

Kleinman, L. I., Springston, S. R., Daum, P. H. et al.: The time evolution of aerosol composition over the Mexico City plateau, Atmos. Chem. Phys., 8, 1559-1575, 2008, http://www.atmos-chem-phys.net/8/1559/2008/.

Kreidenweis, S. M., Remer, L. A., Bruintjes, R., and Dubovik, O.: Smoke aerosol from biomass burning in Mexico: Hygroscopic smoke optical model, J. Geophys. Res., 106, 4831-4844, 2001.

Kreidenweis, S., Tyndall, G., Barth, M., Dentener, F., Lelieveld, J., and Mozurkewich, M.: Aerosols and clouds, in Atmospheric Chemistry and Global Change, edited by: Brasseur, G. P., Orlando, J.J., and Tyndall, G. S., 117-155, Oxford University Press, New York, USA, 1999.

Lara, L. L., Artaxo, P., Martinelli, L. A., Camargo, P. B., Victoria, R. L., and Ferraz E. S. B.: Properties of aerosols from sugar-cane burning emissions in Southeastern Brazil, Atmos. Environ., 39, 4627-4637, 2005.

Latifovic, R., Zhu, Z., Cihlar, J., Beaubien, J., and Fraser R.: The Land Cover Map for North America in the Year 2000, GLC2000 database, European Commission Joint Research Centre, onlien available at: http://www-tem.jrc.it/glc2000, 2003. .

Lee, M., Heikes, B. G., Jacob, D. J., Sachse, G., and Anderson, B.: Hydrogen peroxide, organic hydroperoxide, and formaldehyde as primary pollutants from biomass burning, J. Geophys. Res., 102, 1301-1309, 1997.

Lee, Y. S., Collins, D. R., Li, R., Bowman, K. P., and Feingold, G.: Expected impact of an aged biomass burning aerosol on cloud condensation nuclei and cloud droplet concentration, J. Geophys. Res., 111, D22204, doi:10.1029/2005JD006464, 2006.

Li, J., Pósfai, M., Hobbs, P. V., and Buseck, P. R.: Individual aerosol particles from biomass burning in southern Africa: 2 . Compositions and aging of inorganic particles, J. Geophys. Res., 108(D13), 8484, doi:10.1029/2002JD002310, 2003.

Li, Q., Jacob, D. J., Bey, I., Yantosca, R. M., Zhao, Y., Kondo, Y., and Notholt, J.: Atmospheric hydrogen cyanide $(\mathrm{HCN})$ : biomass burning source, ocean sink?, Geophys. Res. Lett., 27(3), 357360, doi:10.1029/1999GL010935, 2000.

Lyons, W. A., Nelson, T. E., Williams, E. R., Cramer, J. A., and Turner, T. R.: Enhanced positive cloud-ground lightning in thunderstorms ingesting smoke from fires, Science, 282, 77-80, 1998. 
Magi, B. I. and Hobbs, P. V.: Effects of humidity on aerosols in southern Africa during the biomass burning season, J. Geophys. Res., 108(D13), 8495, doi:10.1029/2002JD002144, 2003.

Martins, J. V., Artaxo, P., Liousse, C., Reid, J.S., Hobbs, P. V., and Kaufman, Y.: Effects of black carbon content, particle size, and mixing on light absorption by aerosols from biomass burning in Brazil, J. Geophys. Res., 103, 32014-32050, 1998.

Mason, S. A., Field, R. J., Yokelson, R. J., Kochivar, M. A., Tinsley, M. R., Ward, D. E., and Hao, W. M.: Complex effects arising in smoke plume simulations due to inclusion of direct emissions of oxygenated organic species from biomass combustion, J. Geophys. Res., 106(D12), 12527-12540, doi:10.1029/2001JD900003, 2001.

Mason, S. A., Trentmann, J., Winterrath, T., Yokelson, R. J., Christian, T. J., Carlson, L. J., Warner, T. R., Wolfe, L. C., and Andreae, M. O.: Intercomparison of two box models of the chemical evolution in biomass-burning smoke plumes, J. Atmos. Chem., 55, 273-297, doi:10.1007/s10874-006-9039-5 2006.

Massie, S. T., Gille, J. C., Edwards, D. P., and Nandi, S.: Satellite observations of aerosol and $\mathrm{CO}$ over Mexico City, Atmos. Environ., 40, 6019-6031, 2006.

Mauldin III, R. L.,, Cantrell, C. A., Zondlo, M. A., Kosciuch, E., Ridley, B. A., Weber, R., and Eisele, F. E.: Measurements of $\mathrm{OH}, \mathrm{H} 2 \mathrm{SO} 4$, and MSA during Tropospheric Ozone Production about the Spring Equinox (TOPSE), J. Geophys. Res., 108(D4), 8366, doi:10.1029/2002JD002295, 2003.

McKenzie, L. M., Ward, D. E., and Hao, W. M.: Chlorine and Bromine in the biomass of tropical and temperate ecosystems, in Biomass Burning and Global Change, edited by: Levine, J. S., MIT Press, Cambridge, Mass., USA, 241-248, 1996.

Molina, L. T., Kolb, C. E., de Foy, B., et al: Air quality in North America's most populous city - overview of MCMA-2003 campaign, Atmos. Chem. Phys., 7, 2447-2473, 2007,

http://www.atmos-chem-phys.net/7/2447/2007/.

Pósfai, M., Simonics, R., Li, J., Hobbs, P. V., and Buseck, P. R.: Individual aerosol particles from biomass burning in southern Africa: 1. Compositions and size distributions of carbonaceous particles, J. Geophys. Res., 108(D13), 8483, doi:10.1029/2002JD002291, 2003.

Pósfai, M., Gelencsér, A., Simonics, R., Arató, K., Li, J., Hobbs, P. V., and Buseck, P. R.: Atmospheric tar balls: Particles from biomass and biofuel burning, J. Geophys. Res., 109, D06213, doi:10.1029/2003JD004169, 2004.

Radke, L. F., Hegg, D. A., Hobbs, P. V., Nance, J. D., Lyons, J. H., Laursen, K. K., Weiss, R. E., Riggan, P. J., and Ward, D. E.: Particulate and trace gas emissions from large biomass fires in North America, in Global Biomass Burning: Atmospheric, Climatic, and Biospheric Implications, edited by: Levine, J. S., 209-224, MIT Press, Cambridge, 1991.

Ramanathan, V., Crutzen, P. J., Lelieveld, J., et al.: Indian Ocean Experiment: An integrated analyis of the climate forcing and effects of the great Indo-Asian haze, J. Geophys. Res., 106, 2837128398, 2001.

Ridley, B., Ott, L., Pickering, K., et al.: Florida thunderstorms: A faucet of reactive nitrogen to the upper troposphere, J. Geophys. Res., 109, D17305, doi:10.1029/2004JD004769, 2004.

Rogers, C. M. and Bowman, K. P.: Transport of smoke from the Central American fires of 1998, J. Geophys. Res., 106, 2835728368, 2001.
Salcedo, D., Onasch, T. B., Dzepina, K., et al.: Characterization of ambient aerosols in Mexico city during the MCMA-2003 campaign with aerosol mass spectrometry: Results from the CENICA supersite, Atmos. Chem. Phys., 6, 925-946, 2006, http://www.atmos-chem-phys.net/6/925/2006/.

Sander, S. P., Finlayson-Pitts, B. J., Friedl, R. R., et al.: Chemical kinetics and photochemical data for use in atmospheric studies, evaluation number 15, JPL Publication 06-2, Jet Propulsion Laboratory, Pasadena, 2006.

Seinfeld, J. H. and Pandis, S. N., Atmospheric chemistry and physics: From air pollution to climate change, Wiley, Hoboken, 1203 pp., 2006.

Shea, R. W., Shea, B. W., Kauffman, J. B., Ward, D. E., Haskins, C. I., and Scholes, M. C.: Fuel biomass and combustion factors associated with fires in savanna ecosystems of South Africa and Zambia, J. Geophys. Res., 101, 23551-23568, 1996.

Shetter, R. E. and Müller, M.: Photolysis frequency measurements on the NASA DC-8 during the PEM-Tropics mission using actinic flux spectroradiometry: Instrument description and results, J. Geophys. Res., 104, 5647-5661, 1999.

Singh, H. B., Kanakidou, M., Crutzen, P. J., and Jacob, D. J.: High concentrations and photochemical fate of oxygenated hydrocarbons in the global troposphere, Nature, 378(6552), 50-54, 1995.

Sinha, P., Hobbs, P. V., Yokelson, R. J., Blake, D. R., Gao, S.. and Kirchstetter, T. W.: Emissions from miombo woodland and dambo grassland savanna fires, J. Geophys. Res., 109, D11305, doi:10.1029/2004JD004521, 2004.

Slusher, D., Huey, L. G., Tanner, D. J., Flocke, F. M., and Roberts, J. M.: A thermal dissociation-chemical ionization mass spectrometry (TD-CIMS) technique for the simultaneous measurement of peroxyacyl nitrates and dinitrogen pentoxide, J. Geophys. Res., 109, doi:10.1029/2004JD004670, 2004.

Smith, R., Adams, M., Maier, S., et al.: Estimating the area of stubble burning from the number of active fires detected by satellite, Remote Sens. Environ., 109(1), 95-106. 2007.

Susott, R. A., Olbu, G. J., Baker, S. P., Ward, D. E., Kauffman, J. B., and Shea, R.: Carbon, hydrogen, nitrogen, and thermogravimetric analysis of tropical ecosystem biomass, in Biomass Burning and Global Change, edited by: Levine, J. S., 350-360, MIT Press, Cambridge, 1996.

Tabazadeh, A., Yokelson, R. J., Singh, H. B., Hobbs, P. V., Crawford, J. H., and Iraci, L. T.: Heterogeneous chemistry involving methanol in tropospheric clouds, Geophys. Res. Lett., 31, L06114, doi:10.1029/2003GL018775, 2004.

Trent, A., Davies, M. A., Fisher, R., Thistle, H., and Babbitt, R.: Evaluation of optical instruments for real-time, continuous monitoring of smoke particulates, Tech. Rep. 00252860 MTDC, USDA Forest Service, Missoula Technology and Development Center, Missoula, MT, USA, 38 pp., 2000.

Ward, D. E., Susott, R. A., Kauffman, J. B., Babbitt, R. E., Cummings, D. L., Dias, B., Holden, B. N., Kaufman, Y. J., Rasmussen, R. A., and Setzer, A. W.: Smoke and fire characteristics for Cerrado and deforestation burns in Brazil: BASE-B experiment, J. Geophys. Res., 97, 14601-14619, doi:10.1029/92JD01218, 1992.

Ward, D. E. and Hardy, C. C.: Smoke emissions from wildland fires, Environ. Int., 17, 117-134, 1991.

Weibring, P., Richter, D., Walega, J. G., and Fried, A.: First demonstration of a high performance difference frequency spectrome- 
ter on airborne platforms, Optics Express, 15(21), 13476-13495, 2007.

Wiedinmyer, C., Quayle, B., Geron, C., Belote, A., McKenzie, D., Zhang, X., O'Neill, S., and Wynne, K. K.: Estimating emissions from fires in North America for air quality modeling, Atmospheric Environment, 40, 3419-3432, 2006.

Weinheimer, A. J., Montzka, D. D., and Campos, T. L., et al.: Comparison of DC-8 and ER-2 species measurements on 8 February 1996: $\mathrm{NO}, \mathrm{NO}_{\mathrm{y}}, \mathrm{O}_{3}, \mathrm{CO}_{2}, \mathrm{CH}_{4}$, and $\mathrm{N}_{2} \mathrm{O}$, J. Geophys. Res., 103, 22087-22096, 1998.

Yevich, R. and Logan, J. A.: An assessment of biofuel use and burning of agricultural waste in the developing world, Global Biogeochem. Cy., 17(4), 1095, doi:10.1029/2002GB001952, 2003.

Yokelson, R. J., Griffith, D. W. T., and Ward, D. E.: Openpath Fourier transform infrared studies of large-scale laboratory biomass fires, J. Geophys. Res., 101(D15), 21067-21080, doi:10.1029/96JD01800, 1996.

Yokelson, R. J., Ward, D. E., Susott, R. A., Reardon, J., and Griffith, D. W. T.: Emissions from smoldering combustion of biomass measured by open-path Fourier transform infrared spectroscopy, J. Geophys. Res., 102(D15), 18865-18877, 1997.

Yokelson, R. J., Goode, J. G., Ward, D. E., Susott, R. A., Babbitt, R. E., Wade, D. D., Bertschi, I., Griffith, D. W. T., and Hao, W. M.: Emissions of formaldehyde, acetic acid, methanol, and other trace gases from biomass fires in North Carolina measured by airborne Fourier transform infrared spectroscopy, J. Geophys. Res., 104(D23), 30109-30126, doi:10.1029/1999JD900817, 1999.
Yokelson, R. J., Bertschi, I. T., Christian, T. J., Hobbs, P. V., Ward, D. E., and Hao, W. M.: Trace gas measurements in nascent, aged, and cloud-processed smoke from African savanna fires by airborne Fourier transform infrared spectroscopy (AFTIR), J. Geophys. Res., 108(D13), 8478, doi:10.1029/2002JD002322, 2003.

Yokelson, R. J., Urbanski, S., Atlas, E., et al.: Emissions from forest fires near Mexico City, Atmos. Chem. Phys., 7, 5569-5584, 2007a, http://www.atmos-chem-phys.net/7/5569/2007/.

Yokelson, R. J., Karl, T. G., Artaxo, P., Blake, D. R., Christian, T. J., Griffith, D. W. T., Guenther, A., and Hao, W. M.: The tropical forest and fire emissions experiment: Overview and airborne fire emission factor measurements, Atmos. Chem. Phys., 7, 51755196, 2007b, http://www.atmos-chem-phys.net/7/5175/2007/.

Yokelson, R. J., Christian, T. J., Karl, T. G., and Guenther, A.: The tropical forest and fire emissions experiment: laboratory fire measurements and synthesis of campaign data, Atmos. Chem. Phys., 8, 3509-3527, 2008, http://www.atmos-chem-phys.net/8/3509/2008/.

Zárate, O., Ezcurra, A., Lacaux, J. P., Van Dinh, P., and de Argandoña, J. D.: Pollution by cereal waste burning in Spain, Atmos. Res., 73, 161-170, 2004.

Zhang, Q., Worsnop, D. R., Canagaratna, M. R., and Jimenez, J. L.: Hydrocarbon-like and oxygenated organic aerosols in Pittsburgh: Insights into sources and processes of organic aerosols. Atmos. Chem. Phys., 5, 3289-3311, 2005, http://www.atmos-chem-phys.net/5/3289/2005/. 